\title{
Principals as managers and leaders: A qualitative study of the perspectives of selected elementary school principals
}

\author{
Dean S. T. Cascadden \\ College of William \& Mary - School of Education
}

Follow this and additional works at: https://scholarworks.wm.edu/etd

Part of the Educational Administration and Supervision Commons, Elementary Education Commons, and the Social and Philosophical Foundations of Education Commons

\section{Recommended Citation}

Cascadden, Dean S. T., "Principals as managers and leaders: A qualitative study of the perspectives of selected elementary school principals" (1996). Dissertations, Theses, and Masters Projects. Paper 1539618662.

https://dx.doi.org/doi:10.25774/w4-dpx0-6d52

This Dissertation is brought to you for free and open access by the Theses, Dissertations, \& Master Projects at W\&M ScholarWorks. It has been accepted for inclusion in Dissertations, Theses, and Masters Projects by an authorized administrator of W\&M ScholarWorks. For more information, please contact scholarworks@wm.edu. 


\section{INFORMATION TO USERS}

This manuscript has been reproduced from the microfilm master. UMI films the text directly from the original or copy submitted. Thus, some thesis and dissertation copies are in typewriter face, while others may be from any type of computer printer.

The quality of this reproduction is dependent upon the quality of the copy submitted. Broken or indistinct print, colored or poor quality illustrations and photographs, print bleedthrough, substandard margins, and improper alignment can adversely affect reproduction.

In the unlikely event that the author did not send UMI a complete manuscript and there are missing pages, these will be noted. Also, if unauthorized copyright material had to be removed, a note will indicate the deletion.

Oversize materials (e.g., maps, drawings, charts) are reproduced by sectioning the original, beginning at the upper left-hand comer and continuing from left to right in equal sections with small overlaps. Each original is also photographed in one exposure and is included in reduced form at the back of the book.

Photographs included in the original manuscript have been reproduced xerographically in this copy. Higher quality 6" $\times 9$ " black and white photographic prints are available for any photographs or illustrations appearing in this copy for an additional charge. Contact UMI directly to order.

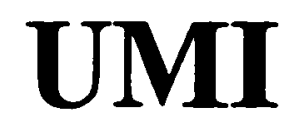

A Bell \& Howell Information Company 300 North Zeeb Road, Ann Arbor MI 48106-1346 USA $313 / 761-4700 \quad 800 / 521-0600$ 
PRINCIPALS AS MANAGERS AND LEADERS:

A QUALITATIVE STUDY OF THE PERSPECTIVES OF

SELECTED ELEMENTARY SCHOOL PRINCIPALS

\begin{abstract}
A Dissertation
Presented to

The Faculty of the School of Education

The College of William and Mary in Virginia
\end{abstract}

In Partial Fulfillment

Of the Requirements for the Degree

Doctor of Education

by

Dean S.T. Cascadden

July, 1996 
UMI Number: 9701087

UMI Microform 9701087

Copyright 1996, by UMI Company. All rights reserved.

This microform edition is protected against unauthorized copying under Title 17, United States Code.

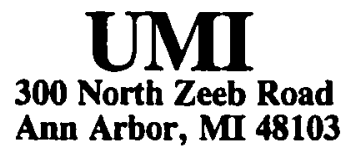

Reproduced with permission of the copyright owner. Further reproduction prohibited without permission. 
PRINCIPALS AS MANAGERS AND LEADERS:

\section{A QUALITATIVE STUDY OF THE PERSPECTIVES OF \\ SELECTED ELEMENTARY SCHOOL PRINCIPALS}

by

Dean S.T. Cascadden

Approved July, 1996 by

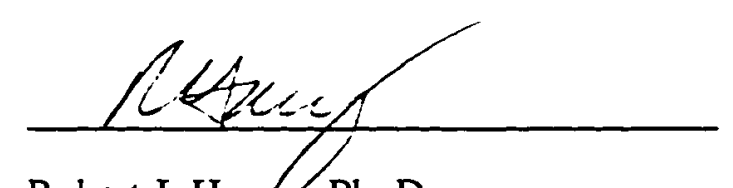

Robert J. Hanky, Ph. D

Chair of Doctoral Committee

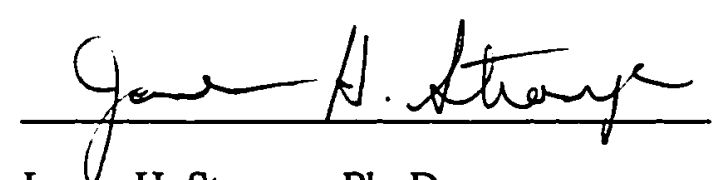

James H. Stronge, Ph. D

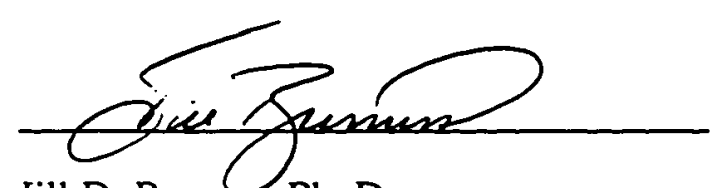

Jill D. Burruss, Ph. D 
This work is dedicated to

\author{
Jesus Christ
}

In whom I live and breathe and have my being.

A wise man will hear and increase learning,

and a man of understanding will attain wise counsel,

to understand a proverb and an enigma,

the words of the wise and their riddles.

The fear of the Lord is the beginning of knowledge,

but fools despise wisdom and instruction.

Proverbs 1: 5-7

iii 


\section{Table of Contents}

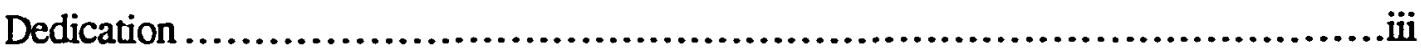

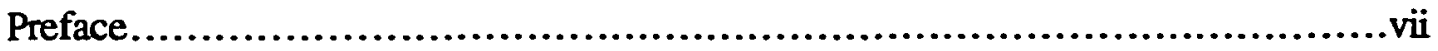

Acknowledgments...........................................................viii

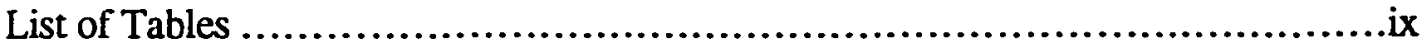

Abstract...........................................................................

Ch. 1: The Problem .............................................................

Principals as Both Leaders and Managers................................2

Leadership and Management.........................................2

The Role of Theory ....................................................4

Purpose.................................................................11

Theoretical Perspective .............................................11

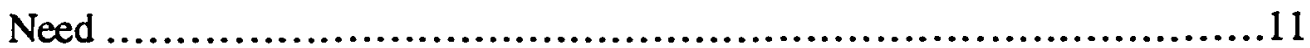

Overview of Methodology and Limitations ............................13

Guiding Questions ...................................................14

Definitions................................................................

Ch. 2: Review of Relevant Literature ..........................................16

The Elementary School Principalship....................................16

Historical Evolution of the Principalship ...........................16

Prior to the 1980s: Principals as Managers................................18

The 1980s: A role in Transition......................................20

The Role of the Principal in the 1990 s.............................28

Leadership and Management...........................................33

Comparison of Leadership and Management .......................33

Management Theories................................................34

Leadership Theories................................................36

Relating Theory to Practice..........................................40 
Ch. 3: Methodology and Procedures...............................................44

Qualitative Point of View and Research Paradigms .........................45

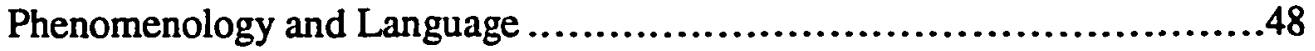

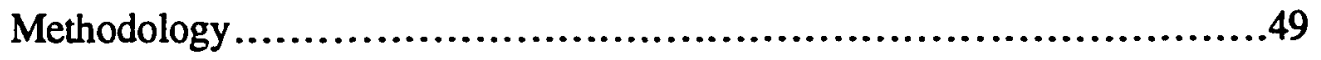

Participants...........................................................51

Data Collection Protocols ............................................52

Data Analysis ...................................................53

Delimitations and Limitations .........................................54

The Researcher as an Instrument .......................................56

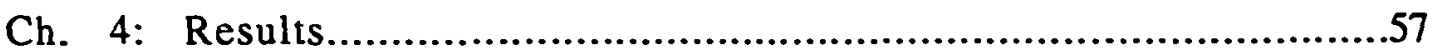

Narrative Descriptions- The Principals' Stories ...........................57

Mr. Lexus (Division A)......................................57

Mrs. Parker (Division A) .......................................66

Mrs. Kaplan (Division A) ......................................74

Ms. Elliot (Division A) ........................................82

Mr. Baker (Division B) ........................................92

Mrs. McGrath (Division B) ....................................99

Mrs. Tanner (Division B) .......................................109

Mrs. Allen (Division C) .......................................118

Dialectic Analysis.....................................................126

Second Level Data Reduction and Display ..........................126

Analysis of Contextual Factors .....................................131

Analysis of Sub Area One .......................................133

Analysis of Sub Area Two .......................................136

Analysis of Sub Area Three......................................138

Emergent Themes and Issues ....................................140

Cross Case Comparisons..............................................144 
Items and Issues from Member Checks ............................146

Ch. 5: Discussion ........................................................ 151

Review of Results....................................................152

Review of Sub Area Analysis........................................152

Principals as Mangers and Leaders: Themes and Issues.................154

Relation of Results to the Literature ......................................156

Enacting an Oxymoronic Role ...................................156

"Being There" .....................................................157

Evolving from Managers to Leaders ................................158

Balancing Culture and Distributed Decisionmaking...................160

Concluding Thoughts...................................................161

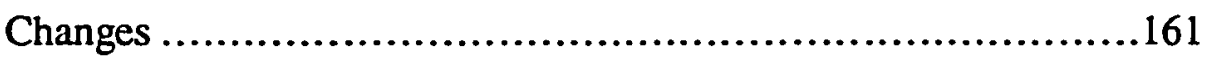

Implications ..................................................... 163

New Questions and Directions........................................164

Appendix A: Interview Guides and Forms....................................166

Contact Visit Guide .......................................................167

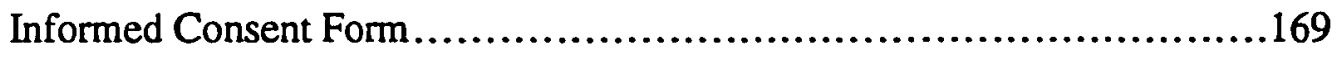

First Interview Guide.................................................170

Second Interview Guide...............................................171

Third Interview Guide .............................................173

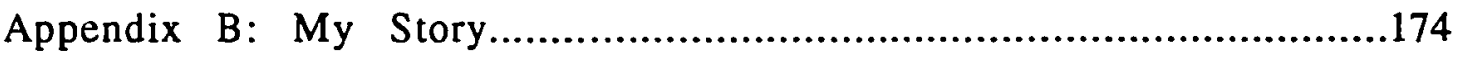

References...................................................................180 


\section{Preface}

This study was conceptualized as a qualitative dissertation, and its format was a compromise between tradition and innovation. It was organized using the traditional five chapter dissertation format, but the functions of some of the chapters have been modified. This preface was written as a guide to the reader for exploring the chapters of this dissertation.

"Ch. One: The Problem" was the theoretical grounding of the study and problem statement. The specific problem statement involved exploring conceptions of elementary principals regarding leadership and management, and this area was found to be intricately intertwined with philosophical and methodological issues of how theory relates to practice and of how theory should guide inquiry regarding practice. The study adopted a phenomenological perspective, and a qualitative methodology using semi-structured interviews.

"Ch. Three: Methodology and Procedures" elaborated on the qualitative methodology and readers unfamiliar with this paradigm are encouraged to access the beginning of this chapter as rationale and citations for this type of study were presented.

"Ch. Four: Results" comprised the bulk of this text. A primary goal of this investigation was to present the views and "voice" of the eight participating elementary school principals. Thus, their stories featuring extensive, direct quotations, were presented first, followed by the researchers analysis where emergent common themes and issues were identified.

"Ch. Two: Review of Relevant Literature" was conceptualized as a "data" chapter and was researched and written after all field work was completed and the study's results including the researcher's analysis were written up.

"Ch. Five: Discussion" relates the findings from the field (Ch. 4) to the published literature (Ch. 2), as contrary to traditional approaches, the field was explored first, then the literature was reviewed. Also, the researchers concluding thoughts were presented regarding: a) how his own views have changed, b) how this investigation will affect his own practice of training and educating future principals and c) new questions and issues that have arisen from this investigation. 
Acknowledgments

- To my participants for talking with me and for being so candid and thoughtful in their responses.

- To my committee for guidance and support:

To Dr. Hanny for allowing me freedom to explore, for not hurting me by helping me too much, and for being a mentor and a listener.

To Dr. Burruss for opening up the qualitative world to me, for being there as an emotional support and listening to me, and for having an open door with a candy bowl.

To Dr. Stronge for keeping me honest and grounded, for believing in my work and trusting me in this project, and for his continued support in employment matters.

- To my family for support and encouragement:

To Crystal, my wife and perfect help mate, for believing in me and supporting my hopes and dreams. You made it all possible by doing much more than your fair share.

To Nora, D. J., Ian and Carter for sharing Dad with his computer and books.

To Lady for always being there to take a break with.

To Mom and Dad for always believing and for support along the way.

- To my friends for listening and encouraging:

To Cindy, Pam, Jan, Hollylynne, Lou, Charlie etal. thanks for really being there. To Norman and other netters, thanks for virtually being there. 


\section{List of Tables}

Second Level Data Reduction and Display

Matrix One: Contextual Factors.............................................125

Matrix Two: Management and Leadership (Sub Area One) ................126

Matrix Three: Role of Personal Views (Sub Area Two)...................127

Matrix Four: Descriptions of Role, School and Work (Sub Area Three).....128

Matrix Five: Third Interview Responses Regarding Emerging Themes .............145 


\title{
PRINCIPALS AS MANAGERS AND LEADERS: \\ A QUALITATIVE STUDY OF THE PERSPECTIVES OF \\ SELECTED ELEMENTARY SCHOOL PRINCIPALS
}

\begin{abstract}
The primary purpose of this study was to explore how selected elementary school principals described and defined their work in terms of leadership and management. There were three subareas of investigation under this primary purpose: a) exploring the principals' conceptions about the constructs of leadership and management, b) exploring the principals' beliefs about the role of their personal philosophies, goals, or values in relation to their practice; and c) using content analysis to explore the language that principals use to describe themselves, their work and their schools. The theoretical perspective adopted for this study was that organizations are constructed human social entities. The focus of this study was to describe the role of the elementary school principal from the perspective and voice of the participants. The data collection was accomplished using semi-structured interviews of eight selected elementary school principals. Results were presented as narrative description, the principals' stories (hermeneutic representation) and analysis (dialectic) where the transcriptions of the interviews were content analyzed for common themes or patterns. Similarities and differences were explored and conceptions and themes generated from this analysis were compared with the existing literature on leadership, management and the elementary school principalship. The descriptions and analysis provided by this study could be used to inform practice, especially for those involved with the training and education of administrators.
\end{abstract}

DEAN S. T. CASCADDEN

SCHOOL OF EDUCATION

THE COLLEGE OF WILLIAM AND MARY IN VIRGINIA 
PRINCIPALS AS MANAGERS AND LEADERS:

A QUALTTATIVE STUDY OF THE PERSPECTIVES OF SELECTED ELEMENTARY SCHOOL PRINCIPALS 


\section{Chapter 1: The Problem}

A major concern of society is the enculturation, socialization and education of youth, and schools are the collective, societal organizations specifically charged with pursuing this purpose. The principal is often viewed as being a very important, if not the most important, factor in the successful operation of schools (Bookbinder, 1992; Leithwood, Begley \& Cousins, 1994), and the role of the principal has been the subject of much research and debate.

\section{Principals as Both Leaders and Managers}

Principals have been conceptualized both as managers and as leaders (Deal \& Peterson, 1994; Duffiel, 1991; Stronge, 1990, 1993). These constructs have different connotations for the performance of administration, and each construct frames the work of administrators in a different way (Deal \& Peterson, 1994; Duffie, 1991; Zaleznik, 1977). However, these constructs are also not well defined and may mean different things to different people (Howe, 1994). This study explored how selected elementary school principals described and defined their work in terms of leadership and management.

\section{Leadership and Management}

One way to differentiate between leadership and management is to focus on how philosophic questions of beliefs, values and goals are addressed. For example, management can be seen as focusing on the "how" of doing something, and leadership as focused on the "why." Educational administration can be construed as leadership- a subjective, value-laden endeavor, where decisions are mostly concerned with prescriptive questions of "why" and "what ought to be"; or it can be seen as management- an objective practice focused on descriptive questions of "how" and "what is". Whereas, questions of "why" and "ought" are philosophic, moral questions in the sense that they must be answered in the realm of values, questions of "how" and "is" are objective questions which are more amenable to empirical research.

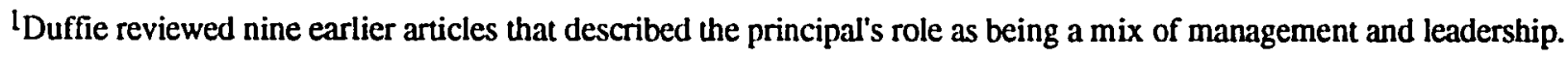


Zaleznik (1977) in an article for the Harvard Business Review was one of the first writers to contrast the constructs of leadership and management in this way. He concluded that "managers and leaders are very different kinds of people. They differ in motivation, personal history, and in how they think and act" (p. 69). Managers were characterized as adopting impersonal, if not passive, attitudes toward goals that arise out of necessities rather than desires. In contrast, Zaleznik's description of the way leaders think about goals was different:

They are active instead of reactive, shaping ideas instead of responding to them. Leaders adopt a personal and active attitude toward goals. The influence a leader exerts in altering moods, evoking images and expectations, and in establishing specific desires and objectives determines the direction a business takes. The net result of this influence is to change the way people think about what is desirable, possible, and necessary. (p. 71)

Duffie (1991) took this conception further by arguing that the management and leadership constructs were aligned with different philosophical schools.

The positivistic school attempts to provide administrators with strategies and methods that help them develop more efficient and effective organizations. Based on empirical research, generic theories have been formulated by researchers to provide practitioners with the necessary analytical skills to enable them to make rational, informed decisions so that organizational goals can be achieved efficiently and effectively (p. 4)

In contrast, leadership was described by Duffie as being concerned with personal visions, beliefs and values. In summation, Duffie stated that,

management is described as being an orientation for action and is based on a "how to" philosophy which takes the form of a science of administration. Thus, management has become associated with positivistic administration theory. Leadership, in contrast, is described as being a reflective and ethical practice in that it is perceived to focus on the people within the organization and the culture created by the actors involved. Its foundations reside in administration as a reflective art. (p. 5)

Both Zaleznik and Duffie conceptualize the constructs as being distinct; however, this is not universally accepted.

Howe (1994), in a review and synthesis of theory and research in educational administration, cited a basic problem with studying this domain. There is no agreement on "whether or not leadership, administration, and management are conceptually distinct terms. For the most part, scholars in educational administration use leadership, administration, and management indiscriminately and accept these terms unquestioningly as institutionalized synonyms" (p. 7). While acknowledging this definitional problem, Howe also stated that "most 
researchers" would agree that a) leadership is not coercion; b) leadership is an influence relationship; c) leadership involves values, culture, and moral/ethical concerns, as well as needs, wants, and aspirations; and d) leadership involves internal feelings and experiences, as well as external actions and behaviors (p. 12).

Shepard, Farmer and Counts (1995) developed standards based on the work of Rost (1993) to compare various definitions of leadership and to contrast them with management. Leadership was described as an attempt to effect real changes using an influence (as opposed to an authority) relationship driven by mutually shared purposes between leaders and followers. A fifth component, philosophic content, was proposed; but the authors argued that the manager, leader and philosopher roles should be kept separate and distinct. It was noted that other theorists (e.g., Sergiovanni, Zaleznik, Bates) had viewed the philosophic and leadership roles as being intertwined and inseparable.

Shepard, Farmer and Counts' separation of the leadership construct from the philosophical construct is interesting, but it may not be ultimately possible. If leaders retain some directiveness, and are influencing followers toward goals, then philosophic content must be included in the leadership construct. "Concern with a goal presupposes a worldview or a philosophical viewpoint that involves a set of beliefs in the nature of reality, the essence of truth, and a basis for forming values... the 'stuff of philosophy" (Knight, 1989, p. 35). A leader who operates without philosophic content becomes a group facilitator, not ultimately concerned with specific goals; and this may be more like the manager described by Zaleznik. The relationship of philosophy to practice for the participants was one of the primary areas of investigation in this study.

\section{The Role of Theory}

An issue that arises in the study of educational leadership and management is the role that theory should play in prescribing practice. Historically, the study of leadership in education was focused on best practices until the Theory Movement in the 1950s. Griffiths (1988) characterized this era as the transformation of educational administration from a practical art with a knowledge base of "best practice" to an academic discipline based on theory. A key event in this era, 
according to Griffiths, was the 1954 National Conference of Professors of Educational Administration (NCPEA) meeting where several highly articulate and charismatic social scientists promoted the following agenda:

1) Better research into educational administration was needed.

2) The research must be theory based (e.g., on social systems theory).

3) Social science was the source of the theories.

4) The social scientists were the ones who could guide the professors of educational administration. (Griffiths, 1988, p. 28)

The social scientists were also deeply critical of the substance and study of educational administration, particularly the lack of a theoretical base. In the following years, their particular view of the field with an emphasis on theory and research came to dominate educational administration.

The core ideas of the Theory Movement have been identified by Culbertson and are characterized as stemming from positivism:

1) Statements about what administrators and organizations ought to do cannot be encompassed in science or theory.

2) Scientific theories treat phenomena as they are.

3) Effective research has its origins in theory and is guided by theory.

4) Hypothetic-deductive systems are the best exemplars of theory.

5) The use of social sciences is essential in theory development and training.

6) Administration is best viewed as a generic concept applicable to all types of organizations. (Culbertson, 1983 as cited in Griffiths, 1988, p. 29)

The theory movement, guided by these principles, produced a large quantity of research on leadership and leader behavior.

The nature of much of this line of research was the identification of two variables, task and human relations (these have however been called various things e.g., initiating structure and consideration, task behavior and supportive behavior, task orientation and relationship orientation), and an investigation of the correlation of these variables with effective leadership. Owens (1991) described how earlier researchers (the Ohio State Leadership Studies, Blake and Mouton with their Managerial Grid) argued that there was a one best or normative approach that included behavior high in both task and people variables. Later researchers (Fiedler with a Contingency Model, House with Path Goal Theory, Reddin with Leadership Styles, Hersey and Blanchard with the Situational Leadership Model) argued for the situational or contingent nature of leadership and that 
particular styles were appropriate for certain situations. However, it is important to note that even "a contingency theory which, though open to multiple contingencies, is still linked to a positivistic notion of theory"(Howe, 1994, p. 26). Thus, the researchers and theorists in the Theory Movement, as Mitchell (1990) describes it, were looking at how leaders were made.

"A review of the educational leadership theories of the past fifty years shows that 'becoming a leader' is the prevailing model of educational leadership" (Mitchell, 1990, p.13). Mitchell further asserted that this movement was founded on the work of Simon who based his work on the philosophy of logical positivism:

The only kind of knowledge recognized by the "becoming a leader" model is empirical.... Leadership is studied in the same way as any other natural phenomenon in nature since leaders are finally physical realities. The essence of leadership is a very high degree of conformity to the laws and principles of the natural phenomena of the world. Thus, the dynamics of leadership involve the leader's possession and use of knowledge, rewards and punishment, and awareness of the basic needs of followers in order to influence and control their behavior. Therefore, much of the research on leadership during this century had focused on acquiring facts about what leaders do or what leaders should know in order to control the behavior of the followers. (p. 13)

The Theory Movement grounded in the philosophy of logical positivism looked at leadership with a "scientific" lens and hoped to deduce generalizeable "laws" that would be useful and hold true across situations. The research methodology employed was the deducing of hypotheses from theory to be tested by observational means. However, this method has drawn much criticism.

Griffiths (1988) pointed out a problem with logical positivism:

The logical positivists believed that something had meaning only if it could be verified by direct or indirect observation. More formally, a statement containing theoretical terms should be tested by a statement containing observational (nontheoretical) terms; logical validity is present if a logical or mathematical tautology exists... The difficulty was with the observation statement, for it is virtually impossible to construct an observation statement that does not include theoretical concepts. Rather than theoretical statements being verified by observation statements, theoretical propositions were actually tested by other theoretical statements, and the verification sought by the logical positivists was never achieved. (p. 40)

Observation was supposed to verify and confirm theory, but observation could not be theory free. The choice of variables, the operationalization of variables, and the measurement of variables involved conscious choices that were theory laden.

English (1994) also discussed this "problem" of positivism: 
The idea that observation as a form of experience verification is really just another point of view often hidden to the observer, is one of the major problems in sustaining logical positivism, behaviorism, and the concept that only observable "facts," are allowed to be used to ascertain what is true. This naive assumption that observation can be "theory-free," is one of the blind spots of positivistic science because it represents an unsupported belief that cannot be supported by experience itself... While positivistic science consists of correspondence to the facts, its hidden premises are unsupportable by any "facts." This blind spot is positivism's implicit conceit. (English, 1994, p. 77)

In other words, positivism claimed that theory can be tested by observation which is theory-free.

However, this is not possible because "experience does not verify the 'facts' independent of a concept of what the 'facts' are within an overall framework of meaning" (p. 77). English termed this a "double hermeneutic" where predetermined perspectives frame evidence collection supporting conclusions, but the predetermined perspective is denied (p. 69).

Immegart (1988), in his extensive review of leadership research, stated that this grounding of research in deductions from theory may have been detrimental to the overall study of leadership.

It is also possible that normal processes of inquiry have unduly delimited and restricted what has been investigated. Through operational definitions, the selection of variables for study, the delimitation and control of those variables, and the determination of the focus of inquiry, the very same studies that have continued to demonstrate the complexity and situational nature of leadership and the need to look at a greater number of variables have tended to remain relatively restricted or selective themselves, and thereby have not very greatly expanded what has been considered.... Perhaps what has been studied has been explored in part because of convenience or because it has been more readily operationalized and measured.... Normal scientific inquiry may have contributed to oversimplification of the notion of leadership and, in so doing, may have limited advances in what is known about it. In this case, there is a need to consider other approaches to collecting and analyzing data about leadership and leader behavior as well as other sources of data about and even broader perspectives on what would be investigated. (p. 269)

However, the Theory Movement, although much criticized for its philosophical inconsistencies and for its methodological shortcomings, is still a dominant force in the United States (Howe, 1994).

In other countries, the Theory Movement has had much less influence. Griffiths (1988), describing how this movement failed to thrive outside of the United States, stated that the Theory Movement's "demise came at the 1974 meeting of the International Intervisitation Programme (IIP) in Bristol, England. The coup de grace was delivered by Greenfield (1975) who made an acrossthe-board denunciation of every aspect of the Theory Movement" (p. 30). He criticized the theorists 
because they split values off from facts. He contended that this resulted in descriptions of organizations that were lifeless, and that theory based only on facts devoid of values was of no use to administrators. This led, in part, to Greenfield's contention that the Theory Movement had produced little of consequence to practitioners. (p. 30)

However the major thrust of Greenfield's critique was epistemological. He argued that organizations are not real, but are social realities which are human inventions (Greenfield, 1975 in Greenfield \& Ribbins, 1993). Thus, there could be no "science" of leadership. However, "the Greenfield critique has been hailed in the British Commonwealth countries and largely ignored in the United States" (Griffiths, 1988, p. 30).

Howe (1994) summarized the situation similarly:

The "theory movement" has had a lasting impact upon educational leadership research in the United States. However, since the movement originated in the United States and only later emerged in other countries, it has had a far less impact outside the United States. Furthermore, educational leadership scholars in Commonwealth countries- England, Australia, Canada, New Zealand- have often resisted scientific, positivistic theoretical perspectives and have argued, in particular, that there can be no scientific theory of educational leadership or educational administration. As a result, they frequently develop and support alternative theoretical perspectives for educational leadership and are often more innovative, original, and open to diverse "ways of seeing" leadership than their American counterparts. (p. 29)

Griffiths (1988) stated that the Theory Movement had two motives, one to understand and the other to predict and control, "but administrative theorists cannot describe organizations nor can administrators control them, and this is the basis for the present turmoil" (p. 40). Theorists from the post-positivist school often argue that the purpose of theory is to interpret the meaning of leadership, not to explain it, predict it or master it" (Howe, 1994, p. 24). Theories following this model are descriptive and open. Chaos Theory, Organized Anarchies and The Garbage Can Model of Decision Making (March, Cohen and Olsen) and Loose Coupling in a Seamless Organization (Weick) are cited by Owens (1991) as examples of this recognition of the complexity of organizations and leadership, and they represent attempts at description and interpretation rather than absolute prediction and strict control.

English summed up the history of the field of educational administration in the United States by stating that educational administration is a product of a double hermeneutic which began as an offspring of scientific management: 
Later, educational administration became thoroughly captured by the behaviorists, and in turn the organizational sociologists. Neither behaviorism nor organizational sociology has provided the explanatory or predictive power of either understanding or advancing the field, or its graduates, to solve the myriad of political, moral, and technological dilemmas the schools face in late twentieth-century America.

Too many educational administrators see themselves as continuing the legacy of efficiency in systems theory and now total quality management. Educational administrators are not agents of moral leadership.... Administrators of our schools look for solutions inside the confines of behaviorism-structuralism that preclude moral leadership because these positivities have never considered values and morality fitting topics of science and hence of doctoral study.

The myopia of the field precludes it from expanding its borders to the arts, where moral dilemmas have been the topic of discussion for thousands of years... "Research" has been thoroughly appropriated by the behaviorists to the point where too few studies that deal with the human dimension are permitted or labeled "too soft" to be endorsed by many professors directing graduate research. Many graduate students have been discouraged from using anything but behavioral-structural premises in their work. Statistical packages dominate the methodologies selected in these circumstances. Blindreviewed journal and conference presentations indicate that dominance and pervasiveness of behavioral-structuralism to perpetuate its own hegemony in thinking about how the field shapes problems and reinforces its own power-knowledge position simultaneously. (p.230-231)

English's solution to this problem is to re-center educational administration in the humanities by concentrating on moral leadership which is distinctively aware of values. "Moral leadership recenters people as agents of change who can shape their environment and the organizations they live and work in to become more fully humane, not simply technocracies devoted to ever more refined efficiencies" (p. 231). This call for moral leadership was also made by Greenfield (Greenfield \& Ribbins, 1993), Hodgkinson (1978, 1991) and Sergiovanni (1990, 1992).

Similar to the calls for moral leadership are calls for Transformative Leadership based on the work of Burns who equated Transformational Leadership with shaping, altering, or elevating the values and goals of the followers through vital teaching (Tierney and Foster, 1989). Foster (1989) states that "Rather than seeing leadership as 'running a tight ship, or as 'achieving organizational goals, 'this approach to leadership addresses change, transformation, and liberation" (p. 6).

Bolman and Deal (1995) in a book titled Leading with Soul stated:

Many people hope that leadership will put us on a more promising path. But what kind of leadership? Here consensus evaporates. Two images dominate: one of the heroic champion with extraordinary stature and vision, the other of the "policy wonk," the skilled analyst who solves pressing problems with information, programs and policies. Both images miss the essence of leadership. Both emphasize the hands and heads of leaders, 
neglecting deeper and more enduring elements of courage, spirit, and hope. Perhaps we lost our way when we forgot that the heart of leadership lies in the hearts of leaders. We fooled ourselves, thinking that sheer bravado or sophisticated analytic techniques could respond to our deepest concerns. We lost touch with a most precious human gift-our spirit. To recapture spirit, we need to relearn how to lead with soul. (p. 5).

DePree (1989) in Leadership is an Art centered leadership in the realm of ideas and echoed similar themes to the writers calling for moral leadership, transformational leadership or leading with soul.

In summation, there seems to be two recurring themes or camps in educational administration (Warner, 1983). One camp believes that educational administration is management science (focused on questions of "how" and concerned with goals of effectiveness and efficiency) that can be studied in a positivistic, objective manner where values do not come into play; they are mostly concerned with questions of what "is". The other camp believes that education is valueladen (focused on questions of "why" and concerned with ultimate goals and ends) that cannot be studied without an explicit, subjective philosophical framework or world-view that profoundly influences all research and decision making; they are more concerned with leadership and questions of "ought".

Deal and Peterson (1994) described this state of affairs in their book The leadership paradox; Balancing logic and artistry in schools. Their solution (also proposed by Stronge, 1990 \& 1993) is to creatively balance the two roles:

By emphasizing one orientation, principals may lose connection with the other. There is, however, another option: to accept the seemingly contradictory approaches as a paradox to be embraced and creatively addressed, not to see them as an either-or choice to be made. High-performing organizations have both order and meaning, structure and values. They achieve quality at reasonable costs. They accomplish goals while attending to core values and beliefs. They encourage both fundamentals and fun. They embrace the dialectic between expression of values and accomplishment of goals. They encourage both leadership and management, symbolic behavior and technical activity. (p. 9)

Thus, these authors prescribe a balance between leadership and management.

The constructs of leadership and management have been identified as being important in the enactment of the principal's role. However, the exact definition of these constructs as well as how they are translated or applied in practice has been a controversial and much debated issue. The purpose of this study was to explore this area by researching practicing principals to explore how they conceptualized their work in terms of management and leadership. 


\section{Purpose}

The primary purpose of this study was to explore how selected elementary school principals described and defined their work in terms of leadership and management. There were three sub-areas of investigation under this primary purpose: a) exploring the principal's conceptions about the constructs of leadership and management; b) exploring the principals' beliefs about the role of their personal philosophies, goals, or values in relation to their practice; and c) using content analysis to explore the language that principals use to describe themselves, their work and their schools.

\section{Theoretical Perspective}

The epistemological perspective adopted for this study was Greenfield's conception of organizations as constructed human social entities. Greenfield and Hodgkinson held that "leadership exists in people's subjective interpretations of experience and constructions of reality; it is an internal phenomenon, and, as such, it is closely associated with values, beliefs, morals, meanings, and even illusions" (Howe, 1994, p. 29). Gronn and Ribbins, two researchers famous for their examination and dissemination of Greenfield's work, stated that Greenfield "sought to develop a systematic view of social reality as human invention, in opposition to the systems scientific perspective of social reality as a natural system" (1993, p. 161). Gronn and Ribbins maintained that to explore educational administration as a created social reality, it is important to ask how an administrator feels about the world, or what the right and proper way is for that administrator to act in regard to that world. In addition, the goal is to recount how actual administrators might construe issues for themselves" (p. 164). Thus, in alignment with Greenfield's (and others') phenomenological epistemology, the focus of this study was to describe the principalship from the perspective and voice of the elementary school principals participating in this study.

\section{Need}

There are three reasons why this study was particularly needed. First, the nature of much work in this area has been mostly prescriptive or opinion pieces (Immegart, 1988; Howe, 1994). 
Many theorists have expounded on what administrators should believe and how they should practice, but fewer studies have explored what administrators actually believe and how this affects their practice. The second reason why this study has relevance is because of the persistence of the Theory Movement's influence in the United States. Many of the theorists and philosophers discussing the need for moral leadership and the importance of values and beliefs have been from outside the United States, and perhaps this type of thinking has not really penetrated the United States and is not being experienced by practicing administrators whose work takes place within the still dominant legacy of scientific management and the Theory Movement. Finally, the use of qualitative methodology with inductive analysis has been lacking in this area. The Theory Movements' emphasis on objectivist, quantitative and positivist research has dominated the studies in this area. In this line of thought, Immegart (1988) stated that:

Much remains to be done in mapping the leadership domain, in identifying dimensions and variables critical to the phenomenon (as well as their linkages), and in developing viable conceptualizations and constructs to guide research. Both positivistic and naturalistic approaches warrant attention in this regard...certainly some effort should be directed toward the development of grounded theory utilizing the naturalistic paradigm. (p.273)

Howe (1994) discussed "several new directions emerging in the discussion of theory for studies of educational leadership" which include: "a call for inductive, naturalistic theories for the development of 'grounded theory' (theory emerging from or grounded in the data) based upon 'thick description' of real leaders in real settings" and "a focus on theoretical perspectives that treat language, values, beliefs, moral/ethical issues, culture, meaning, and the individual or social construction/interpretation of reality" (p. 22).

The results of this study could have implications for both the practice of educational administration and the education and training of educational administrators. By studying the perspectives of elementary school principals, their voice can be heard. The perspectives of the participants presented in this study could be used by developers and designers of training and education programs to inform the debate about what "ought" to be done to educate and train future principals. 


\section{Qverview of Methodology and Limitations}

The theoretical perspective adopted for this study was that organizations are constructed human social entities, and the focus of this study was to describe the role of the elementary school principal from the perspective and voice of the participants. Qualitative methodology was chosen, specifically, data collection was accomplished using a series of three semi-structured interviews with eight selected elementary school principals. The first two interviews were conceptualized as data collection, while the last interview, conceptualized as a member check, performed the dual roles of data collection and interpretation. Results were presented in two parts: a) narrative description, the principals' stories (hermeneutic representation) and b) analysis (dialectic) where the transcriptions of the interviews were content analyzed for common themes or patterns. Similarities and differences between participants were explored and conceptions and conclusions generated from this analysis were compared with the existing literature on leadership, management and the elementary school principalship. This literature, presented in chapter two, was accessed only after fieldwork and analysis were completed.

Certain methodological decisions gave rise to the following limitations:

1. Only elementary school principals participated so generalization to middle or high school principals is limited.

2. The small, purposive sample drawn from three school divisions in the Tidewater Virginia area may not be representative of other contexts and this limits generalizeability.

3. The views of participating principals were solicited during three interviews held in the Spring of 1996, and no observational data or views of other stakeholders were included in this study; the relatively short contact time and the focus exclusively on principal's views as expressed to an interviewer are limiting to generalizeability. 


\section{Guiding Questions}

The following question, designated as the grand question and primary purpose, served to focus and organize this investigation:

- How do the participating elementary school principals describe and/or define their work in terms of leadership and management?

The three sub areas of this investigation with their guiding questions are listed below:

- What conceptions do the principals have regarding the constructs of leadership and management?
A) How is management defined or described by participants?
B) How is leadership defined or described by participants?
C) How do participants describe the relationship of the two constructs?
D) How do participants perceive themselves functioning in terms of the self- defined constructs of leadership and management?

- What do the principals believe about the role of their personal philosophies, goals, or values in relation to their practice?
A) What roles do participants believe their personal philosophies, goals, or values should play in their practice?
B) What effect do the participants perceive that their personal philosophies, goals, or values are actually having in their schools?
C) What external restraints or constraints, if any, do the participants perceive on their role in relation to personal philosophies, goals, or values?
- What language (e.g., metaphors, word pictures and descriptions) do the principals use to describe themselves, their work and their schools?
A) How do the participants describe their work?
B) How do participants describe their roles?
C) How do participants describe their schools? 
D) How do these descriptions relate to the constructs of leadership and management as defined by the participants?

\section{Definitions}

Elementary: pertaining to grades $\mathrm{k}-5$.

Principal: the person designated as the head of a school.

Qualitative: a research paradigm emphasizing an insiders view of socially constructed reality, understanding the perspectives of participants, and recognizing the subjective nature of all interpretation.

Phenomenological: a philosophical school which views reality as socially created.

The terms management and leadership were not defined in this section by the researcher because part of the purpose of this study was to have participants define these terms for themselves. The terms were defined by the researcher at the conclusion of the study in Appendix B: My Story. 


\section{Chapter 2: Review of Relevant Literature}

The primary purpose of this study was to explore how selected elementary school principals described their work in terms of leadership and management. The focus of the study was to describe the role of the elementary school principal from the perspective and voice of the participants, and the researcher chose to do the fieldwork and analysis before accessing the published literature. Thus, the function of this chapter is different from the literature review in a traditional dissertation. In a traditional dissertation, the review of literature is usually done before the investigation and provides the theoretical base for the study. In this qualitative dissertation, the theoretical basis of the study was outlined in the first chapter and this literature review was conceptualized as an additional data chapter. Field data from the participating principals was presented in chapter four, "library data" from published literature was contained in this chapter, and the design of this investigation called for the two data sources to be compared in the final, discussion chapter. In this chapter, relevant literature was reviewed and synthesized in two sections: "The Elementary School Principalship" and "Leadership and Management."

\section{The Elementary School Principalship}

This section of the literature review focused on conceptions of and previous studies of the elementary school principalship. The focus was on the historical development of the principal's role, especially how the educational reforms of recent decades have impacted conceptions of the principalship in the 1990 s.

\section{Historical Evolution of the Principalship}

Richardson, Short and Prickett (1993) stated that the title of principal of an elementary school was first used in New York about the middle of the 19th century. They traced a historical development of the role through five stages: a) single teacher schools, b) head school teacher, c) teaching principal, d) building principal, and e) supervising principal. These authors also noted that the principalship has come full circle from instructionally focused, to administration and management focused, and now back to an instructional focus. 
The first principals were called "head teachers," who, although in charge of the school, spent most of their time in instructional programs teaching. The increasingly complex organizational demands of schools forced many principals to abandon instructional duties for management functions. To be successful today, principals have gone full circle back to being the instructional leader. (p.6)

These authors also noted that the principalship role has changed in recent years from an "order giver" in a top down system to more of a facilitator in a more distributed system. Teaching, inspiring, communicating and influencing were listed as hallmarks of an effective instructional leader.

Bookbinder (1992) described the evolution of the principalship in similar fashion. He noted that prior to 1850 the role of the principal was mostly clerical but by the end of the 1800 s the responsibilities had grown beyond records and reports to school organization and general management. By 1900 the principal was considered the directing manager rather than the presiding teacher. By the mid 1900s a supervisory function was added to the role with principals overseeing instruction.

The essential features of the principalship became apparent by the close of the twentieth century and have not undergone substantial change since that time. Certainly the duties and responsibilities have grown and increased in complexity, however principals continue to serve in the twin functions of providing instructional leadership and managing school affairs today, just as they were called to do one hundred years ago. (p.10).

Commenting on the implications of this evolution, Bookbinder stated,

The administrative duties of the principal were in place before the supervisory function was fully realized; as a result, the former has often tended to occupy the major portion of the principal's energies and efforts. Further, in many school systems, it was the superintendent who assumed the supervisory role and the improvement of instruction. (p. 11)

Bookbinder also noted that when supervision was delegated to the principals it was characterized as "inspection" and this conception of top-down supervision is still evident in "too many of today's public schools" (p.12).

Richardson, Short and Prickett (1993) and Bookbinder (1992) described the role of the present day principal as being in transition from management dominated to more leadership oriented. Prior to the 1980 s, the role of the principal was often described as being dominated by 
management, but this role conception was altered by educational reforms during that decade. This thesis was explored in the following sections.

\section{Prior to the 1980s: Principals as Managers}

In the 1970 s the role of the principal was characterized as being management dominated. Wolcott (1973) in his classic, qualitative ethnography about the elementary school principalship, portrayed Ed, the man in the principal's office, as a middle manager. For example, "Ed seemed to be moved about through most of his day by little problems brought to him or created for him by others rather than by any grand design of his own of what he wished to accomplish" (p. 34), and

the answer for the principals I met and observed to the question of what to do next seemed to be to let the position run them. Perhaps it is the absence of a self-generating sense of direction that provides the most telling and frequently heard criticism of elementary school principals. (p. 314).

In the final chapter, containing his own reactions and reflections, Wolcott stated:

The principalship is a manager's task. In addition to the prerequisites for selection, the constraints on the position are too many, the opportunities too few, to make it sufficiently attractive to recruit and retain many truly dynamic leaders.... Greater attention to the school's instructional program on his part would probably be perceived by his staff as a sign of his dissatisfaction with their present efforts, and overt efforts at involvement in that direction would be perceived as interference. (p. 325)

Like Wolcott, Blumberg and Greenfield (1980), after surveying the historical evolution of the principalship role, concluded that it was managerial:

School principals are, for the most part, managers; their work environment gives most of them little choice in this matter. While this situation does not prevent a few committed and talented individuals from achieving excellence as instructional leaders, most principals find themselves frustrated by their inability (be it skill, knowledge, or time allocation) to move beyond the management functions inherent in the role of principals as it has evolved during the past hundred years. (p. 46)

Educational Research Services (1982) summarized research conducted in the 1970s concerning the role of elementary school principals and also emphasized management functions.

Some of their more salient conclusions included:

- Elementary school principals function as educational leaders, chief administrators, and operations managers of their schools. As educational leaders, principals are responsible for maintaining and improving the quality of the instructional program in their schools. As chief administrator in the school, the principal is a representative of the school system management and implementor of school board policy and central management decisions. As school site manager, the principal is in direct charge of both the immediate and the continuing operations of the school. (p. 85) 
- Studies indicate that principals typically spend a greater amount of their time on administrative tasks than on instructional tasks, that many principals are infrequent visitors to the classroom, and that many principals spend most of their time in the central office area of the school. (p. 85)

- Principals report spending less time on instructional leadership activities than they would like.... time some principals allocate to curriculum development is related to their perceptions of its importance to central office superiors. (p. 85)

- Principals derive professional satisfaction from decision making and prefer to have control over most decisions affecting the operation of their school. They generally are reluctant to share site-level decision making.... Principals feel that, if they are to function as managers, they must have the authority to manage. (p. 87)

Thus, the elementary school principalship of the 1970s was characterized in an ethnography and by reviewers of empirical research as a role dominated by middle management functions.

The role of the elementary principal is related to the historical development of the larger field of educational administration. The rise to dominance of management functions in educational administration was documented by Callahan (1962) in his classic text Education and the Cult of Efficiency. He stated that from 1900 onward business values and practices dominated educational administration to the point that by 1930 "school administrators perceived themselves as business managers, or, as they would say, 'school executives' rather than as scholars and educational philosophers" (p. vii). This time period is significant for it was the formative period for educational administration as a professional field, and this period saw the genesis of university studies and programs in educational administration. Callahan maintained that as the profession and the accompanying university studies grew, both were focused on the practical, concrete, localized problems of school administration as "the courses which were developed in administration provided training in the kinds of activity (records and reports, cost accounting, child accounting, and general business management) with which superintendents on the job were preoccupied" (Callahan, p. 196).

Callahan also chronicled how management functions came to dominate the development of the field of educational administration:

By 1930 the professional work in administration had reached a kind of maturity and the pattern of work which was being taken by hundreds of students was firmly established. On the basis of an examination of the content of courses that were offered, of the textbooks 
which were used, of the topics that professors of educational administration deemed important, and of the doctoral studies which were done, it is clear that the nature of this work was, as Jesse $\mathrm{H}$. Newlon put it, "permeated with the philosophy of management, of business efficiency" (Callahan, 1962, p. 199)

Callahan reported that Newlon conducted content analyses of textbooks for educational administration and found that over eighty per cent of the pages were devoted to

"the purely executive, organizational, and legal aspects of administration. Almost the entire emphasis is on the 'how' of administration. There is virtually no discussion of the 'why'..." Newlon also found, and thought it significant, that none of these books attempted to develop a philosophy of education or inquire "deeply into the larger purposes which administration is designed to serve." (Callahan, 1962, p. 200).

Callahan concluded that from the formation of educational administration as a discipline, it had been overly concerned with efficiency and other business principles to the detriment of educational principles, and "the whole development produced men who did not understand education or scholarship. Thus they could and did approach education in a businesslike, mechanical, organizational way" (1962, p. 247).

Callahan's critique focused on the more generic educational administrator and the development of educational administration as a field, but the dominance of the management function he chronicled in the field of educational administration was consistent with the characterization of the principalship being dominated by management functions in the 1970 s as previously documented. Since that time, the conception of the role of the principal has been greatly modified.

The 1980s: A Role in Transition

Beginning in the 1980s, the effective schools movement emphasized the principal as instructional leader and the educational reform movements have emphasized the development of site based management and shared decision making. These forces have caused a conceptual shift involving the role of elementary school principals. Two texts of the 1980s, Krajewski, Martin and Walden (1983) in a text subtitled "Leadership for the 1980s" and Hughes and Ubben (1989) in a text subtitled "The elementary school principal as leader and manager," emphasized the developing emphasis on the principal as leader. Both texts focused on the elementary school principalship and both prescribed a mix of management and leadership for the role. However, both texts were more 
prescriptive than descriptive and emphasized what the role could or should be. These texts of the 1980s showed the elementary principal's role to be in transition. To understand why this transition came about and the depth of its effects, the context of reform surrounding schools since the early 1980s was explored in detail.

Smith and Andrews (1989) described the importance of viewing the principal as an instructional leader. "Taken collectively, the 'effective schools' studies reflect the view that the direct responsibility for improving instruction and learning rests in the hands of the school principal" (p.1). Four characteristics of instructional leadership were identified: a) the principal as resource provider, b) the principal as instructional resource, c) the principal as communicator, and d) the principal as visible presence. This role of instructional leadership was conceptualized as being done in addition to the role of building manager.

We must not lose sight of the fact that there is everyday interaction between building management and instructional leadership. Clearly, also, the myriad tasks that make up the job must get done. It is not that some tasks can be set aside; rather, the issue concerns importance and value and how the principal allocates discretionary time to the various tasks that must be done. (p.24)

This new role was not seen as an easy addition for many principals:

As a group, principals say they lack time for supervision of instruction because they do not have adequate secretarial assistance or support staff to handle routine duties. Principals feel there is an imbalance in the allocation of authority and responsibility between the central office of the school district and individual buildings. Too little of the authority for operating the building is delegated to principals; however, principals sense that they are held responsible for running a good school. Others express feelings that the day-to-day needs of the school are so demanding that there simply are not enough hours left in the day for instructional leadership activities. (p.24)

This difficulty in implementing the instructional leadership role was shown by research that compared how principals felt that they should spend their time with how the time was actually spent. "School management was considered less important than program development, but it received far more of the principals' time and attention" (p. 26). At the same time that instructional leadership was emerging as a popular part of the principal's role, schools were being greatly affected by school reform movements.

Jacobson and Conway (1990) described three waves of educational reform. Each of these waves was initiated by a report and each focused on a different area of education. The first wave 
sparked by the 1983 report A Nation at Risk: The imperative for educational reform focused on the need for reform and on standards. The second wave focusing on teachers began in 1986 with the release of the Holmes Group's Tomorrow's Teachers and Teachers for the 21st Century. The third wave of reform focused on administrators and was initiated by the release in 1987 of Leaders for America's Schools.

Farrar (1990) examined the first wave of educational reform in detail. She noted that the reforms of the 1980s were "enacted by political entities empowered to mandate reform in local schools" which resulted in reforms which were "astonishing in both number and comprehensiveness and for the speed with which they have been enacted" (p.5). These unprecedented effects of a reform movement on the practice of education were linked to three factors that converged in the early 1980s: a) "The Reagan education agenda sought to reduce every aspect of the federal role in education" creating a "vacuum in educational leadership while simultaneously urging state governments and private enterprise to step in and fill the void" (p.5); b) both state government leaders and business executives became interested in and willing to take a more active role in education reform, business executives were particularly concerned about the possible quality of the future workforce; and c) a number of nationally commissioned reports appeared that set the tone and agenda for the rush of reforms.

The report of the National Commission on Excellence in Education (NCEE), A Nation at Risk (1983), was far and away the most influential....Deliberately written in nontechnical but dramatic language, Risk drew wide public readership.... One conservative estimate is that the report reached at least 4 million citizens, a number that would be larger if it were possible to calculate the number of people who shared copies or read newspapers that reprinted the report. The impact of Risk is hard to overestimate. It produced a firestorm of publicity for education in general while solidifying the excellence framework that guided the first wave of education reform in the 1980s. (p.7)

Farrar (1990) stated that while the reports often emphasized that the United States was "in the midst of a national crisis caused by the schools' inability to turn out the kind of workers needed for an increasingly sophisticated economy," it was also noted that "the reports provided little solid evidence to back up these assertions" (p. 7). Commenting on the first wave of reform, Farrar (1990) wrote: 
The chief difficulty with the first-wave reports is their assumption that the existing educational system is basically sound, that schools can be improved by fine tuning and doing more of what they do rather than by redesigning the system. This is particularly paradoxical in the case of A Nation at Risk, whose commission was convened by an administration more critical of the educational establishment than any in recent memory. The commission's formula for pushing back the tide of mediocrity was to shore up the systems with salary increases, more academic courses, higher standards, and more time in school-to wit, incentives and regulation. None of the commissions provided much hard or soft evidence as to why they thought that would work. (p. 10)

The author concluded her scrutiny of the first wave of education reform by stating that the proffered recommendations were very enticing to the newly empowered state authorities because "they were reforms that could be mandated from the state house and passed down to local schools for relatively rapid implementation," and that most states avoided the more costly and reform proposals and "favored less costly approaches that increased graduation requirements, introduced testing for promotion and graduation, and made it harder for people to become certified as teachers" (p. 11).

The author's greatest criticism of the first wave of reform was that

"educational excellence is not amenable to implementation by regulation or by scattering fiscal incentives.... Policymakers can manage what they control: macro-policy-funding, curriculum frameworks, teachers certification, textbook selection and the like. But they have limited control over daily events in schools" (Timar \& Kirp, 1988). Findings of this sort are not surprising; the surprise is that states so quickly forgot, or did not heed, what is perhaps the single most important finding of educational research in the 1970s: that people who work on the front line of education- teachers and administrators- will be involved one way or another in decisions about what to do to improve schools.

Kowalski and Reitzug (1990) characterized the second wave of reform as addressing

concerns of centralization and mandates by emphasizing the need to restructure schools.

A realignment of authority, deregulation, and development of school-driven reform agendas represents initiatives spawned by convictions that reform needed to include new roles for teachers and administrators. "Professionalism" and "empowerment" emerged as key words in speeches made by education leaders. (p. 283)

Petrie (1990) began his examination of the second wave of reform by stating that the first wave of educational reform

was characterized by the imposition of top-down reforms that essentially asked us to do more of the same but to do it better. The second wave of educational reform, perhaps best exemplified by the Holmes Group Report, Tomorrow's Teachers (Holmes Group, 1986) and by the Carnegie Forum Report, A Nation Prepared (Carnegie Forum, 1986), was characterized by a recognition of the systemic nature of the educational enterprise and the necessity of putting the teacher at the center of educational reform. (p. 14) 
Two conceptions of putting the teacher in the center were examined: teacher as technician and teacher as professional. In the technician model the reformers implied that "teachers are somehow not up to the mark in terms of quality and performance and that we must somehow select them better, prepare them longer, test them harder, and get rid of the incompetents more cheaply" (p. 14).

Petrie (1990) argued for the teacher as professional model and noted that this model required fundamental, systemic change.

It is not easy to envision the kind of professionalism being called for on the part of teachers being inculcated solely within a college or university program for teacher education. Still less is it a professionalism that is amenable to hierarchical control by a principal or superintendent or state-level commissioner of education who somehow can direct every move of the teachers and know how to evaluate every judgment and adaptive change made in thousands of different contexts. It is much more nearly the view of a profession of reflective practitioners who practice together and who learn together through their joint enterprise. (p. 22)

This new view of the teacher as professional called for a new vision of educational leadership.

Thinking about teachers and teaching in these ways calls for a new vision of educational leadership, one concerned less with micromanaging teaching and more with facilitating the work of semiautonomous, reflective practitioners exercising professional judgment. Leading professionals is simply different from leading hired hands. This new vision of educational leadership strongly suggests a rethinking and reordering of the educational leadership tasks in our schools. (p. 27)

This type of observation led to the third wave of reform.

The third wave of educational reform focused on administrators and can be conceptualized as having two parts. The early part of the third wave focused on administrator preparation and was initiated by the report Leaders for America's Schools (1987), the second part of the wave focused more on the practice of administration and was initiated by the report Principals for 21 st Century Schools (1990).

Jacobson (1990) examined the first part of the third wave focusing on administrator preparation and concluded that the basis of this reform was "really an attempt to create a more cohesive synthesis between theory-based research and field based practice" (p. 32). He focused his attention on the problems of administrator preparation as enumerated in Leaders for America's Schools a report of the National Commission for Excellence in Educational Administration 
(NCEEA) and published by the University Council for Educational Administration (UCEA) in

1987. Ten deficiencies were enumerated by the report: a) the lack of definition of good educational leadership; b) the lack of leader recruitment programs in schools; c) the lack of collaboration between school districts and universities; d) the discouraging lack of minorities and women in the field; e) the lack of systematic professional development for school administrators; f) the lack of quality candidates for preparation programs; $g$ ) the lack of preparation programs relevant to the job demands of school administrators; $h$ ) the lack of sequence, modern content, and clinical experiences in preparation programs; i) the lack of licensure systems that promote excellence; and $\mathrm{j}$ ) the lack of a national sense of cooperation in preparing school leaders.

Jacobson emphasized that many of these recommendations had the goal of bridging a gap between university theory and school practice. Commenting on the lack of definition of good educational leadership, he wrote:

"The complete administrator," argues Achilles (1984, p. 41), "knows what to do, how to do it, and most important of all, why an action is appropriate." Achilles contents that: a) "what administrators do" relates to administration as a science and should be the subject of research and theory testing; b) "how administrators do what they do" relates to administration as a craft and should be the subject of practice and theory-using; and finally, c) "why administrators do what they do" relates to administration as an art and should be the subject of conceptualization and theory-building. Achilles contends that at present even the best administrator preparation programs unfortunately usually provide no more than two components of this essential trinity. (p. 33)

Jacobson, referencing Pitner (1988), also identified four key discrepancies between training in university programs and the job demands of school administrators:

1) Differences in time constraints. The student of administration is taught to carefully reflect upon solutions to potential problems, whereas the administrator's work is more often characterized by snap decisions covering a multitude of disjointed issues.

2) Differences in role. The student of administration functions in a subservient role, whereas the practicing administrator assumes a superordinate position within the organizational hierarchy.

3) Differences in communication. The student of administration is trained to communicate through the written word, whereas in daily practice the administrator typically depends on face-to-face verbal communications.

4) Differences in affective relationships. The student of administration functions in an environment in which ideas and rationality are prized and feelings are largely irrelevant, whereas the administrator's world is far more volatile, and environment in which angry parents, excited students, and aroused employees may combine to overload administrators with emotional barrages. (p. 35). 
Jacobson traces these discrepancies to the theory movement of the 1950 s. This movement sought to establish educational administration as a social science using logical positivism as a basis to do systematic research leading to theory building. A creative synthesis of research and practice was proposed to remedy the imbalance of the theory movement:

Now reformers of the third wave, having considered the implications of a restructured educational enterprise, are recommending that the "is" and the "ought" of educational administration be once again more closely connected. Theory building and theory testing need not be dismissed from the preparation of administrators. Indeed, aspiring administrators should be encouraged to study the art and science of administration in order to improve the craft of administration. A deeper understanding of what administrators do and why they do it can only improve how administrators do what they do. Therefore, practice must become an equal partner with research in the preparation of educational leaders. (p.41)

Richardson, Short and Prickett (1993) described the effects of educational reform on the role of the principal. These authors discussed more the aggregate effects of reform rather than examining the successive waves, noting that "commissions have recommended that schools be restructured to become flexible, autonomous units capable of solving problems at the school-base level" (p. 26). Citing Principals for 21 st Century Schools a report issued in 1990 by the National Association of Elementary School Principals, Richardson, Short and Prickett (1993) stated that "primary in the restructuring movement is school-based management and decision-making," which makes schools "more collaborative with greater participant involvement in all aspects" (p. 28). This change in school structure has changed the principal's role: "restructuring of public education has focused the role of the school leader squarely on facilitating the development of school organizations that engage participants in collaborative efforts and shared governance" (p.30).

As a response to restructuring, many writers have prescribed the normative use of goals, vision, values and culture by principals to facilitate unity in a collaborative system that uses distributed decision making. This type of leadership has often been labeled symbolic or moral and some have likened this type of thinking to a fourth wave of school reform.

Leithwood, Begley, and Cousins (1994) stated:

With empowerment and school improvement as goals, more research simply describing typical practice does not seem likely to be of much use in the development of future leaders. Results of research on effective current practice appear to be quite useful in describing in more detail the qualities valued in future school leaders. This research confirms the central 
role that the principals' goals play in understanding the source of effective practice. These goals form a central part of the vision principals use to bring consistency to an otherwise unmanageably diverse set of demands. Developing a widely shared, defensible vision is central to future school leadership. (p. 22)

Hodgkinson (1991) in his book on educational leadership subtitled "The Moral Art" stated:

The reason the science of administration-or of organizations-does not work is stupefyingly simple: the central problems of administrative theory are not scientific at all, but philosophical. That is, the central questions of administration deal not so much with what is, but what ought to be; they deal with values and morality. (p. 7)

Similar themes were expounded by Sergiovanni in Value-Added Leadership (1990) and Moral Leadership (1992); and also by Greenfield and Ribbins (1993) and Mitchell (1990) who argued for the importance of values in a phenomenological approach to educational administration.

Robbins \& Alvy (1995) described the concept of school culture as a powerful force.

Within any organization, there is an "inner reality" (Deal \& Peterson, 1993) or culture that influences the way people interact, what they will and will not do, and what they value as "right and rude" (Little, 1982). This inner reality reflects what organizational members care about, what they are willing to spend time doing, what and how they celebrate, and what they talk about.... Despite its pervasive nature, culture or inner reality is often overlooked as a critical force.... Because the way people interact daily or "do business" at a site dramatically influences its ultimate productivity for all members, culture is a powerful school improvement tool. (p. 23)

The role of culture in leading schools was emphasized by the contributors to the 1987

Yearbook of the Association for Supervision and Curriculum Development which had leadership as its theme. For example, Deal (1987) wrote on "The culture of Schools," and Owens (1987) wrote on "The leadership of educational clans;" in analyzing his case studies, he wrote:

The clan is a useful metaphor for describing the structure, the "glue," that coheres the school's members. The nearly total socialization of the clan members is highly motivating; it legitimates the authority system and ensures predictable job performance without close, detailed surveillance by the hierarchy. Leaders of educational clans must devote time and skill to both symbolic leadership and culture development if they seek to lift the organization from functional adequacy toward educational excellence. (p. 26)

Sheive and Schoenheit (1987) wrote on "Vision and the work life of educational leaders" while

Sergiovanni (1987) in writing on purposing and empowering stated:

Successful leaders expect adherence to common values but provide wide discretion in implementation. They are outraged when they see these common core values violated. The values of the common core are the non-negotiables that compose the cultural strands, the covenant that defines the way of life in the school. On the other hand, the teachers enjoy wide discretion in organizing their classrooms, deciding what to teach, and when and how, providing that the decisions they make embody the values that make up this covenant. 
Successful schools are both tightly and loosely structured: They are tight on values and loose on how values are embodied in the practice of teaching, supervision and administration. (p. 124)

In a later work, Sergiovanni (1995) added a caveat that there could be a dark side to school culture as "Strong cultures are committed cultures, and in excess, commitment takes it toll on rational action" (p. 111). He then described the importance of "loyal opposition". Janis (1971) wamed of similar problems and needs in his classic article titled "Group think."

Reitzug (1994) critically examined the role of culture in systems whose ultimate goal is empowerment and observed:

The discussion of the leader's role in the organizational culture literature, however, resorts to prescriptive recommendations for how leaders should shape organizational culture and remains grounded in conceptions of directionality and influence.... Critical theorists argue that the role of the leader as manager of the organization's culture is, in effect, simply a different form of control, one that is manipulative in its subtlety and, in essence, more pervasive than traditional bureaucratic forms of control because it attempts to impact thought as well as action. (p. 285)

Maxcy (1991) also raised a similar concern about the writings focusing on leadership by culture, values or morals, "there are several problems with this notion, not the least of which is the assumption that the principal is somehow invested with a moral superiority by virtue of his/her position as principal" (p. 123).

Reitzug (1994) described the dilemma facing educational leaders:

Whether leaders mandate compliance with organizational goals (as in traditional perspectives of leadership), or whether they influence subordinates to embrace specific notions of organizational culture, the key issue remains the same: How do leaders know that the organizational direction suggested by their goals, values, beliefs and assumptions is the best one?... On the other hand, if leaders do not attempt to influence followers to pursue courses of action that they perceive to be correct, are they not shirking the responsibility for organizational direction? (p. 286)

Reitzug's solution (Also embraced by Maxcy and Sergiovanni) is to conceptualize the role of the leader as empowering followers and embracing more democratic notions of leadership.

The Role of the Principal in the 1990 s

A number of writers have noted that the role of the principal has been greatly affected in recent decades, especially by school reform and restructuring, presently it revolves around 
leadership and management. Richardson, Short and Prickett (1993) commenting on the role of the principal stated:

The principal is responsible for leading and managing the school. Being in charge of the school means being visible to students, staff, and the public. The principal cannot sit at a desk behind closed doors hoping that everything gets done. The school organization does not function in a vacuum, it must have a viable, visible, sustaining force. That force is the principal.... The principal is currently viewed as the person "in the middle." The principal is perceived to be a true middle manager, being bombarded from above by superintendents and school boards, from below by teachers, and from both sides by parents, community and students. Additionally, the continuing educational reform movement places much emphasis on the instructional leadership role of the principal which is a different role from that historically practiced by many administrators. Consequently, school boards and superintendents expect principals to implement administrative policy while teachers and students expect instructional leadership and a supportive climate. (p. 5)

The role of principal has evolved to contain elements of both leadership and management. In one sense, it is easy to characterize the role as a mix of the two functions, but the enactment of this mixed role may be very difficult for practitioners. Bookbinder (1992) noted the difficulty in enacting a mixed role:

The effective and productive principal is able to maintain a balance while performing as an instructional leader and effective school manager. There are a multitude of factors and environmental issues which might suggest that this balance is an impossible goal, however, the author's approach to the principalship would suggest that unless these two, productive instructional leadership and effective school management, are occurring there is little reason to argue for the continuation of the principalship as we know it. (p.12)

Robbins and Alvy (1995) noted similar themes; the principal's role may be increasingly emphasizing leadership, but it cannot escape the historical management emphasis:

Although the concept of the principal has shifted from "gatekeeper" to "instructional leader," "collaborative decision maker," and "leader of leaders," any discussion on leadership can become a romantic concept if leadership is not discussed hand-in-hand with management.... Effective principals are effective managers. (p. 10)

Historically, the management functions of the principal are well established, but the emphasis on leadership orientation is newer and it may be to early to accurately characterize what the effects of recent educational reforms will be.

Principals have been particularly affected by school restructuring, and it is difficult to predict exactly what school reform will mean to principals. Kowalski and Reitzug (1993) postulated two possible scenarios for consideration: 
Scenario A: School administrators become more specialized in instructional practices and group decision making. Teachers gain stature and are given greater freedom to make critical instructional decisions. Faculty view the principal as a source of professional knowledge. The relationship between the principal and the faculty is one of professional peers, not superior-subordinates. Yet, the principal continues to oversee managerial tasks, but much of this work is now completed by support staff or technology.

Scenario B: Reformed schools divide responsibilities into two major categories: instructional and managerial. Teachers assume much of the responsibility for decisions focusing on curriculum and instruction. Principals assume responsibility for managing physical resources. Principals oversee budgets, facilities, food programs, and the like. Their contact with teachers are limited to functions where instructional programs require the use of resources.

One view postulates the principal as a manager and the other as a leader. Which role may eventually dominate is not yet known, but it is clear that the principal of the 1990 s is presently expected to perform both functions.

To begin to answer the question of what the role of the principal will be in restructured schools, Murphy and Louis (1994) collected and commented on nine case studies. The purpose of the book was described in the preface:

For nearly a decade now, we have witnessed ongoing efforts to restructure schooling. These transformational reform efforts are taking root in schools throughout the world. Some schools are emphasizing school based management and shared decision making. Others underscore the centrality of parental voice and choice. For some schools, renewed emphasis on a coherent shared vision of pedagogy forms the core of improvement efforts. For still others, the spotlight is on the professionalization of teaching. And in some instances, reform is anchored in multiple improvement strategies, often with a focus on improving success for marginal students. A central ingredient in all of these various restructuring initiatives is the redesign of work for the major educational shareholders. This volume focuses on the ways in which the work of one particular role groupprincipals- is being shaped by transformational reform measures. (p. vii)

The authors stated that the case studies collected supported the claim that "principals have experienced more change under school reform than any other group" (p. 25).

Hallinger and Hausman (1994) in a case study subtitled "Principal role ambiguity in restructured schools" stated "the principal's authority to command has eroded-even as the school's responsibility to act has been heightened. At the same time, none of the traditional managerial responsibilities of principals has been reduced" (p. 163). Murphy (1993) noted this increase in managerial responsibility, "Reform means that there is simply more to do at the school level than was previously the case. Interestingly, this heightened responsibility to manage reform often 
comes at the expense of the principal's educational/instructional role" (p. 35). Principals also report having overwhelming workloads, lack of time to do all that is expected and conflicting expectations "especially signals to emphasize a bottom-up management strategy while the central office itself maintains a traditional top-down decision-making model" (p. 41).

Glickman, Allen and Lunsford (1994) reported that $66 \%$ of the principals in their case study "thought that their role has significantly changed. A change from a traditional, directive administrative role to one of facilitator and organizer was most frequently mentioned. Other descriptors for their new role were encourager, supporter, organizer and enabler" (p. 207). The authors noted that there was considerably less agreement on role changes as compared to agreement on changes in focus, interrelationships and activities. This discrepancy was explained by the observation that the principals existed in a dual system- they were today's principals in tomorrow's schools.

In every case, these principals work in local districts in which school boards and state policy hold the principal legally responsible for what occurs in his or her school; this has not changed. In most cases, the districts and boards have supported their principals involving faculty in shared governance, but they have not changed board policies to make the governing group responsible for the school. As a result, these principals have had consciously to distribute their legal power and become an equal vote among many, even though the superintendent, the school board, and the outside community will hold the principal chiefly, if not solely, responsible for the successes or failures of the school. (p. 216)

Murphy and Beck (1994) in the introductory chapter to the case studies postulated six metaphors to "paint a portrait of the type of administrator needed in tomorrow's schools" (p. 9): a) Principal as servant, b) Principal as person in community, c) Principal as moral agent, d) Principal as organizational architect, e) Principal as social advocate and activist, f) Principal as educator.

They concluded the introduction by stating:

As principals reenter discussions about schooling and about their roles in educational processes, they must resist the tendency to oversimplification. Transformative school leaders must be able to balance a variety of roles, to move among them as needed, and to live and work with the contradictions or ambiguities that acceptance of multiple roles may bring. Furthermore, they must be able to articulate the factors necessitating these many roles. They must understand the many facets of education and the multiple requirements and potentially contradictory challenges facing school leaders and be able to explain and defend their positions to critics. (p. 15)

A similar point has been made by other theorists. 
Bolman and Deal (1991) prescribed "reframing" as a way for managers to deal with the complex, surprising, deceptive and ambiguous nature of organizations. "Each of the frames offers a different perspective on what leadership is and how it operates in organizations" (p. 422). The four frames were a) Structural emphasizing analysis and design, b) Human Resource emphasizing support and empowerment, c) Political emphasizing advocacy and coalition building, and d) Symbolic emphasizing inspiration and framing experiences.

Deal and Peterson (1994) applied this type of idea specifically to schools, and emphasized the paradoxical nature of the principal's role.

One's ability as a manager is related to the capacity to see and respond to technical, rational issues. Managers help to create direction, order, and stability in order to improve outcomes. But effectiveness as a leader is related to the capacity for understanding and responding to situations in symbolic ways. Leaders infuse an enterprise with passion, purpose, spirit, traditions, and values. (p. xiii)

In our view, education may be best served by principals who are bifocal, who can combine managerial tasks with symbolic sensitivity and passion, who are simultaneously efficient managers and effective leaders. (p. xii)

The key according to these authors is "to accept the seemingly contradictory approaches as a paradox to be embraced and creatively addressed, not to see them as an either-or choice to be made" (p. 9). To fully understand this proposal, one must put aside Western type thinking with its dualist nature.

In Taoist traditions, philosophers use the concepts of Yin and Yang to depict opposites that when combined make a unified whole.... The same need for balance is true of oft-cited management-leadership polarity. The concept of paradox in a principals' work stresses the ability to embrace these supposedly opposing poles, to become a technical artist or and artistic technician. By merging different, seemingly conflicting roles, school leaders can bring harmony and balance to the situation and deal with complex puzzles at the same time.... Every even or situation presents opportunities for leading while managing, managing while leading. (p. 43)

The principal's role as it has evolved is a mix of leadership and management. Further the role is subject to confusion and multiple, complex demands and prescriptions. The role is also being enacted in a system that is undergoing rapid and pronounced change often with contradictory demands. At the same time, principals are being called on more than ever before both to be active 
in defining their own role and in doing more of what other's prescribe. Perhaps embracing paradox is the only logical and rational solution to an illogical and irrational situation.

\section{Leadership and Management}

This section of the literature review focused on leadership and management. There was not a bright line of distinction between the two constructs in the literature and various authors have classified the field in different ways. Thus, this section of the literature review began with a review of how leadership and management have been compared, then historical reviews of the development of management and leadership theories were presented, and finally, a review of some conceptions of the relationship of theory to practice was presented.

\section{Comparison of Leadership and Management}

Hickman (1990) compared leadership and management in this way:

The words "manager" and "leader" are metaphors representing two opposite ends of a continuum. "Manger" tends to signify the more analytical, structured, controlled, deliberate, and orderly end of the continuum, while "leader" tends to occupy the more experimental, visionary, flexible, uncontrolled, and creative end.... The prototypical manager is the person who brings the thoughts of the mind to bear on daily organizational problems. In contrast, the leader brings the feelings of the soul to bear on those same problems. (p. 7)

The manger's mind loves the management-by-objectives (MBO) approach. The leader, however, would much rather practice management by walking around (MBWA), talking with people, getting in touch with their roles within the organization, and leaming how they perceive their roles, all in a very informal, unstructured manner. Managers like control; leaders prefer empowerment. (p.10)

Similarly, Owens (1991) contrasted two major theoretic orientations to organizations that he labeled classical (or bureaucratic) theory and human resources development. Classical theory emphasizes top-down, hierarchical systems with clear rules, procedures and standards. Human resources development "emphasizes using the conscious thinking of individual persons about what they are doing as a means of involving their commitment, their abilities, and their energies in achieving the goals for which the organization stands" (p. 48). Control is accomplished through socialization for the purpose of identification with the organization's culture rather than through rules and close supervision. The culture makes clear what the organization stands for (values and 
beliefs) and is communicated symbolically through stories, legends and rituals. Owens highlights the differences between these two models using McGregor's (1960) Theory X and Theory Y.

Theory $\mathrm{X}$ posits that workers are lazy and need close supervision to be coerced by formal leaders to pursue organizational goals. Theory $Y$ assumes that workers will exercise initiative and responsibility toward achieving organizational goals if work is satisfying and creative. Owens also cites Argyris (1971) who posited that Theory X gives rise to Pattern A leader behavior which has two principal forms:

Behavior Pattern A, hard, is characterized by no-nonsense, strongly directive leadership, tight controls, and close supervision;

Behavior Pattern A, soft, involves a good deal of persuading, "buying" compliance form subordinates, benevolent paternalism, or so-called good (that is, manipulative) human relations.

In either case, Behavior Pattern A, whether acted out in its hard or its soft form, has the clear intention of manipulating, controlling, and managing in the classical sense. (Owens, 1991, p. 49)

Theory Y assumptions give rise to Behavior Pattern B leadership. "This is characterized by commitment to mutually shared objectives, high levels of trust, respect, satisfaction form work, and authentic, open relationships" (p. 49). It was noted that Pattern A soft is often mistaken for Behavior Pattern B, and this has caused much confusion. Also contributing to confusion is that behavior that certain theorists might classify as management is labeled leadership by others. For example, Argyris' Leadership Pattern A would be characterized as management according to Hickman's (1990) typology.

\section{Management Theories}

Owens (1991) classified theory and research on organizations into four eras: Classical (1910-1935) emphasized task efficiency; Human Relations (1935-1950) emphasized the importance of people; Systems (1950-75) emphasized both task and people; and Middle Range (1975-present) emphasized task and people. In addition, the first three eras are characterized as being prescriptive and view organizations as closed systems, while the last era is characterized as being descriptive and views organizations as open systems. Odden (1995) postulated a similar classification with three basic schools of thought on management: classical or scientific 
management, human relations, and open systems. All three of these schools have offered different though complementary views of managers in bureaucracies.

Bureaucracies are hierarchically structured organizations, with service providers or workers at the bottom and mangers at the top of the organizational structure. Workers provide the service or make the product (do the work) and managers supervise an control workers (do the thinking). Each higher level office in the system has control and supervisory authority over a lower office.... Explicit rules and regulations control behavior. (p. 179)

The Classical Era, also referred to as the Bureaucratic or Traditional Era, focused on task efficiency and had great influence on educational administration. Taylor's book The Principles of Scientific Management (1911) promoted a) time and motion study to increase efficiency, b) standardization of efficient procedures, c) incentive pay and task assignments, and d) close supervision; and Weber's bureaucratic apparatus with its emphasis on a) division of labor, b) hierarchy of authority, c) rules and procedures, and c) impersonal relations to avoid friction and waste are characteristic of this era.

Owens (1991) described the Human Relations Era as a reaction to the de-humanized Classical Era. Mayo, with the Western Electric Hawthorne Plant Studies, established the importance of morale, group dynamics, personal relations and the importance of social and psychological factors in worker motivation. The writings of Barnard and Follet also emphasized the importance of people and human relations. Barnard identified and discussed the influence of the "informal organization", while Follet emphasized the need for "coordination" in all phases of administration.

Systems theory was in a sense a synthesis of classical and human relations thinking. (Open systems theory also broadened the frame of reference by recognizing the effect of the outside environment on the organization.) The most well known theory from this school was Getzels and Guba's (1957) two dimensional model which emphasized the interaction of the Nomothetic (organizational) dimension with the Idiographic (personal) dimension. Behavior of the worker was seen as a function of the interaction between the institutional role and the personality of the individual. Assumptions of this model were that the system would tend toward homeostatic equilibrium by self regulatory processes using feedback. 
Owens (1991) maintained that open systems approaches eventually led to contingency theory. "Contingency theory represents a middle ground between a) the view that there are universal principles of organization and management and b) the view that each organization is unique and that each situation must be analyzed separately" (p. 81). Contingency theory did begin to recognize the complexity of most organizations, but as Howe (1994) maintained, even though open to multiple possibilities contingent on environmental conditions, contingency theory was still trying to be prescriptive and generate universal laws of management.

Some writers have questioned the usefulness of management theory to modern organizations (Owens, 1991; Sergiovanni, 1995). These writers noted that management theory was developed in the context of bureaucratic systems and organizations comprised mostly of white males. Application of these theories to schools is problematic because key assumptions of the theories are violated. This issue was discussed in the latter part of this literature review in the section titled "Relating Theory and Practice."

\section{Leadership Theories}

A number of writers have developed leadership theory classification schemes which included topics such as: a) trait theories, b) behavioral theories, c) power approaches, d) situational or contingency theories, e) instructional leadership, $f$ ) transformational leadership, $\mathrm{g}$ ) cultural or moral leadership, and g) value-added or visionary leadership (Odden, 1995: Razik \& Swanson, 1995; Keith \& Girling, 1991; Taylor, 1994). This review of leadership theories was organized using Mitchell's (1990) simplified classification scheme which postulated three historical eras of theory about leadership: a) Being bom a leader (trait theories), pre-1948; b) Becoming a leader (behavioral theories including situational and contingency approaches), 1948 to present; and c) Being a leader (phenomenological approaches including cultural, moral and visionary leadership), late 1970s-present.

The "born leader" era emphasized trait theories and attributed "leadership to hereditary traits of certain individuals. Leaders posses certain extra-ordinary personal traits which predispose them for leadership roles" (Mitchell, 1990, p. 7). Early researchers examined great historical leaders 
and tried to develop lists of common traits that would reveal the single best "heroic" leadership style (Keith \& Girling, 1991). The advent of large scale psychological testing in the military after W.W.I provided a large body of data to test this type of theorizing. By 1948, "Stodgill found 124 different traits identified in the literature of the theorists," and it was questionable "just which traits were true leader traits" (Mitchell, 1990, p. 8). After this time, studies of leadership shifted in attention away from traits and toward leader behaviors.

Mitchell (1990) asserted:

"Becoming a leader" is a model of educational leadership which assumes that leaders are made, not born. Although countless variations exist within this broad category of "becoming a leader," those who hold this view agree that leadership is influencing the "behaviors" of the leader and followers in efforts to achieve goals in given situations. Whether the concern is focused on the behavior of the leader and follower to accomplish a task (Taylor's "scientific management") or on the behavior of the individuals relating to each other in groups and organizations ("human relations" and "organizational development") or on the style of the behavior appropriate for a leader in a given situation ("leadership contingency" and "situational leadership"), the common assumption is that becoming a leaders is primarily what a person does in a relationship with followers. ( $p$. 13)

Mitchell maintained that this type of leadership theorizing was heavily influenced by the positivistic Theory Movement of the 1950s-70s. Leadership was studied using empirical methods with the goal of developing laws and principles; "thus, the dynamics of leadership involved the leader's possession and use of knowledge, rewards and punishments, and awareness of the basic needs of the followers in order to influence and control their behavior" (p. 13).

Chemers (1984) reviewed the behavioral oriented approaches in detail. This era had roots in Lewin's (1939) work. Lewin identified three leadership styles: autocratic, democratic and laissez-faire. "The importance of this study was not so much in its results but in its definitions of leadership in terms of behavioral style" (Chemers, 1984 in Wren, 1995, p. 84). In the 1950s a number of independent researchers using empirical methods attempted to identify and develop theories about leader behavior.

The nature of this line of research was the identification of two variables, task and human relations (these have however been called various things e.g., initiating structure and consideration, task behavior and supportive behavior, task orientation and relationship orientation), 
and an investigation of the correlation of these variables with effective leadership. Owens (1991) described how earlier researchers (the Ohio State Leadership Studies, Blake and Mouton with their Managerial Grid) argued that there was a one best or normative approach that included behavior high in both task and people variables. Later researchers (Fiedler with a Contingency Model, House with Path Goal Theory, Reddin with Leadership Styles, Hersey and Blanchard with the Situational Leadership Model) argued for the situational or contingent nature of leadership and that particular styles were appropriate for certain situations. However, even though these later approaches recognized the importance of context for leader behavior, they were still fairly prescriptive in promoting certain leadership styles for certain situations.

Odden (1995) noted that

A second school of leadership developed in the 1950s and the 1960s and centered around power and various definitions of power. Etzioni and others postulated several alternative concepts of power-coercive, renumerative and normative, formal and informal, etc.- and how they were deployed by leaders and responded to by employees (p. 183)

Mitchell criticized both the "born" and "becoming" models of leadership because "neither model considers the part which beliefs, values, moral judgments, feelings, motives, intentions, dreams, hopes, illusions, and imaginations play in what leaders actually do" (p. 18) He posited a new conceptual tool to examine educational leadership, phenomenology, which he equated with "Being an educational leader."

A phenomenology of educational leadership is the analysis of the subjective experience, or consciousness, of leadership in education. In contrast to theories of educational leadership which focus on the personality traits and genetic inheritance of successful leaders, on the behaviors and knowledge of effective leaders, or on an appropriate style of behavior for a particular situation, a phenomenology of educational leadership focuses on the "is-ness," the nature and meaning of educational leadership. The phenomenological method can be used to analyze the subjective and interpersonal dimensions of educational leadership and to reflect on what educational leadership means in itself as a state of existence for leaders and followers. (p. 19)

Greenfield (1974) also called for viewing educational administration with a phenomenological lens. He maintained that human action and intention were the stuff from which organizations were made; and objected to viewing educational administration as a science by postulating "an alternative view which sees organizations not as structures subject to universal laws but as cultural artifacts 
dependent upon the specific meaning and intention of people within them" (Greenfield \& Ribbons, 1993, p. 4).

Burns' (1978) groundbreaking book Leadership introduced new ideas and vocabulary into the leadership literature. Two types of leadership were identified: transactional and transforming. Transactional leadership was characterized as occurring when

One person takes the initiative in making contact with others for the purpose of an exchange of valued things. The exchange would be economic or political or psychological in nature: a swap of goods or of one good for money; a trading of votes between candidate and citizen or between legislators; hospitality to another person in exchange for willingness to listen to one's troubles.... The bargainers have no enduring purpose that holds them together; hence they may go their separate ways. A leadership act took place, but it was not one that binds leader and follower together in a mutual and continuing pursuit of a higher purpose.

Contrast this with transforming leadership. Such leadership occurs when one or more persons engage with others in such a way that leaders and followers raise one another to higher levels of motivation and morality.... Transforming leadership ultimately becomes moral in that it raises the level of human conduct and ethical aspirations of both leader and led, and thus has a transforming effect on both. (Burns, 1978 in Wren, 1995, p. 100).

Couto (1993) noted that Burn's original concept of transforming leadership has been modified by others into transformational leadership. Couto noted that Burns' transforming leadership "changes some of those who follow into people whom others may follow in time" and changes "leaders into moral agents," and that Burns was careful to distinguish this from heroic or charismatic leadership (Couto, 1993 in Wren 1995, p. 103). It is asserted that the change to transformational leadership was not only a change from adjective to noun, but a new and different view that focused more on what the leader does to followers. Lost was the two way influence and instead organizational culture was emphasized to

create increased motivation in followers to attain the leader's designated outcome and eventually to perform beyond their own as well as the leader's initial expectations. The transformational leader has transformed followers into more highly motivated followers who provide extra effort to perform beyond expectations of leader and follower. (p. 104)

This distinction made by Couto is similar to Argyris' distinction of Pattern A soft and Pattern B. Ouchi (1981) postulated Theory $\mathbf{Z}$ which is similar to transforming leadership. Theory $\mathbf{Z}$ emphasizes the leaders ability to create an organizational culture where open communication, trust, and commitment to organizational goals is fostered. Consensual decision making and shared goal 
development contribute to a strong and consistent organizational culture that insures that efforts are closely and constantly aligned with organizational goals and objectives (Razik and Swanson, 1995, p. 50).

Odden (1995) listed Visionary Leadership as the most recent era, and this type of leadership is dependent on

whether the leader has a vision for the organization, can communicate that vision to the members of the organization, and then can empower service providers or production workers to implement the vision. Vision would include not only the definition of the business of the organization, but also the values and norms that would guide the implementation of the vision. (p. 183).

As theory in leadership and management has evolved, the emphasis has moved away from technical management and more toward visionary leadership. Also, the role and perception of theory itself has also changed from being prescriptive to being more descriptive. The proposed role of theory in present day practice was explored in the final section of this review. Relating Theory to Practice

Sergiovanni, Burlingame, Coombs \& Thurston (1992) noted that educational administration is a practical, applied field. The dominant approach to this field was greatly modified in the mid-1950s by a new program that came to be known as the theory movement.

The rationale for this new program directly challenged older beliefs about the training of administrators. First, the newcomers argued that traditional programs in educational administration were based on "war stories" about the ways that practitioners had plied their trade. These war stories had two shortcomings: They were idiosyncratic and they could not be accumulated. The stories were tales of individual deeds; these deeds were driven by the unique characteristics of the actor and of the situation. Equally, the stories could not be gathered, compared, and winnowed into a body of useful information. The stories had no common denominators: the language used to describe, to explain, and to predict the world in which the administrator acted was particular to that actor, time, and place.

In place of the private and the unique, the newcomers argued that social science methods produced empirical generalizations and theories. Starting with single research studies, social scientists such as sociologists and psychologists independently developed sets of research findings. These findings initially created empirical generalizationscommonalties that could be found when several independent research studies were compared. As these studies and empirical generalizations accumulated in journal articles, theories could be developed. These theories linked characteristics of actors and situations in ways that explained what was happening as well as predicted what would happen. Social science theories could provide public and cumulative knowledge about educational institutions and their administration. (p. 177) 
The implications for practitioners were clear; "faced by a practical situation, educational administrators should determine what empirical generalizations and theories could be applied," as "most engaged with the theory movement took the position that theory should prescribe practice" (p. 178).

The authors maintained that in recent decades, four challenges to the theory movement have arisen: educational administration as a) political, b) following rules, c) a craft, and d) ethical behavior. The political challenge took administrators out of the knowledgeable technician role and into a political actor role where "their judgments were frequently challenged, their authority disputed, and their power limited" (Sergiovanni etal., 1992, p. 180). The following rules challenge placed the administrator in a bureaucratized and legalized system where choice and decision making were very constrained. "Instead of autonomous actors, educational administrators act as agents of the state and are bound by the rules of the state" (p. 183). Administration as ethical practice frames the administrator as one who is concerned with creating environments for students and teachers that are fair and just.

Educational practice as craft (Blumberg, 1989) emphasized the development of a theory of practice.

Educational administrators develop a sense of what problems are like and of what solutions are possible in the same way that potters gain a sense of what the clay is like and of how this particular lump of clay might be shaped. This craft knowledge is gained over time as the craftsperson works in the medium and discovers what is possible or impossible with the particular lump of clay or block of wood. By reflecting upon the medium and its limitations, the craftsperson comes to have a store of practical wisdom. This wisdom is not static but grows over time and can be communicated in part to others who have not worked in the medium; only other craftspersons of the medium can fully grasp the meaning of discussions about working that medium. (Sergiovanni etal., 1992, p. 183)

The authors maintained that most practitioners have this view of administration emphasizing the particular and the variant, which is different than professors who are more interested in the universal and invariant. "Professors produced theories that suggested the universal and unchanging characteristics of clay; potters wanted information on the particular and changing characteristics of a piece of clay" (p. 184). The theory of practice emphasizes both the vision of the end product and a recognition that this will be influenced by the medium; "a theory of practice 
would examine the ways that craftspersons translate their visions given the problems of that particular piece of the medium" (p. 184).

Similar views were expressed by Kessels and Korthagen (1996) who traced the issue to classical philosophy. Knowledge as Episteme- the scientific universal was promoted by Plato, whereas knowledge as Phronesis- the contextual, practical wisdom was promoted by Aristotle. The authors argue that the epistemic view has dominated the study of education and a move to more phronetical conceptions of preparing for practice is warranted. Theories are important, but the emphasis is on perceiving the contextual situation clearly; the universal is subject to the particular situation instead of vice versa.

Kowalski and Reitzug (1993) stated there has been a recent attempt to balance theorypractice relationships in educational administrator preparation. Practitioners benefit from both theory and craft knowledge and the key is not choosing between them, but joining and fusing them (p. 11). It is proposed that the study of administration be balanced along three continua: a) craft knowledge - theory b) experiential training - classroom learning, and c) management - leadership. Sergiovanni (1995) conceptualized the principalship as reflective practice, "a science of the practical- a science that stems from theories of practice and that provides principals with practical as well as theoretical mindscapes from which to work" (p. 32). This is not a rejection of theory, but a recognition that the principal handles complex problems in turbulent environments under indeterminate conditions. These situations may violate the assumptions of traditional management and leadership theories.

The principals of the 1990s are faced with pressures for restructuring and reform that are forcing changes in the conceptions of their roles. At the same time new theories of leadership and management that are more descriptive than prescriptive are gaining popularity, and the role and place of theory itself in educational administration is being re-examined. Murphy and Beck (1994) described these conditions as being unique in that they are allowing principals to have an unprecedented voice in defining their own role and the larger roles of schools. But they also warned of a danger: 
Failure on the part of principals to enter into (and remain in) constructive dialogues on these topics could mean that others- not intimately related to or affected by schooling-will define missions, visions, standards, roles, and responsibilities. For nearly a century, this has occurred as others have defined who principals are and what they do. School leaders should be more proactive in shaping what the principalship is to be as we enter the 21st century. (p. 16)

In alignment with these conceptions, the focus of this study was to describe the role of the elementary school principals from the perspective and voice of the participants. 


\section{Chapter 3: Methodology and Procedures}

The primary purpose of this study was to explore how selected elementary school principals described and defined their work in terms of leadership and management. There were three sub-areas of investigation under this primary purpose: a) exploring the principals' conceptions about the constructs of leadership and management, b) exploring the principals' beliefs about the role of their personal philosophies, goals, or values in relation to their practice; and c) using content analysis to explore the language that principals use to describe themselves, their work and their schools. The methodology chosen for this investigation falls within the qualitative classification.

Krathwohl (1993) distinguished qualitative methods and a qualitative point of view. "Qualitative methods may or may not assume a qualitative point of view (QPV)" (p. 321). This study utilized both qualitative methods and a qualitative point of view. Using the qualitative point of view

researchers seek to learn how people understand their world and their surroundings... One is studying the meaning-making process, asking, "How do these individuals construct the meaning of their world?" This knowledge is a social construction of behavior... People are seen as acting according to the meaning of things and persons to them; their reality is socially constructed. From this viewpoint, it is necessary to see the world through the eyes of the actor to reach a full understanding of the purpose of that person's acts..... Phenomenologists argue that it is an individual's perceptions that count. (p. 322)

Krathwohl emphasized that "although anyone can use qualitative methods, not all who do so will adopt some form of qualitative point of view" (p. 323).

Berg (1989) also characterized qualitative methodology, and stated that:

quality is essential to the nature of things. On the other hand, quantity is elementally an amount of something. Quality refers to the what, how, when, and where of a thing-its essence and ambiance. Qualitative research thus refers to the meanings, concepts, definitions, characteristics, metaphors, symbols, and descriptions of things. In contrast, quantitative research refers to the counts and measures of things. (p. 2)

Berg's description and contrasts are more concerned with methods than point of view. Research can be conducted from an essentially quantitative viewpoint, even when exploring qualitative issues as described by Berg. 
Krathwohl made a further distinction between the quantitative and qualitative points of view:

the kind of social science that views such knowledge (results of research) as local and context-bound and encourages multiple meanings of situations without encompassing the explanation of those meanings in a single generalization is quite different from that sought by most quantitative social scientists. Social scientists in general may not embrace the natural sciences model, but neither are most willing to move as far from it as the fully committed QPVers believe is appropriate. (p. 323)

The purpose of the design of this study was to generate a qualitative (point of view), understanding and description of elementary school principals from the perspective of and in the voice of the participants.

\section{Qualitative Point of View and Research Paradigms}

Guba (1990) posited an analysis similar to Krathwohl's by applying Kuhn's ideas about paradigms to educational research (Kuhn's original work, The Structure of Scientific Revolutions, 1962, was focused on the natural sciences). Guba loosely defined a paradigm as "a basic set of beliefs that guides action, whether of the everyday garden variety or action taken in connection with a disciplined inquiry" (p. 17). Guba stated that there are three areas or questions that a paradigm must address: a) the ontological-what is knowable or real; b) the epistemological-how one comes to know, or the nature of knowledge; and c) the methodological-how one goes about finding knowledge.

The answers that are given to these questions may be termed, as sets, the basic belief systems or paradigms that might be adopted. They are the starting points or givens that determine what inquiry is and how it should be practiced. They cannot be proven or disproven in any foundational sense; if that were possible there would be no doubt about how to practice inquiry." (p. 18)

Guba also outlined the basic beliefs of some paradigms used in educational inquiry.

The first paradigm discussed was conventional positivism which Guba maintained had dominated inquiry from the time of Descartes until recently.

The basic belief system of positivism is rooted in a realist ontology, that is, the belief that there exists a reality out there, driven by immutable natural laws. The business of science is to discover the "true nature of reality and how it "truly" works. The ultimate aim of science is to predict and control natural phenomena. Once committed to a realist ontology, the positivist is constrained to practice an objectivist epistemology. (p.19) 
The objectivist separates the observer from the observed and adopts a distant, noninteractive posture. Values, biases and other subjective factors are excluded. The methodology chosen is experimental/manipulative where "questions and/or hypotheses are stated in advance in propositional form and subjected to empirical tests (falsification) under carefully controlled conditions" (p. 20).

Guba stated that postpositivism is a modified version of positivism with the goals of prediction and control intact and a heritage of rationality and striving for certainty. Ontologically, the postpositivists believe that reality does exist, but is imperfectly experienced or perceived by sensory experience. Epistemologically, the postpositivists retain objectivity as an ideal, but recognize that it cannot be achieved in an absolute sense. Postpositivists attempt to approach objectivity by striving to be as neutral as possible; by requiring reports of inquiry to be consistent with the scholarly tradition of the field, and by subjecting inquiries to review by peers (refereed work). "The latter two requirements also make it virtually impossible for new paradigms to assert themselves, an advantage not lost on the power brokers who protect and defend the (new) hegemony of postpositivism" (p. 21). Methodologically, postpositivism relies on multiplism and triangulation.

If human sensory and intellective mechanisms cannot be relied upon, it is essential that the "findings" of an inquiry be based on as many sources- of data, investigators, theories, and methods- as possible. Further, if objectivity can never be entirely attained, relying on many different sources makes it less likely that distorted interpretations will be made. (p.21)

Postpositivism also tries to correct some of the imbalances of positivism in the areas of rigor/relevance, precision/richness, elegance/applicability, verification/discovery by placing more emphasis on the latter of each pair.

A third paradigm discussed by Guba was Critical Theory (e.g., neo-Marxism and feminism). These theorists see the act of research as a political act because the choice of a value window in inquiry empowers some and disempowers others. The goal is to transform the world by raising the consciousness of the oppressed. However, Guba pointed out that this paradigm, in 
essence, seeks to replace one dominant world view (positivistic) with another (the world view of the inquirers).

The final paradigm discussed was constructivism, which Guba identified as his own orientation. Constructivism is a radical departure because constructivists "feel that the positivist (and postpositivist) paradigms are badly flawed and must be entirely replaced" (p.25). Four tenets of constructivism were listed: a) the theory ladenness of facts - facts only exist within a theoretical framework and reality only exists within the theoretical framework; b) the underdetermination of theory - no theory can be ever fully tested and facts can be explained by many theories, thus no unequivocal explanation is ever possible; c) the value ladenness of facts - similar to the theory ladenness tenet, facts can only be "seen" through a value window; and d) the inability to separate the inquirer and the inquired into - inquiry is the interaction of a researcher with a participant. Two implications of this last tenet are a) there is no longer a separation of ontology and epistemology, reality can only be apprehended by individuals, thus what is known and the knower become fused; and b) knowledge is seen as a human creation, never certifiable as ultimately true. Epistemologically, this is known as subjectivism. "If realities exist only in respondent's minds, subjective interaction seems to be the only way to access them" (p. 26).

To understand the difference between positivistic and constructivist ontology and epistemology, one can examine a famous philosophical question: "If a tree falls in the forest and there is no-one around to hear it, does it make a sound?" In the natural sciences the answer to this question seems apparent- of course it does, the action of sound is independent of human experience! However, in the social sciences, the answer may be more tricky, especially if the question is framed with social science constructs: "If a person leads, and no one is there to observe it, is there leadership going on?" The question is designed to ask if the phenomenon of leadership is dependent on human ability to perceive it. Constructivists believe that it is dependent, because the construct is a human description and needs a human describer to be used.

Guba also outlined the methodology of constructivists.

The constructivist proceeds in ways that aim to identify the variety of constructions that exist and bring them into as much consensus as possible. This process has two aspects: 
hermeneutics and dialectics. The hermeneutic aspect consists in depicting individual constructions as accurately as possible, while the dialectic aspect consists of comparing and contrasting these existing individual (including the inquirer's) constructions...

Constructivism thus intends neither to predict and control the "real" world nor to transform it but to reconstruct the "world" at the only point at which it exists: in the minds of constructors. (p.27)

Guba ended his essay with the idea that each paradigm has its merits and drawbacks, and that the struggle for primacy was irrelevant.

Each paradigm can be useful for particular research problems. This study was centered in the constructivist paradigm, and the following decisions were made: a) the researcher was the primary data gathering instrument; b) the research was collaborative so there were not subjects, but rather participants; $c$ ) the goal of the study was to construct a view of the elementary school principalship from the perspective of and in the voice of the participants-the only reality that was of interest was the reality of the participants, because it is within that subjective, personal reality that the principals act; d) the focus of the investigation was on meanings, perceptions and conceptions of things rather than on their implementation or in observable action; and e) the way to obtain access to this type of subjective understanding was through language, by talking with the participants.

\section{Phenomenology and Language}

The theoretical perspective of this study was that organizations are constructed realities.

Greenfield, in applying phenomenology to educational administration, stated:

We live. And in living we believe, assert self, establish order around us, dominate others, or are dominated by them. Action flowing from meaning and intention weaves the fabric of social reality. It is true that organizations appear to be solid, real entities that act independently of human control and are difficult to change. Yet the paradox is that the vital spark, the dynamic of organization is made from nothing more substantial than people doing and thinking. Organizations are limited by and defined by human action. In their deepest reality - that is, in their subjective reality - they are simply manifestations of mind and will. (Greenfield \& Ribbins, 1993, p. 92)

Phenomenology emphasizes the importance of individual perceptions. Organizations are imbued with meaning by those who belong to them and this meaning is expressed in language. "Language, because it is a primary revealer of beliefs about organizations and their members, is a phenomenon that helps to uncover constructed reality. It is evident, therefore, that anyone seeking 
to understand organizations such as schools or important stakeholders in organizations, such as principals, must consider language" (Beck \& Murphy, 1993, p. 7). Immegart (1988) in reviewing earlier work states that research shows that principals "talk from two-thirds to threefourths of the working day," that "administrative work is largely linguistic work," and that "it follows that the way to study what administrators do is to study their talk" (p. 39). Although this study did not record principals' talk in the natural setting, it did attempt to explore their world by analyzing oral responses.

\section{Methodology}

The data collection was accomplished using a series of semi-structured interviews with selected principals. Two types of results emerged from the interviews: a) narrative description- the principals' stories (Guba's hermeneutic), and b) analysis- emergent themes and limited generalizations (Guba's dialectic). The dialectic process utilized analytic induction where the transcriptions of the interviews were content analyzed using emergent coding categories for common themes or patterns. Similarities and differences were explored and conceptions and conclusions generated from this analysis was compared with the literature on mangers leaders and the elementary school principalship. Prior to data collection this literature was not explored in detail. This was a conscious decision to prevent the results and conclusions of previous studies from unduly influencing data collection and analysis in this study.

The concept of triangulation was used in gathering data, but in perhaps an alternative sense of the word. Krathwohl (1993) described triangulation as coming from surveying where three points can be used to affirmatively establish position; in qualitative research, triangulation is often conceptualized as using multiple sources, methods or observers. Postpositivists would argue for multiple sources of data from multiple stakeholders. For example, in this type of study, a postpositivist might want to examine the constructs of leadership and management from the principal's perspective as well as from the perspectives of his or her subordinates and supervisor(s). However, phenomenologists argue that it is personal perceptions that drive action. Krathwohl (1993) related an example of this. 
It does not make any difference whether you and I see a supervisor as hostile. As quantitative researchers, applying a low-inference rating scale to her overt supervisory behavior, we might find little or no evidence of hostility. But if subordinates see the supervisor's behavior as hostile, it will affect the way that they react to that person's supervision. To understand the reaction, we must understand the world as the subordinates see it; without that, the supervisor's actions might mystify us. (p. 323).

This study only investigated the perspectives of elementary school principals, but triangulation was used in that the central question was approached from three different directions represented by the sub-areas of the investigation.

Seidman (1991) described the purpose of qualitative interviewing and its relation to generalizeability this way:

The purpose of an in-depth interview study is to understand the experience of those who are interviewed, not to predict or to control that experience. Because hypotheses are not being tested, the issue is not whether the researcher can generalize the finding of an interview study to a broader population. Instead the researcher's task is to present the experience of the people he or she interviews in compelling enough detail and in sufficient depth that those who read the study can connect to that experience, learn how it is constituted, and deepen their understanding of the issues it reflects. (p. 41)

Generalizeability is not as important to the qualitative and constructivist paradigms as it is to the positivistic paradigms. The positivistic paradigms emphasizing reason and the discovery of universal laws seek to deduce generalizeable principles that can be applied trans-situationally. The qualitative, constructivist paradigm emphasizing language seeks reconstruction of experience and understanding from the participant's point of view. Knowledge is seen as being situational and contextual (Krathwohl, 1993).

Seidman (1991) elaborated on two alternatives in qualitative research to generalizeability:

First, the researcher may find connections among the experiences of the individuals he or she interviews. Such links among people whose individual lives are quite different but who are affected by common structural and social forces can help the reader see patterns in that experience. Those connections the researcher calls to the readers' attention for inspection and explorations. Second, by presenting the stories of participants' experiences, interviewers open up for readers the possibility of connecting their own stories to those presented in the study. In connecting, readers may not learn how to control or predict the experience being studied or their own, but they will understand better their complexities. (p. 42)

Following this paradigm, this study attempted to identify trends and themes within the group of participating principals, but generalizations to the larger world of educational administration were left mostly up to the reader. In a quantitative study, if a sample is randomly drawn from a 
population, then inferential statistics can be used to see if differences found in results are significantly representative of the population. Then, conceptual generalization can be done from the population of the study to the reader's target population. This study provided description and identification of trends and themes within the participant group, but did not have generalizeability, in the quantitative sense, as a goal.

\section{Participants}

The participants for this study were elementary school principals whose schools are within a one hour drive (60 miles) of Williamsburg, VA. A sample of eight participants was obtained by soliciting superintendents' and professors' nominations of exemplary or outstanding principals. Criteria for inclusion in this study included a) being nominated as exceptional, outstanding or high quality by a superintendent or professor; b) having been in administration for at least three years; and c) agreeing to participate in the study.

Originally, in January of 1996 , six school divisions were contacted for permission to conduct this study for a total of 69 possible participants. Three divisions were eliminated from this pool: a) one division's approval process was deemed too lengthy and it was eliminated; b) a second division granted permission to conduct the study, but no suitable participants were identified; and c) a third division granted permission, but all of the possible participants declined participation. The three remaining divisions contained 51 possible participants. Approximately 25 principals were identified as being exemplary by professor and superintendent nominations and were contacted by letter and a follow-up phone call about the possibility of participating in the study. Eleven of these principals agreed to a contact meeting to hear more about the possibility of participating. Three principals declined to participate after learning about the study in the contact meeting. One cited a lack of time for the interviews and two were concerned with both confidentiality and time issues. The eight principals who agreed to participate came from three divisions (four from Division A, three from Division B and one from Division C). 


\section{Data Collection Protocols}

The study design used the Three-Interview Series format (Seidman, 1991) for interviewing. All interviews and meetings took place at the principals' offices in their schools. Before beginning the process, contact was established with the participants with a half hour personal visit. The purpose of the contact visit was a) to begin to establish rapport; b) to explain the study's purpose, nature and conditions for participation; c) to ascertain if the potential participant was willing and able to participate; d) to obtain informed consent; and e) to discuss times, and dates for the first two interviews. Appendix A contains the Contact Visit Guide and the Informed Consent Form used in these meetings.

The purpose of the first interview was gather factual information on the principals and their schools; and to explore how they perceived themselves, their work, their roles and their schools. The purpose of the second interview was to gather data on the main content questions concerning leadership \& management and the role of personal educational views. The third interview was a member check where each participant had a chance to review his or her story as represented by the researcher. The third interview was conceptualized as part of both data collection and data analysis. Appendix A contains the guides used for each of the interviews in this study. The first two interviews were tape recorded and transcribed word-for-word. The researcher transcribed 10 of the 16 data interviews himself, and hired a professional transcriber for the remaining. The third interview was not taped, but instead the researcher recorded notes using pencil and paper.

Seidman (1991) recommended 90-minute interview periods spaced from 3 days to a week apart as an ideal or normative framework (it was recognized that circumstances often cause deviations from this framework). This structure "allows time for the participant to mull over the preceding interview but not enough time to lose the connection between the two," and the 90 minute time period is found to be substantial, but not overwhelming- "It's long enough to make them (the participants) feel they are being taken seriously" (p. 14). "With the contact visits, the telephone calls and letters to confirm schedules and appointments, and the three actual interviews, interviewers have an opportunity to establish a substantial relationship with participants over time" 
(p. 15). The interviews in this study were scheduled for 90 minutes, but many were concluded before the full time allotted. Often the researcher and participants chatted more informally during the remaining time.

The first two interviews (data collection) were scheduled at the time of the contact visit and were generally spaced two weeks apart. These took place February-April of 1996 . The third interview, conceptualized as a "member check", did not take place until the data from the first two interviews had been condensed and interpreted into each principal's story. Each participant was able to review and comment on how their story was being represented by the researcher, and emerging themes from ongoing data analysis were also discussed during the third interview. These third interviews took place in May of 1996.

\section{Data Analysis}

The results of this study were presented in two parts: a) description, Guba's hermeneutic; and b) analysis, Guba's dialectic. Miles and Huberman (1994) discussed three phases of qualitative data analysis: data reduction, data display and conclusion drawing/verification. They emphasized that each of these phases is a part of the analysis and involves choices and interpretation by the researcher. In this study, the description of the principals' stories served the purposes of data reduction and display, while the analysis served the purposes of further data reduction, data display and conclusion drawing/verification.

The data gathering interviews (one and two) were taped and transcribed to produce a "text" to work on. The first task of interpretation was to develop descriptions of: the participants; their contextual situations; their perceptions of their work, schools and roles; their views on management and leadership; and their perceptions of the role of their personal educational views. These descriptions were called the "principals' stories." To protect anonymity, all schools, localities and people were given pseudonyms in the write-up of the study. The second task was to perform content analysis on the stories to discover common themes or patterns, and to discover emerging similarities and differences between and among participants. 
Content analysis followed the principles of analytic induction. Huberman and Miles (1994) stated that:

At the heart of analytic induction is the thesis that there are regularities to be found in the physical and social worlds. The theories or constructs that we derive express these regularities as precisely as possible. To uncover these structures, we use an iterative procedure-a succession of question-and-answer cycles-that entails examining a given set of cases and then refining or modifying those cases on the basis of subsequent ones.... Inductive and deductive analyses are mixed. When a theme, hypothesis, or pattern is identified inductively, the researcher then moves into a verification mode, trying to confirm or qualify the finding. This then keys off a new inductive cycle. (p. 431)

The content analysis began with a second level reduction and display of the data accomplished by creating four matrices dealing with contextual factors and the three sub areas of the investigation. Analyses of the data were then organized into four sections: a) trends and commonalties that emerged from each of areas represented by the matrices were noted, analyzed and commented on; b) themes and issues that emerged from the reduction and analyses of the data were discussed; c) cross-case comparisons were made; and d) items and issues discussed in the third interview member checks were noted and commented on. The analysis and the third interview member checks proceeded simultaneously. Thus, the third interviews were both data collection and part of data analysis.

The analysis process was inductive in that it began with the data and not the theoretical constructs. Discussing this, Seidman (1991) stated,

I do not begin to read the transcripts with a set of categories for which I want to find excerpts. The categories arise out of the passages that I have marked as interesting.... When working with excerpts from interview material, I find myself selecting passages that connect to other passages in the file. In a way, quantity starts to interact with quality. The repetition of an aspect of experience that was already mentioned in other passages takes on weight and calls attention to itself. (p.100)

It was only after the regularities of the data had been identified and analyzed (in chapter four), that comparisons were made to theoretical constructs from the literature (in chapter five).

\section{Delimitations and Limitations}

There are a number of decisions or delimitations that were made in this study that limited its scope and generalizeablility. This study had a small number of subjects $(n=8)$. This was a conscious decision that was made in an attempt to cover the topic in more depth than breadth. The 
small sample size allowed the interviewer to spend more time with each participant than would have been possible if a larger sample were to be used. Limiting the participants to elementary school principals was done in order to control some of the institutional differences. Elementary schools tend to be headed by one person (as opposed to a team of administrators), there are more elementary schools to choose from and the schools (because they are neighborhood based) tend to have a little more individual character than the larger middle and high schools. The study was limited in geography and this was a reflection of limited financial and time resources, however, this also helped in controlling institutional variation as each school was under the same state and regional influences. The geographic limitation still allowed a variety of schools to be sampled in terms of locality, size and demographics.

The study adopted a theoretical perspective that limited data collection to the perspectives of the participating principals. No attempt was made to explore the relationship of the principals' subjective realities with the views of other stakeholders. Also, little attempt was made to determine if the perspectives of the principals were manifested in any concrete or objective way. The study was wholly focused on the perspectives of the participants as revealed in interviews and no observation or other "objective" methods were employed.

These delimiting decisions gave rise to the following limitations:

1. Only elementary school principals participated so generalization to middle or high school principals is limited.

2. The small, purposive sample drawn from three school divisions in the Tidewater Virginia area limits may not be representative of other contexts and this limits generalizeability.

3. The views of participating principals were solicited during three interviews held in the Spring of 1996, and no observational data or views of other stakeholders were included in this study. It is possible that participant responses were affected by perceived "response sets" where their answers were altered "in the direction the respondent deemed socially desirable" (Krathwohl, 1993, p. 392). The relatively short contact time and the focus exclusively on principals' views as expressed to an interviewer are limiting to generalizeability. 
The Researcher as Instrument

Guba (1990) stated that one tenet of constructivism is the interaction of the researcher and the participants in research. This study endeavored to present the subjective realities of the participants, but it was also recognized that this can only be a re-presentation, because the results are a subjective interpretation of the participants' perspectives by the researcher. Some commentators liken the researcher in a qualitative study to the data gathering instrument in a quantitative study. Thus, a description of the researcher was written (prior to the data collection) to allow the reader to asses the "researcher as instrument" and to state possible researcher bias for the reader to be aware of when reading and evaluating the results and discussion sections of this investigation. This description is contained in Appendix B: My Story. 


\section{Chapter 4: Results}

The primary purpose of this study was to explore how selected elementary school principals described and defined their work in terms of leadership and management. There were three sub-areas of investigation under this primary purpose: a) exploring the principal's conceptions about the constructs of leadership and management, b) exploring the principals' beliefs about the role of their personal philosophies, goals, or values in relation to their practice; and c) using content analysis to explore the language that principals use to describe themselves, their work and their schools. The results of this study are presented in two sections. The narrative description of the principals' stories served the purpose of data reduction and display. The dialectic analysis continued the data reduction and display and added the element of conclusion drawing and verification leading to limited generalizations.

\section{Narrative Descriptions-The Principals' Stories}

The following narrative descriptions are interpretations drawn from participant interviews one and two (see appendix A for specific interview questions). These stories have been reviewed by the participants and modified to reflect input from the participants during the third interview "member check". Each story followed a format developed from the three sub areas of this study: a) the stories began with the participants' description of their selves, their schools and their work; b) then the participants' conceptions about the constructs of leadership and management were explored; and c) finally, the principals' beliefs about the role their personal, educational views should play were related.

\section{Mr. Lexus (Division A)}

Mr. Lexus described himself as having evolved from a manager to a leader of leaders who emphasizes choice and distributed decision making:

In retrospect, I thought that the leadership of the building should be more than just one person and that the teachers really were in control of a number of areas that they really didn't think that they were in control of, or should be in control of. They didn't see themselves as leaders.

We tried to make some decisions that involved the teachers to a greater extent, because I could see that anytime they had anything to do with the decision, and they 
supported the decision, it was more successful-not only easier to implement, but much more successful. If it was just my idea and they're going to do it just because he said he wanted to do it, some of the things would not be successful. At that point in time, I didn't know that it was empowering, but I felt that they had more power than I could effect change with-together collectively, as a group. There were some rocky times though because of the people who were there a long period of time, kind of set in their ways.

Mr. Lexus describes his current philosophy as follows:

So again, its all along the lines of developing them as leaders in the building. People are not real comfortable. Some people said, "I don't want to be a leader" I said you are a leader; you're a leader in your classroom. So whether you want to be or not, if you don't want to be a leader outside your classroom, that's fine, that's your choice. But, you've got to be a leader within your room.

\section{Mr. Lexus also extended this philosophy of choice and empowerment to parents:}

It evolved to the point where we encouraged and requested parents to come in, look us over, and make requests as far as teachers. That was not well received by the faculty and a lot of parents really didn't accept that responsibility. But, I opened it up much greater than it had been before. Parents loved it. Teachers may not have thought it was the best thing to do, but we continue to do it.

It starts with my philosophy on choice. I really feel that if your going to get as much out of a kid as you can, you've got to have the parents behind you. And it really makes it easier not only for the child, but for the teacher to be able to function, for me to be able to function, if the parent has the opportunity to have some choice into where their child is in school-what teacher their child has.

Teachers thought that that was a kind of a wishy-washy thing to do. But, my philosophy was hey, I'm not God here and when I place a child in a class, I just know where he is academically, I know what the teachers have said about the child. The parents know him a whole lot better and if they have any input then we take that into consideration.

Mr. Lexus' Role. When asked to describe how he would like to be viewed in the

principalship, Mr. Lexus responded:

I really want to see myself as a leader of leaders. That's kind of evolved as we used to be referred to as the instructional leader of the building, but it's more than that. It's trying to get teachers to lead within their classrooms or outside their classrooms. I'm also seen as a supporter, as an encourager. Someone who is going to be there if they need me, but I don't want to get in their way. Hopefully they see me as someone who is supporting and encouraging them and allowing them to grow. I hope they don't see me as dictatorial, I don't know how they could... but, you never know.

Mr. Lexus also related how his role had evolved:

I don't want people to do it because I say they should do it. That's not the way it should happen. I tried to get to a point where maybe if I gave the idea, I needed somebody to bite on it, then they would take it as far as it would go. I would have loved for them to have the idea and then for me to give the support.

Mr. Lexus related that eventually it did evolve to the point where ideas and initiatives were coming from the staff as well as from him, and he became more of a leader of leaders: 
They came to me all gung ho and had been reading about it and wanted to do it next year. At that point, I didn't know too much about it, didn't want to squash any creativity that they had, but I said to them we really need to take this slower than what you are willing to do. I know you want to get it out there and do it. It has to be a three year thing. One year we have to learn all we can about it. I will support you, I'll buy any literature, I'll send you to any conference we can afford. (The second year would be teaching others and the third year would be implementation)

I said, it's your responsibility, the two of you want to do this. So you're going to have to take the ball with it and you run with it. I'll be there right behind you, but I won't be out front with this. I thought then it might die- didn't want it to die, but wanted them to be able to do this. They did.

One of the teachers came to me later and said, "I'm so glad that we took that time to do that, because had we done it the way we wanted to do it, it would have failed completely, because we didn't actually take the time to research it, to prepare the parents, and we didn't even think about preparing the parents and of course we would have implemented it, and nobody would have known what was going on.

Mr. Lexus' career. Mr. Lexus started as a teacher for five years in third through fifth

grade. During that time he worked on his Masters' degree in administration. His desire to go into administration started early:

I knew very early on in teaching that I wanted to go into administration. There was an economic situation also. I'm almost embarrassed to say that was part of it, but that was part of it. Economically, we wanted to start our own family. My wife was a teacher and we were only making about $\$ 7,500$ a year each. This was a way to make more money, but in the back of my mind, I thought that I was successful as a classroom teacher, and I was working with other teachers. I thought, hey, maybe I could effect more kids through the teachers. I always felt that I could do that, but the economic was part of it.

Mr. Lexus spent one year as an Assistant Principal at two schools and took over the principalship at one of those schools when his predecessor was promoted to central office. He described his early career in these words:

The school had been run by this prior principal who had been there since the opening of that school. She was very strong and very well liked. I really had no problem coming in and taking over. I was compatible with her organizational wise, and really agreed with a lot of the things she had begun there. But, as the year progressed, I saw rather quickly that she was a one woman show; she did it all. Even to the point where she did a lot of clerical work for the teachers. I really never saw that as necessary, I really tried to get the teachers, at that point even to accepting the responsibility of the management and the running of the school. There was a little bit of a rub that way for teachers as they were not familiar with that kind of thing, even given the opportunity or given more opportunity to give input. But, even at that time, I was probably more of a manager than I see myself at this point, because I really did manage the structure and manage the time. I was just really a caretaker that first year.

As we got involved in that school we started doing some neat things. We started proposing some new things to do like parallel block scheduling, keeping teachers with kids for two years. Those kinds of things, we did some Gizelle training which is preschool- 
developmental training. We really started some things that I felt really comfortable with and proud of at the school that we got the teachers to accept.

Mr. Lexus described his method for introducing change in detail. "Teachers were given the opportunity to talk about it, discuss it. I didn't really force it on them, not until we discussed it one year." Later, teachers came and asked if they could implement what had been talked about. "So really, it was initiated by me, but it was adopted and adapted by the teachers."

Mr. Lexus further highlighted the difference between he and his predecessor:

I had requested that the teachers be more responsible. For instance, the prior principal wrote the whole Self Study for accreditation. She did it all herself. That was supposed to be done with committees. It was interesting, the year that I was there with her, there was this mid-term evaluation of what had happened prior, and she sat down and wrote it all herself. I, not knowing any better, thought that's the way it's supposed to be. When I came on board, and realized that there was supposed to be committees and all that But, that was just part of her style, she didn't want that to get in the way of the teaching.

After seven years, Mr. Lexus was chosen to start a new school where he would be for seven more years. At this new school, he was given an opportunity to design things more than inherit things. Early in this process there was a "pivotal meeting":

It was an interesting meeting. A couple of people have referred back to that meeting. What I was talking about was just general stuff like parallel scheduling, how the organization would be running. I had a teacher come who had quite a reputation in the division for being very outspoken in faculty meetings-questioning the authority, questioning principals.

I had heard about her. She didn't have to move, she was just requesting a transfer. Towards the end of the meeting, I had gone through everything I thought I should go through, and she raised her hand and said "OK this is fine, everything you've said is fine, I understand and I agree. but I want to know about YOU." And I went, "Whoa, OK, lets get into it." That broke the ice with her, she chose to come. She's probably one if the best supporters that I had at that school. She still continued to question, but I encouraged her to do that.

She continued to think about what we were doing, talk about what we were doing, present to the faculty why we were doing things. She wasn't just a yes person. She did get on some people's nerves, but I thought it was great. I had heard about her reputation, and I thought this was going to be interesting to work with this person because I thought she can really cut you to the knees, and she was very articulate, very bright woman. She started asking me about this and about that, getting down into the basics. I said to them at that point, we were going to work on that together. It wasn't going to just be me.

She came on board, and we'd have faculty meetings and she'd question. I would really encourage that to happen because I could say something and you could hear it one way and this person another way, and perceptions could be altogether different. She would come back and say "are you saying this or do you really mean this? Or, why do we do that?" It gave me a chance to think about what I was saying, how I was presenting it and trying to be more cognizant that this was being heard by 50 or 60 other people. Some of the other teachers did not care for the way that she did that. 
Mr. Lexus is now the principal of a specialized school in it's first year of operation. In this present school, Mr. Lexus has had even more of an opportunity to develop things from the ground floor. In talking about this opportunity, he emphasized the importance of "beginning with the end in mind" and developing mission and vision as a group.

I have more of a staff. I have two directors and a librarian and a reading teacher and all of these people have been supportive in what we are trying to establish. That core of people over the summer before we came, we sat down and said which direction should we be going. Content is something we focus in on, but it's going to have to be content devised and developed by the teachers.

When I was appointed to this position, I though that there was going to be this big team from central office that comes in and says this is what this (specialized school) should look like. That didn't happen. For the first two or three weeks, I was relieved of my responsibilities at the other school in March. Which was unusual. I moved into central office and in two or three weeks, people said "Well, lets take a look at it." I said, "Wait a minute, I'm just myself, you know I really don't think that I should be the one to develop this program because its counter productive to everything that I've tried to do with the faculty." And, I didn't have a faculty, so what was I going to do? I determined that we needed to come up with a concept-beginning with the end in mind- what should be here. We wrote up a concept paper. That was a different way to start this school.

We said, we want the children to be interactive, we want the teachers to be facilitators with the learning, we talked about constructivism, and how we wanted that involved. From there, we had the teachers develop this development plan. They developed the mission. I wasn't about to do the mission, I thought that was crazy for me to come up with the mission.

With the development plan, with the School Improvement plan, it should be teacher driven, it should be teacher involvement. It was supposed to be done by October 1 , and I said there's just no way I can do it by October, because I can't get the faculty involved enough to get a product that would be suitable enough for us. I did get a little concern form one of the regional directors, by the time December rolled around I got a call "Well we gave you a couple of extra months, now where is it?" I said well remember, this is what we are trying to do and on and on. Finally, by the end of that conversation she said, "You sound like you're doing exactly what we want you to do, I understand why you need the time. You take as much time as you need." And, we got it to her in mid-January. It's the beginning of it, there's still a lot of work and we're still working on it. It has evolved to the point where everybody's on a committee and everybody is working in areas. They're all volunteer.

When asked where he saw his career going on from the special school, Mr. Lexus replied

that, "At one point in time, I though that I would like to do some central office work." However, now he feels differently:

With my experience with this school, and my experience of me working out of central office, in the interim time before this building was ready, I'm not sure that I would be comfortable in central office. The autonomy you have in a school is much greater than you have at central office. The feeling that I had when I left the classroom, being that I could effect more kids by working with the teachers that work with those kids- I could effect more kids by working with the principals-I don't know whether I could or not. 
Mr. Lexus feels that he already has some influence across the division:

They want to adapt what we are doing to a division wide effort. So, again even though we are doing it at this level, we can have and effect for other schools, if they want to join in, or if they want to use that. I do not want to leave the school division. I'm really happy with this position. Someone mentioned that later on they may need a (special school) director, I don't know. I thought it was clear before in my mind, but it's not as clear now.

Mr. Lexus' school. The school is in it's first year of operation, and is specialized.

Children come by choice, parents have to apply, and are accepted by lottery. The school is exceptional in having access to resources, and is designed to offer specialized curricula and

programs. Mr. Lexus described the ambiance or atmosphere of the school as follows:

I want it to be open, I want it to be friendly, I want it to be professional. The main part, that I want people to do, is be able to talk to people when they come in. They need to be comfortable and secure here so that they can give that off to people who are coming in. I want people to get together and feel comfortable with working with each other. I'm real interested that everybody works with everybody. I really want the kids to feel secure, and safe and happy. That's why we stand at the door and give hugs and talk to everybody and try to get to know the kids and their names.

Mr. Lexus' work. Mr. Lexus summarized his work as, "Typical day is contact with kids,

contact with teachers." He uses the computer network to keep contact with the staff using a teacher memo as well as informal meetings:

Teachers come in around 7:00-7:15. So I deal with issues and things that they have at that point. The kids come in with the bell at 8:05 so I try to be out front with the busses, announcements at 8:30 so I try to be around helping the kids with announcements. Then the day just kind of evolves responding to, some of it is reacting to things that are happening.

I told teachers last week I'd be coming in to observe and leave a little note. I don't do formal observations and conferences anymore. I'm not really convinced that that changes teacher behavior. There was a point in time that I would do 200-250 observations and conferences over a period of a year. Or, I would work with a teacher that I thought was kind of weak, and do the observation counts- I never saw a teacher improve using that method. They would do what I asked them to do, and when I left they would do what they thought they should do. I never really saw that it effected any change. But I did tell the teachers in a memo that I'll be coming around and doing a five- ten minute observation, and what I do is I go in and sit down for 5 or 10 minutes, write them a note and address the classroom, the management, whatever they are doing.

What I do now is management by walking around, a lot of management by walking around. It's funny because some teachers feel that he doesn't really know what's going on because he's not in my room. They don't know me yet, I know what's going on. I don't have to be in their room. I know by listening, I know by seeing, I know by talking to the kids, I talk to the kids a lot. Just informal stuff on a regular basis, you can find out a lot.

With the specialized school and it's larger staff, Mr. Lexus has found the need to establish a more formal communication system also. "We have a senior staff meeting every Monday 
morning with program directors, the reading teacher, the librarian and one of the counselors.

That's something new that $I$ had never done before." He found that, "we need to sit down at a regular time and just take an hour and just kind of talk about what's happening that week, the direction that we're going. Just come together, and that's worked out very well."

Mr. Lexus' views of management and leadership. For management,

The first thing that comes to mind is the physical plant. Managing the physical plant, making sure that everything is appropriate-heat, air conditioning, cleanliness, appearance. Next would be managing people, managing time, managing space and managing money. Those are the kind of areas I see as management. I don't have a whole lot of flexibility with the money issue because that's a real central kind of thing.

I control the time management, I manage space, I manage people as far as where they are in time in space within the actual schedule of it. Once that gets organized, I really don't have to do anything with it. I do the schedule, I schedule everyone in, and certainly they can have input if they want to go at a different time. However, the scheduling of the time is to have common planning time or collaborative time together. There's no infringement on that time. I want to make sure that we use the time we have available to us to the maximum.

Materials wise the only thing I have to manage is the copier and the laminator. Teachers are given a thousand copies a month; we have a machine that copies smarter than most of us, and shuts them down at 1,000 copies. We do have an allocation money wise, but I don't get the money. The funds stay at central office, and I can use that to purchase materials from the warehouse, paper and items that way. I kind of have to watch that. As far as space, there's not a lot of say in this building about who goes where as far as grade levels.

Leadership was described as "treating the teachers as leaders and encouraging them to be leaders within their classrooms foremost, but also outside their classrooms if they choose to do that." To develop these leaders, specific roles were set up and teachers were encouraged to choose a role to pursue:

We look at five areas to be leaders: reflective practitioners, educational entrepreneurs, staff developers, curriculum developers, or teacher researcher. We kind of identified those areas, and people could be more than one of those areas. I channel articles, readings, to certain people based on their interest. I do a lot of sharing, copying effective school practices that I receive and think that its good, and encourage people to do the same thing. They don't always have a lot of time to do that, their time is really spent in the classroom. I do get a number of people that go beyond and do the readings and share, and I encourage that. I encourage them to be proactive, to begin with the end in mind.

I try to encourage them not to see money as an obstacle or time and space as an obstacle. If they can think of something that they can support, and value and present. Hey, let's go for it. Let's convince somebody that you want to do it this way and let's see how it can be done. I'm not really tied to show me the research or you can't go forward, but it has to be supported. I try not to answer questions that people ask me, especially questions of philosophical type things where I think they should be coming up with the answers. I'll come back with "What do you think, where do you see yourself, where do you think these children should be?" 
I don't get a whole lot of questions because they think "Well he's not going to tell me the answer." I want them to be able to reflect and come up with their own. When I started this, I really learned from two people that did give all the answers. That was back in the time when I was taught that was the thing to do, you were supposed to lead the school and manage the school. You had all the answers. Quickly, I moved away from that. I was uncomfortable with it.

This type of organization and leadership does require a lot of time and energy of the staff:

I've never seen a faculty like this, they will come on weekends and over holidays and spend endless hours at night. I don't encourage them to do that, but if they want to, III provide the time- I'll open up or stay open. All my peers are asking, how do you get them to do that? I really don't know. It's not a motivational type of thing, maybe it is, I don't know, but it's an enabling type of thing. Enablement to come here and do what they want to do.

Mr. Lexus saw the constructs related in that

I think you have to do both, you cannot be an effective leader and not manage the building. The little things will kill you. If you don't attend to the details of the job, you can be the most eloquent speaker and know exactly what you are doing, but if the busses don't leave on time, if discipline is crazy, if you're not using the space, if you don't have any money, leadership is not going to do you a thing. I'm not exactly sure you have to have an equal balance, but I would like to see leadership as higher than management. But you've got to be able to manage time, space and money.

He saw management as part of leadership, or the two overlapping. However, he then stated:

Even the smallest thing could affect your leadership. What I see as management has to be taken care of in order for effective leadership to occur, be established or flourish. I can't see anything that would be outside it, so management in leadership is best.

Mr. Lexus' role as a manager and leader. Describing his own role, Mr. Lexus stated:

I see myself as actually evolved from the manager at the beginning of this time that I started, to now getting into the leadership part of it. I was really a strong manager. It's not been a tug, I've really been comfortable with moving away from that. In order to enable people to take on leadership roles is more difficult than to manage them, by far more difficult. You don't know how much to push or where. You kind of have to get to know the person and see how they act and react with other people in order to encourage them to get out there and take some risks. You get burned a lot by surprises. You encourage somebody to try or to take a risk and they fall flat on their face, you got to be there to pick them up. There might be some one that's there underneath them in the process. You gotta make sure you cover your ground that way.

Mr. Lexus sees his role in the leadership process as follows: "We can't all be going off in different directions, we need some focus to it. I guess that's the way I come in. Trying to provide the focus, trying to kind of keep things together."

He also commented on the need to interact with people outside the school: 
I spend a lot of time on that phone, networking with people outside the building. Probably more so than many of my peers. Central office, supervisors, directors-trying to encourage them to get involved or share with them what we are doing. I have no problem taking risks, but I don't take risks in a vacuum. I take risks only if other people know about it. I feel very supported by central office, from the superintendent on down. They collectively as a whole should be more in touch with what's going on in the schools; I never see them in the schools. The actual directors at central office control many of the budget functions, we as principals or leaders in schools have to go to them and ask for things, it shouldn't be that way. We're able to utilize that money to its fullest. They should do centrally what I try to do here, throwing out ideas, taking risks, they should have been coming up with plans. They should be the clearinghouse of the ideas and the brainstorming. I don't see that happening to a great extent.

As for management, "Everybody has their own responsibilities," secretaries, custodians

and teachers. "I don't see it as a daily function that anybody has to go around and make sure that they are doing their job, it's an expectation." Mr. Lexus also emphasized the routine, "once things were established, starting this school management wise was easy, the schedules were prepared and done and I didn't have anybody come and say this schedule doesn't really work."

The relationship of leadership and management was implied as Mr. Lexus stated:

I tend to see that teachers don't see the total picture sometimes, they tend to see what is happening in their four walls, but they don't see how it affects outside of that area. That can really throw a wrench into things. I try to keep a framework of not just what is going on in this building, but what is going on in the division.

Role of personal, professional views. Mr. Lexus characterized himself as more

collaborative than directive:

I'll share my views with anyone who wants to hear them, but if they don't actually agree with them, that's fine. I'd like to hear how they feel. And if works for them, hey, as long as it works, I'll support it, if the kids are progressing and are successful.

He was passionate about having high expectations:

I do believe all kids can learn, but they learn differently and at different rates. Our expectations should be that they will learn. There certainly are constraints to that that we don't have any control over, but we shouldn't focus in on those constraints, we should do whatever we can to make sure that the kids are successful in whatever they try to do.

I really want everyone to have the same thing, high expectations of the kids and the teachers. I really think that you raise to what is expected of you. Don't put anybody down. Don't determine at the beginning that they can't do it. They might not be able to do it, but don't figure out long before you actually know that you can't.

As far as his personal role, Mr. Lexus stated:

I see myself as a trailblazer, but I'm not out there alone, there might be some people back there, but they're right here, right, right with me. I don't think you can afford to be out there by yourself. You have to have the majority of people with you if you are going to do 
any traveling. I guess that I don't see myself way out in front. I see, in comparison to my peers, myself way out in front, but in this building I don't want to see myself way out in front.

When asked about any constraints or restraints, he replied:

I don't have any. I could say that I would like to do this with that money or this money. Money might be a constraint, but I don't really see it as a constraint. If we really thought it should be done, we should find a way to do it. I may do things unorthodox, I don't always go by the book, but I'm not afraid to do that, so I don't see the book as a constraint. If I think it should be done, it will be done. The constraints are probably more in our head than in central office.

Working with central office was not seen as a problem, but these insights were offered:

Central office has been incredible with the latitude they gave us. I've been in the division for twenty something years so they know I'm not crazy and they do have a certain amount of trust in what I can do, but I still am amazed at the amount of latitude and there were no constraints with it.

I don't see constraints, I could have seen things as a constraint, but we just try to do it, and often we can. Constraints are a thing of your own, you've got to push the parameters. I think it's because I know people, I know how it works and it's the politics of the whole thing too. I will say to others, why don't you ask? I've never had a problem when you can propose and support and show the reason and the rationale.

You have to know how to work with people. I hope I would never treat the lowest person in the division any less than I'd treat the superintendent. Some way that guys going to help you, unstop a toilet or... When the new superintendent came in, I didn't know him, but he knew me. I made sure he knew me, and knew what I was doing. My peers were complaining that he didn't know their names. "How does he know your name?" Because I put it out for him, you just can't sit back. Not that I was trying to use him, but you have to play the game.

\section{Mrs. Parker (Division A)}

Mrs. Parker described herself as an innovator, and change agent with a service mentality.

She is very excited about change, but sees change as a collaborative venture.

The exciting thing is we are getting a reputation nation-wide as a division that's on the cutting edge of things. A lot of that has to do with the superintendent. A very driven individual, and requires that of his people. He really looks for strong commitments in them. A strong service orientation and it's nice as it fits with the way I tend to think about things. My business cards have my home phone number on them. I do this job basically 24 hours a day. Fortunately, the security system is the only group that believes me enough to call at four o'clock in the morning.

I really believe strongly in a personal touch and a personal level of involvement. Our job is not to be here to do a job, but to serve the clients. We've got to really not just promote education today, but we've got to market it. Marketing and sales are two different things, and I think we've been in the monopoly business for quite a while, then we moved into "We'll put up a good front, we'll get PR going, we'll publicize the great things we do". But to really improve you've got to look at where are the skeletons in your closet, find those and address those, and sometimes that's a pretty uncomfortable spot to be in. 
Mrs. Parker's Role. When asked to describe herself and the way she functioned as a principal Mrs. Parker stated:

I'm a people person. I'm not a real manager. I probably drive people wild because I like change; I think it's exciting and fun. I'm innovative. The phrase that bothers me the most is: "We've done that before, or We've always done it this way." But, I also recognize that most people aren't real comfortable with change. So I try to make sure that I balance out and give a comfort level of lots of encouragement to try new things, but not a mandate that you have to do it. I believe in teachers buying into what they are doing so that they have some ownership in it rather than just doing it because somebody said you have to.

When asked how she would like to be perceived, Mrs. Parker responded:

I'm the supporter, I'm the encourager. I've been in the place where I'm the fire-er, I don't like being in that spot, but I can do it. I don't do mandates, and sometimes people will get frustrated with me with that because I'll look and I'll say if you're waiting for me to make the decision, I'm not going to do it. You are the ones who are out there in the trenches in the front. You've got to live with it, so come to me with some solutions or some ideas and we'll talk through it, but I'm not going to tell you what to do. And they'll look at me like, "There she goes again!" As you move from the way of the principal as the manager of the building to a leader of leaders as Schlecty defines it, you have to give people the chance to lead and a lot of times they don't want to lead. It's easier to not. So there's some resistance there and there's also the worry, well what if I make a wrong decision? I'm just a teacher, and my point is you are THE teacher. Yes you need to make the decision, you make thousands of decisions a day, and you can make another one. You can do that.

She also described her role in these terms:

Devil's advocate a lot of times. I was given a "Yes, but" fly swatter. It's one of those killer phrases that put in obstacles to a discussion. Instead of saying "yes, but", the situation should be "why not" or "what if" or "why can't". Exploring possibilities. We've got the "Yes, but" fly swatter every now and then to tell us "don't tell me why it won't work, tell me what might make it work, how we could make it work, or what it is that we need to change."

Mrs. Parker's Career. Mrs. Parker began her career teaching kindergarten and transferred

into an EMR program. After four years she retired from teaching and started a family. She decided to return to education with the idea of going into supervising special education programs.

During her internship in supervision, there was an opening for an assistant principal and she was

offered that position to fill out the remainder of the year. She then returned to kindergarten teaching for two and one half more years, became an instructional specialist at two schools for one year, and then was selected to be an assistant principal for a year. She moved to a principalship the next year, and has been at the same school for five years. During these years she went to several different universities and just took what she needed to be certified as an administrator. She had 
previously been in a Master's degree program. When asked when she first knew she wanted to be principal she responded:

I think I first knew when I actually did the internship and I saw that the way my mind worked, I'm more suited to big picture ideas and how the pieces fit together. It was very difficult the next year to go back into a classroom and concentrate on kindergarten curriculum. I kept thinking, but when they get to fourth grade they're gonna.... I kept trying to think big, and it was hard to go back and narrow your scope. I started working on my Master's degree when I got out of Baccalaureate. I just felt that in some point in time that would be something I would want to do.

When asked about her career plans she stated:

When I started out, I think my goal was to be a director of elementary Ed, or something like that. I don't know now. I really don't. I love being in the school setting. I don't know if I'd like being in the central administration building setting. For the time being, I'm real comfortable right where I am and I'm not imagining it ever getting to the point where I say I've done everything I can do in this job, and it's time to move to other challenges.

Mrs. Parker's School. Mrs. Parker described her school as one of the largest elementary schools in the division, and because of it's large size, there is a full-time assistant principal. It is also a neighborhood school, with great community involvement. It is not greatly impacted by low SES ( $21 \%$ on free and reduced lunch), but very impacted by the military. "Even though we don't have a lot of cultural diversity, within our school, we have cultural experiences within our school with the travel in the military." There is a 70-30 racial balance with no bussing.

When asked what the ambiance of the school was, Mrs. Parker responded:

It's a comfortable place, but a focused place. When you walk in these doors, you're here for the business of learning. You have respect for other people and the responsibility to make sure that not only you benefit from the educational experience, but those around you are able to also. The community should want their kids to come here. That they don't feel the need to send their child to a private school or to sign up for a magnet school because they're better. In our mission statement we looked at who our clients were and what it was we truly believed was our responsibility in educating children. We talked about educating the whole child before... Well, actually we're an educational institution, it is our job to provide for the academic needs of the child, social where they fit in, to embody that emotionality in the right channels, but that maybe it wasn't all our jobs.

Mrs. Parker's Work. Mrs. Parker's work was described as follows:

The really good thing about our school is that I don't spend a lot of time putting out fires. It really is a school that I get to think a lot about what we want to do. I monitor and adjust where we need to. I'm not constantly faced with an office full of children needing disciplinary issues. I hope it's because of what I get to do, the thinking, the planning, the implementing. 
On a typical day Mrs. Parker arrives at 8:00 and takes care of details associated with opening the school, "by 9:30 that's pretty much slowed up. Instruction is well under way by then. Usually by that time, I take a tour of the school, take a walk around and see how things are going."

Mrs. Parker is very involved in overseeing what's going on in the classrooms.

My goal was to have every child write me a letter requesting that I come and listen to them read or share writing with me or something like that. So, I'm either making appointments with the kids or I'm going to the appointments that I've had (almost 900). I go into the classroom, I don't have them come to me. I go in there and we sit and read some. At the same time, I see some things that are going on in the classroom. And then I go in for short visits... I don't do very many going in for half an hour, take my notepad and script out things. It really has to do with my personality. Sometimes, I go in and I just do a random... who's asking questions, what's the depth of the questions, how much time is teacher talk. Sometimes I'll go in and actually script, sometimes I just say, I want to see you doing a shared book activity, I'll come in at your shared book time. I want to see how your writer's workshop is working, have a child share a portfolio with me. Or, I'll go in during math class and say explain to me what you are doing, what do you know about multiplication? Kind of just keeping a finger on things. I do a lot of real quick in and out kind of things.

Mrs. Parker tries to avoid her office. "I try not to stay in here more than I have to, it's a pretty

grim place." When asked why she might stay in the office, she replied:

When I need to return calls, or I'm expecting someone to come, I'll piddle; but I'm not a real good piddler. I tend to get involved in too many different things and I spread and it makes a mess. These are awards, and I need to sign all of those. I personally read all of the report cards. I know the kids by name, I even know all of them. Most of the parents... at least if I see the child with the parent, I can put the name together. Usually call them by the right name, but we have a lot of parent involvement so I spend a fair amount of time with that too.

Mrs. Parker describes her afternoon in similar terms to her morning as far as handling details:

Afternoon is same as morning was, figuring out who needs what, "I need this by tomorrow, what do you think about this?", clearing things for a calendar, running ideas by. I read anything that is to go home to parents, I read it first to proof read it, edit. Just to make sure that we have the right messages going out, another set of eyes. I don't get into what they run off the copier. I'm not into micro-management. I spend a lot of time talking to parents and teachers on, how are things going, what do you think about such and such, almost like a survey assessment.

As far as yearly cycles go, Mrs. Parker does not see much change. There are certain very busy

periods like opening and closing of school. She described it this way:

August is the busiest month, trying to get the class settings ready and the lists typed up, make sure you have all the people you want. I've yet to have a full staff at that time. That's a real chore. Staff development you need to do and the initiatives and the letters to the faculty and the staff welcoming them back. I haven't found a slow month yet. I really haven't. It all tends to run at a pretty quick pace. Even though you try to spread them 
through the year, they get heavier at that point. It's not a steady flow, but it's got peaks and not big peaks. Kind of cut off mountains. It's always busy, the end of the marking period is higher, that's self imposed. I'm the one that chose to review all the report card. I chose to personally sign the awards, rather than using a stamp, but those are things that I feel are important. So, they're worth spending my time on.

Mrs. Parker's views on leadership and management.

Management is dealing with the logistics of how to make things work within your school. More along the lines of scheduling, lining things up, trying to make sure things run according to a schedule. If you were designing an agenda or a program, that would be the management aspect. What you determine to do first, how you prioritize things. It doesn't have much to do at all with leadership.

Leadership is the visionary, setting goals, figuring out if you're on target for those goals or off. I love listening to the Covey tape of "Seven Habits of Highly Effective People" it talks about management, the leaders and the workers. The workers clear the forest, that's their job. The middle managers they're encouraging them on, keeping their blades sharp, and all that. The leader is the one that has climbed the tree, and is looking for where it is they want to go. Often times what you find is the leader calls down and says, "We're heading in the wrong direction. You've got to stop and go right" Very often the managers will call back and say, "No, we can't stop we're making progress!"

Unless you know where you are going, unless you have someone to do that visioning for you and to see if you're on the right track, and monitoring, you can often find yourself on a road that is not taking you in a direction you want to go. The system tends to self perpetuate itself, and you keep rolling down that wrong road. Or, doing the same thing you've always done, and getting the same thing you've always got, and wondering why you're not getting any better.

Mrs. Parker also felt that managers spend more of their time dealing with the urgent important, whereas leaders should be focusing on the not urgent, but important things.

Mrs. Parker described the relationship of leadership and management in these terms:

They're related in that you need both of them. You need to find a balance for both of them, if not you end up again just kind of scheduling things and moving ahead, but you don't know if what you're doing is making a difference or not, unless you have the leadership aspect. If you have the leadership aspect without the management, you tend to flounder in all these ethereal ideas and feel we should and why can't we's but you won't be able to get the pieces together to make it line up and work. I think that's where you can balance things well between your administrative staff or between leaders you've recognized in the school, because generally you're better at one than the other so you have to find someone who can balance you out. If you're not good at the details, then you need somebody who loves doing details, and pondering through the everyday things.

Mrs. Parker stated that conceptualizing management as contained within leadership would be the optimum arrangement, but that management and leadership overlapping was the way they most often function, with separate areas of leadership and management and a large section where the two overlap. She stated: 
It sure is easier to make management decisions when you know what your optimum outcome is. If you know we're going to protect the instructional day as much as we possibly can, then someone who is managing things is not going to design fifty pull-out programs to occur in a week. They're going to look at that driving force of the leadership that says this is what we need to be about.

Mrs. Parker's views on her role as a leader and manager. Mrs. Parker described herself as

more of a leader than a manager:

I'm better at the leadership stuff. I have people that can manage things very well and I rely on them to be able to do that. My assistant principal is real good at managing things. I rely on her a lot, and certain people on the faculty that I know are good sequential, think it out types. I can do the logic stuff, and I can do the sequential stuff, but the nit picky stuff I'm not real good at.

I'm better at the big pictures and then figuring out how the little pieces work. Managers tend to like the little pieces all lined up in a row to know that they're going toward the other place. Communication is the hardest part of it all. It really is. What I say or write or send across somebody's desk, they look at it with their own set of lenses, and they perceive certain things about it. Then they tell the next person about it. It's kind of like that rumor game, by the time it gets to the end of the line, it's changed around a bit.

Mrs. Parker also talked about the difficulties of trying to distribute and balance the

leadership and management functions:

I think the staff expects the leadership mostly to come from me, and sometimes when I try to just sit and be quiet, we have a very quiet meeting. They kind of wait to see what I'm going to do or what I'm going to say. I have some people who will really come forward and tell me exactly what they think about something.... I don't like to be THE leader, I like to be part of the leadership.

Mrs. Parker also recognized that her ability to delegate, even within the management functions, was limited:

I can only expect other people to manage the other things so much which is why I try to have a hands-on approach to most things because I realize that it's part of what I need to be able to do, to manage. Different reports that we need to write, things that just have to be done, I can't always rely on other people to do that. Because, I'm the main source that they come to with things. If somebody wants to bring something up at a faculty meeting, they come through me to do it, so I need to set the agenda.

Describing the changing role of central office, Mrs. Parker stated:

We were very used to a central office that told us what to do. The dictates came from on high, and we're the middle managers who implemented what we were told. The role has changed to where the supervisors now are responsive to what we say are the needs. People are at different levels of buy in of whether they're really going to do that or not. We laughingly say that "We do site based management as long as somebody else didn't want to do it." Or if it's something that maybe you're going to catch a lot of flak on, that's very often given to us, "You make that decision, you're the one's in the trenches." Which also means that you're the one in the front lines that is going to get shot at first. But, when people do start shooting at you, you are supported, it comes very quickly to aid with that. 
The people who like that and will take a risk and make decisions about things, it's been good that we are able to do that. The people who like to do what they are told to do, and if you have a concern take it to central office, they make the decisions. To them, it feels like they have kind of been dropped. While support may be there, you also sometimes wonder, well is it really and truly.

Mrs. Parker recognized that is was sometimes easier to implement a top down mandate, but that

there were reasons to distribute leadership:

Because you truly are the community school, the first place the parents should come to to ask the questions. You look rather ineffective if you say "I don't know why we do it that way, why don't you call somebody else and ask them. If you're going to be the one that's putting it into action, I think you should be the one that's able to say "Yes, I'm the one who made that decision."

I think we've moved beyond the management issue, and the management issue was when the people that were principals were the excellent football coaches. They were good at strategically laying things out with do this, do that, do the other, and not a lot of questions asked of things. Leaders are required to do a lot of mediating, marketing, communicating. I don't think that those are skills that managers necessarily posses. When they started looking at what differentiated successful schools from those just getting by, they saw more leadership skills than they did management. They looked at the practice of the principalship and the practice of teachers within buildings and saw a common thread with schools that make the most progress and are moving ahead and seem to be on the cutting edge of things. They're the schools that you see more forethought and planning rather than just doing the routine of the day. I think the position has evolved because of people. It wouldn't have been recognized, if there weren't some people out there already bucking the system.

We happen to be lucky to have a superintendent that buys into that management style. He stood up and said it would be much easier to be a dictator and run a totalitarian regime, this is the way it will be and you will do, and if you don't like what I say, then I'll cut your head off. That would be the easiest thing to do, but it probably would not be the most effective thing to do.

Mrs. Parker's beliefs on the role her personal educational views should play. Mrs. Parker

saw the role of her personal beliefs being bounded, but important.

You have to do it all within the context of State laws and federal laws of what's allowable and what's not. But, I think your beliefs are what guide your vision, and the culture that you develop within your school. It gets translated verbally, it gets translated non-verbally. What things you put emphasis on and how much accountability you hold for different things. The screen we put everything through is, "Is it good for kids?"

There were other areas that Mrs. Parker personally emphasized:

I feel that there is an amount of character education we should do, even though that's not part of an identified curriculum. I just feel a responsibility developing the citizenry of the future, we have that responsibility and obligation. I think that it's important to be very tolerant of other people and accepting of other people, and encouraging.

As far as developing the vision, Mrs. Parker stated: 
I'm probably the one who is most vocal about it. As soon as I say, "what do you think about this?", they're jumping on the wagon. There's not a great deal who will come forward and say I'd really like to do such and such, maybe some, but I'm probably the one who spends the most time on the professional magazines, reflecting on things like that. My bent is looking for things that are new and different, so I kind of go out and seek them. The others are involved in the day to day, how do I teach Johnny to read. I think probably I don't always come up with the idea, but I come up with it most of the time.

However, in developing the vision, Mrs. Parker saw herself as marketing, more than selling.

I tend to more market something, than I do sell it. I see those as different functions. Selling is: this is why you need what I'm going to give you, and I've got the biggest and the best and the neatest, so of course you'd want mine rather than wanting anybody else's. Marketing is you find out what the need is and then you design something that meets that need and put it out there. Is this what you were looking for? That's why I try to spend a lot of time listening to the staff, the parents and the kids, to find out what it is you're wanting. What would make this be the thing that you just say, I got to have that. I probably don't try to come up with too many things that it's just my idea and I push it forward. If I'm out there by myself, I'm not usually going to go.

When asked about constraints on implementing vision, Mrs. Parker was concerned about

the conservative direction of the state board of education. "I'm worried about who it is that they're listening to. I don't know that they're always the people that are in there day to day." Another concern was testing:

I hate standardized tests. The optimum way of showing that you've learned something is to be able to demonstrate it, to be able to write about it, to be able to talk about it. Picking it from a choice of four or saying whether it's true or false, that's small potatoes. That's something you can learn for the moment and forget tomorrow. If you've have to sit and reflect on it and analyze it, and be able to turn it into your own words, then you do know that. I believe a lot in student presentations.

Another concern was the image of the education profession.

We've also allowed ourselves to not be treated as professionals and we don't act as a profession a lot of times. We'll see things going on that have no business going on, but we turn a blind eye to it because it's easier to do nothing. I think that's not right.

External constraints were also mentioned:

Expectation from a community and the taxpayer base also impinge. When you think back to most of the people in leadership positions, some were raised in the seventies and some go back further. The way people interacted was different. In the seventies it became the norm and the expectation to question things and to think that everything that was organized was wrong. There's a deep dark secret to all of this, so you began being very suspicious and looking for problems. It used to be if the teacher called the parent and said your child misbehaved in school today, the child was definitely going to have a problem. Now it's "what do you mean he misbehaved?" and "why did you ask him to do that", and "what right do you have to... " You really go on the defensive a lot of times in trying to deal with things. When I was growing up, if the teacher had called my mother or my father, there 
would have been no questions asked of that teacher, "are you sure?" Now, there is, and so it's hard to listen to what people are saying without being defensive about it.

One constraint described was the way money was allocated and spent:

One of the biggest things is, do you have the money to support what you want to do. We pretty much can manage our budgets under the guidelines that are given to us of this can come from this fund, this can come from that fund, you can use this, you can't use that. When the budget freeze came, we had no determination of I'll give up this to continue that program. It was just, no, that will stop. In crisis situations you revert to old ways, that's the easiest thing to do.

We've worked a lot on equity doesn't mean equality, I think before we worked on an equality system. Everybody gets this whether you need it or not. Now it's justify to me that you need this or share with me why, or free up that money to go to somebody else who desperately needs it, if you don't have that need in your building, and maybe you'll get some more. One of the big things, instead of using a lot of consumable workbooks, we've opted to go with classroom sets that could be a resource book. Thinking that if we did that, the money that would be normally allocated to us for like everyone to have an English book, that we would get that money to be used in a different way. Usually what's happened-until we went forward and said this really is not equitable- is "oh you don't need that money, well we'll just use it over here for something else that we need." I didn't say I didn't have needs, I just didn't need what you were specifically offering, but I did need something else. So it would have been nice to be able to come back and say I don't want to buy the literature anthologies, but I want to buy a lot of trade books and novels. Until very recently that wasn't the case. It's still a lot of we can make decisions and things, but there's still an old guard way of thinking, and a lot of times you don't know that that's the way they are thinking, until something happens, and then you go into "wait a minute."

\section{Mrs. Kaplan (Division A)}

Mrs. Kaplan described herself as a no-nonsense, business-like principal who is building a

community in her school that has a culture of encouraging student achievement in a variety of

areas. Her passion for encouraging students in diverse areas comes from her personal educational

history, where she had felt a lack of support and encouragement.

We're trying to give children the opportunity to develop leadership roles. My generation, women didn't do this and if you weren't cute and assertive, you just sat, and if you were like me, you read all the books and that's just what you did, and really didn't know what you could do. And it's not just the brightest who can be leaders. Because these kids, who might not have all the academics, or don't think they have, or we don't think they have; once you get them hooked onto something, then you can make the applications and transfer those skills. Children need to know that they are valued for who they are as an individual, and so we have to provide opportunities for them. Yet it takes a lot of time, and some times we think it's taking instructional time, but we have to learn that all of these things help with instruction. It might not help on every multiple choice or true and false whatever, but if you can get these kids hooked on reading, it is going to increase their reading. If you can get their parents in there to see their book that they did or encourage children to participate in oratorical contests, then you're developing kids as leaders. And, you can't wait until they're all in 8th grade or 10th grade for that to come out. They all have something to offer. 
For me this is something that emerged and is solidified by what I've read. It's emerged from me as a person by my own jog from here to there. I wonder what I could have been if somebody had mentored me. And I don't think we do that enough for kids, and it's the kid who doesn't cause the problem who's apt to get left, who's very quiet.

The job of providing a comprehensive education that fosters the development of the whole child (academic, social, emotional and physical) is seen as the responsibility of the whole school community as emphasized by the slogans, "Education is everybody's business" and "It takes a whole village to raise a child." Mrs. Kaplan also stated:

The first thing I tell new parents is: Children come first. I'm strict, but I'm fair. The kids, and the staff will tell you that. I expect a lot from the kids, I expect a lot from the teachers, and expect a lot from myself. By teachers, I mean everybody, custodians, teachers, assistants-we're all teachers for these kids.

Mrs. Kaplan's Role. When asked to describe herself, Mrs. Kaplan stated:

I'm not the most gregarious kind of person, but I think that I'm a compassionate person and I'll do everything that I can, but I am business like. I'm pretty open, you would know where you stand, but I try to look at all the avenues before I make a decision. I do run a tight ship.

When asked if she was collaborative, she responded:

We do try to empower teachers, but it's very difficult, because you find that many people do not want to be empowered, they want to be told what to do, and that's that, because once you're empowered, it means that you have responsibility and you really have to put forth some extra effort. So I can say that I've really tried to work at that, but there are some things that every superintendent that I've worked for has said, "You're the one in charge, and some of those are your decisions, and everything cannot be a democracy." I know that I've worked at it, but there are days when it's much easier to dictate. But, we learn and evolve and grow.

When asked how she would like to be perceived, Mrs. Kaplan responded:

I guess as a person, one who's willing to listen, who's compassionate, but also that understands that the children come first, and that we do not have time for petty kinds of things in a building. Basically, I'm here to help to develop leaders in this school, whether children or adults.

Teachers usually don't or haven't looked at themselves as a leader, they looked at themselves as an isolated person in that classroom. This is something I've worked with teachers on in the last couple of schools, getting some people in to work with them and let them understand and develop them as leaders. Because they are leaders, not only in the classroom, but in the school and in the community. That's a different way to look at it then what has been the norm. The principal has been the leader, and the teachers followed. That's not what we're trying to do.

Mrs. Kaplan also described her views on how the role of the principal has changed:

There were many elementary principals who were really high school people first. They realized that there is sornething to be said about people in the principalship that have had 
that background at that particular level, as opposed to just being certified as an administrator. It makes a difference with the teacher's perceptions because most of the time you've been there and can walk in their shoes. Some of the administrative things are the same, but the instruction is not.

Mrs. Kaplan's Career. Mrs. Kaplan began her teaching career in a religious order.

The community life was first, the teaching, the job, was second. So, when I was all of 19 , they sent us out to teach. We were not quite finished with our degrees, but schools had to be staffed. So we got approximately two years of college, with a lot of it being theology. I was to teach first grade. Which is the last grade that I probably want to teach, or anyone thought, because I was very, very quiet and serious. However, you do what you're supposed to do. For seven years I taught first grade or second grade. That's how I got into teaching.

Mrs. Kaplan described transferring from the religious order into secular society as being difficult, but as being helped by a good mentor:

I was very fortunate to have met the Dean of Students at (her college) who helped me and guided me. It's hard to understand when you're that old, 27 years, and you don't have any money and you've never worked except in a convent or teaching and scrubbing and cleaning and all of that. So I finished my degree, he helped me.

Her career in public schools was characterized by a rapid rise into administration which she also credited to having met good people who encouraged her.

I started working in the public schools in the city of Pittsburgh. If I hadn't had seven years of experience behind me, going into a classroom in the middle of the year, I probably would have walked out like the other people who did. Within the next year, I was promoted to a team leader. I worked there for about five years in second grade, then I worked for a publishing company, then I moved down here and it was the year of integration.

When they saw my resume and that I had worked in a disadvantage school even though it was the best second grade that I ever had, they hired me and sent me down to (a school) which was under court order to be a primary neighborhood school downtown. They put me in first grade, which was last on my list of grades to teach. I taught for one year, then I was a consultant for half a year. Then I was an AP, then I became principal.

Basically I arrived here because people had said something to me. I never believed that I could do all these things. I was also very fortunate with the people I met in the administration building. They encouraged me too, and opened up the consultant position to an assistant principal which they didn't have before. They wanted to know why I hadn't come up to apply for the position. I didn't know that I would have the requirements. I had a master's degree in curriculum. Which I think really helped me, I think I'm a better principal because I have the curriculum background. Basically I was encouraged to apply for an AP and encouraged to apply for a principal's position. We didn't have to go through the paperwork and interview with ten people, basically they called you. And it is a lot different, I've asked myself how I would have survived with a panel interview, but apparently they saw something there and this is my twentieth year as a principal.

This is Mrs. Kaplan's third school. She spent ten years at the first one and five each at the other two. When asked if she thought is was good to move, she replied, "In ten years you've taken a 
school to do different kinds of things and it's time to move on. We'd done some things instructionally and the super said why don't you try those things in another place." When asked if she had further career plans, Mrs. Kaplan responded, "At one time I thought I wanted to be in charge of elementary instruction, but then I looked at it and saw the people always going to meetings."

Mrs. Kaplan's School. Mrs. Kaplan's school is not a specialized one, but it has a lot of special programs. The special programs along with some court ordered bussing bring a variety of students in. She also characterized it as relatively small (it's the smallest of the three she's headed). The school has a regular k-5 elementary program and a special needs program that Mrs. Kaplan is overseeing. The whole school is her responsibility, which is new this year. She described this transition as, "It is a different paradigm, because the teachers down there did their thing, and the teachers up here did their thing. So it's growing pains right now, but I think it's coming along nicely." Most of the time the special needs program is separate, but there is increasing integration between the two programs. Mrs. Kaplan has two administrative assistants overseeing the two programs. She described that position as follows:

They do not get paid like an AP (a sore spot)- regular teacher's salary plus ten extra days. They do much more work. They're supposed to be certified as an administrator. Their prime responsibility is discipline and a learning activity for them to see if they really like admin. and for us to see- The Peter Principle does come in. There are things you have to do as a principal that are somewhat like a teacher on a larger scale, but there are some things that are unique.

Mrs. Kaplan also described a number of special instructional programs. Many of these programs enjoy wide community support and focus on recognizing student achievement in a variety of areas "We try to let our kids know that we're not in this alone, that education is everybody's business, and it takes a whole village to raise a child. We try to work with different areas of the community."

When asked how she would like the school to be known, Mrs. Kaplan replied:

It's a place for kids where all kids are made to feel welcome. People come in and you can tell it's a place for kids. Kids' work is up. Children seem very happy. I want it to be a school where it is very evident that all our children are safe, not only physically, but psychologically. It should be an inviting place. I want to be a school where we tap into the complete person we develop the whole child. It sounds like a trite comment and everybody 
uses it, but we're talking about not only academics, but an emotionally healthy child, we're talking about the Arts. And, we want this to be a place for them to feel successful at where they are. That leads to the foundation of what they can do when they go onto the next level. Elementary school is a school for elementary kids. It's not, as people keep saying, a place to get them ready for the next grade. You have to do what they're doing at that particular grade. I want these children to continue to think they are all artists, and I could never say that because I could not draw a straight line, and I don't want them to feel that here.

Mrs. Kaplan's Work. Mrs. Kaplan described the overwhelming nature of her work load:

There is too much put on everybody. We like to say that we have site based management, but when it fits we use that term, but the role of the principal has changed. When I first started, I used to teach some classes, work more with kids and was able to do more instruction. I haven't stopped since I came into the building. It makes it very difficult, because we're always reacting to crises. I told a teacher who's interested in administrationyou're always in crises management as a principal and that's the sad part, there's not enough hours in the day. We started at 7:45 with a staff meeting, to take care of buses, cafeteria. I dealt with a bus incidence, two discipline slips from the bus, and a parent with an incident at the bus stop. I talked to a counselor because we have child protective services incidents, with children. Then I had to talk to children on the bus, and talk to transportation, and had the nurse check the children and had the secretary to draft a letter to the parents of the kids on the bus. I had to deal with a permanent sub issue. A few other things, and I got you right at 10:30.

Mrs. Kaplan emphasized that the crises situations and the busyness is part of a typical day, and she added these comments:

The afternoon is very typical, I try to make sure that I have walked the building at least once. My observation and my leadership is by walking around, which is different than I would like to do. Which is different than I had to do before. The job has changed, which is a concern, because the stress level is so much higher for every person in education, teachers, principals, superintendents, everybody. Tomorrow we have a lot of child studies to do, and parent conferences.

When asked about yearly cycles of work, Mrs. Kaplan responded that there are always things to

do. Child studies, testing, staff evaluation/oversight, and dealing with social/family problems

were mentioned particularly:

At one point I would have answered differently. Now, it's an ongoing merry-go-round. It used to be that we'd say that January and February were slower months, even as far as teaching goes, it's not. Now I'm trying to catch up on children who need to go through child study, because we need to go through as many modifications and strategies in the classroom before we take them to that next level, and before we say they need to be evaluated. So I work with the teachers prior, but during this time we need to set up meetings to meet everybody's schedule, and parents' schedules because we do want parents at those meetings, it's very important. It makes things difficult, and you have to get all that in.

We test too much and we don't have time to teach, and we're not evaluating on what the children need to be evaluated on. Our children have made a lot of progress, but it doesn't always show up the first year. And, with so many new children in 3rd, 4th and 
5th grade, over half the classes, they do not have the culture of the school, so it takes a year to get the children and the parents to understand the culture of the school-we are about business and we try to do things a little differently.

I feel as a principal, I owe it to every staff member to spend time with them at the beginning of the year and at the end of the year, on an individual basis. But as far as doing a whole lot of writing and clinical observation, if I had a staff member who was really having a lot of problems, that would be a little different, I would have to do that. But, I've also found that some of the things that lead to people that should not be re-hired are things that can be documented very easily, like not showing up for work on time, not showing up, not calling, not being where you're supposed to be. Those kind of things where you don't have to sit in a classroom. And, not being a member of the team. I know by walking around and listening to kids. Bus duty, cafeteria duty, in the halls- I do try to talk with them, in the classroom.

The kids you really know are the kids that are either sent to the office or there are so many emotional problems or family problems that you do know those ones. The other kids you don't know as well because they're not the ones you have to spend so much of your time on. We spend $90 \%$ of our time with $10 \%$ of the population. Today, we are spending more and more time with family problems, custody cases, having to get subpoenas. Which means another call to the liaison person who helps us with that. All of these kind of things, the social, the emotional, that at one time we did not have to be involved with. That's what is taking the energy of everybody. Children cannot learn, contrary to what everybody thinks when they're so upset, like the case we had yesterday and today. The child has been abused by the natural father, gone to court in Georgia, child has been abused by the mother, now it's the new step-father.

Mrs. Kaplan's views on management and leadership. For Mrs. Kaplan, management is:

Making sure all the I's are dotted and all the T's are crossed. Following all the rules and regulations of the state and federal government and the procedures of the school system. Anything that makes the school run smoothly and efficiently. It's putting everything together. When you get down to it, especially in an elementary school, where you're dealing with the whole person, everything seems to interact. If the busses are not running on time, it affects your instructional program. That's where your leadership should be in. So if you don't take care of why busses aren't there, or if teachers are not at their duty stations when they should be there, then that becomes a management issue, but it effects instruction. Management seems to take an inordinate amount of time when you're trying to make sure all the rules and regulations are followed, whether it's due process for children, due process for teachers, it has to be followed. Management, it affects leadership.

Leadership is having an understanding and a vision of where you want your organization to go. To be able to convey that to your clientele and your employees and in some way hopefully they come to the realization that that is also their vision and they are the leaders in it. Everybody tries to become a member of the working team. It's different than management because the leadership has to be there, or a school could be run by a robot. Leadership takes an awful lot of time because you've got to articulate what you want, not just to the staff members, but to the parents and the community.

They're related because if you don't have the management, then it is usually very difficult to keep it all together and carry the vision. But, if you're always spending your time in management, which too many times today we feel we are, you never get time to do the leadership, because you are trying to do other kinds of things.

If you don't have enough management, you are always putting out fires, so you don't have the time or the energy to devote to leadership. Our problem today is we're doing too much crisis management. More so than we ever did. With staff members and children. There are just more crises. This year we've had more people with medical leave, accidents with workers compensation, problems with pregnancy, who's subbing for 
whom, who might have to go on leave. I almost need a score card to remember who's here on what day. That takes all management, that's the paperwork that's connected with worker's compensation and family medical leave, we may not have to do all of it, but we have to be aware that this is the procedure that has to be followed so we can talk to personnel or payroll to make sure that the employee has information.

I have a full time administrative assistant, for the third year. The management for discipline is her responsibility, but I cannot totally delegate that as I feel that I need to be involved in little people's problems. It's my job to be on top of that, whether we need social services, social worker, child study, or psychiatrist, we have to look at all of those issues. My administrative assistant does take care of textbooks, scheduling for some of the field trips, those kinds of things I've been able to delegate. I don't need to get involved unless I get a call and someone says something's not right. The testing, but I still get involved in that, because testing is so crucial, but it's more or less supporting and training people.

Mrs. Kaplan sees the two constructs as overlapping and cites the smooth operation of the

cafeteria as an example:

It took teamwork of the children, the parents, the cafeteria staff and the teachers to make it run. And if a simple thing like that doesn't run well, it carries over not just to the serving line, it carries over in the cafeteria through lunchtime, but it also carries on upstairs if the teacher couldn't implement what they need to do for instruction. I think that there's a lot of overlap.

\section{Mrs. Kaplan's views on her role as manager and leader.}

It's evolved. I was more authoritarian in some of those areas than I think I am now, but it often depends on where they are coming from. You just learn which people you can depend on and how things should be run. The leadership is an ongoing process to empower people, but I've also found out that most teachers do not want to be empowered, no matter what they say, because it means they also have to think. And, it means that they have to be involved in that process and they can't just blame the principal.

In leadership you still have to be a people person, and my demeanor might be one thing- I'm a very intense person and I know that. I'm not your party person. I am about the business of what I'm here for. That's always difficult for some people to understand. So you continually work at trying to get people involved. And you find that people are very emotional about all this, but you can agree to disagree, and if you disagree, that's $O K$, because we have an understanding that it's all right to disagree as long as you can back up what you're saying. Sometimes we'll change, sometimes we'll not.

Mrs. Kaplan discussed her and other's roles in leading the school:

The reflective part comes when you have a chance to skim journals, to go to conferences to listen and to bounce things off some of your key people. My reading person here is excellent. It was difficult for the people who were here before as we differ from them, and I also brought some people with me. And some of these people are movers and shakers.

We always seem to be ahead of the game, I had a supervisor tell me that, you have an uncanny way of knowing what is coming, you're already doing it when everybody else is just starting to think about it. I never looked at it that way, I thought that it was just what you did. We are trying new things, and when you have the kind of kids we have today you can't do what you did before. You just can not do it. Teaching is different, being a principal is different, different than it was eight years ago. It's more draining, more burnout, and more stress. But we try new things, I wouldn't want it any other way. 
When asked about the role of central office, Mrs. Kaplan replied:

The superintendent has a vision, there's no doubt in my mind what he stands for. The people I usually call on, they always come through. I think many people at central office are just like everybody else, overworked. They're too many jobs to do, that when you need them, it's hard to get them. But, I feel supported on the whole.

Mrs. Kaplan also stated that she wanted direction as well as support:

There are some things I feel have to be system wide. Once (an instructional method) is a philosophy, it should be that everyone adheres to it, because some of the problems we're having in this school is that people have not been, and we get the children in the upper grades, they are lost, because it's not the same thing. But, it doesn't mean that they are all on the same page. Some of those kinds of things, we need to have some consistency in the system, particularly this city that's so transient.

In her own school, Mrs. Kaplan has, at times gotten very directive, after collaborative efforts have not yielded results:

And, that's been where I differentiate in leadership being collaborative. Even though in adult education they say, when they're ready they'll do it. Well, I don't buy that. We were at the point where we needed to go because obviously what we were doing was not working. If you keep on doing the same things, you get the same result.

However, she also related trying to be collaborative at first:

One of the things you try to do is sell things to key people and you hope that they'll try it in their classrooms, and get them to continually talk about it. When they do, you have more people coming on board.

Mrs. Kaplan's beliefs on the role of her personal educational views.

Being a leader means having a vision and knowing where you want to go, you can't help but have your own philosophies and goals and values system in play. Hopefully, you would take into account other people's philosophy, to try different kinds of things. Basically, my philosophy is that kids are important, we need to teach the whole child and not only part of them. In teaching the whole child, we have to reach their emotional needs, and today more so than in any other time in my career. You have to take care of the intellectual, the cognitive, but you also have to take care of the creative, and I would not have said that maybe 20 years ago to the extent I say it now. My philosophy as a principal is to do for kids and teachers what no one did for me.

Mrs. Kaplan cited the following things as evidence of her views being implemented in the school:

a) "when all the kids in this school think they're artists, that's one of the things we're trying to do," b) when the kids use manners and are polite, c) when "kids here want to come to school," d) when "we can't keep up with the books in the library, and we've spent a fortune on books, and they're being used." However, Mrs. Kaplan emphasized that this was not her doing alone: 
It takes everybody. Also, because whether I'm here or not it should run. The leadership has to come from whoever is here. We try to get teachers to understand that they are leaders also. In fact we've done some workshops with teachers on that. That's still difficult. There are some things I let a committee decide, others we do it because it's important for the kids.

When asked about restraints or constraints on implementing vision, Mrs. Kaplan

specifically mentioned a lack of flexibility in spending ("Finances affect what you can do. We really don't have options and we're not given a lump sum usually"), and lack of flexibility in personnel issues:

We have due process procedures, your hands get tied in personnel issues. If so and so doesn't buy into this program, I shouldn't have to have them put in for the transfer. I pretty well have done that, but it doesn't go anywhere if they don't want to transfer out. It doesn't mean that they are not a good teacher either.

It takes a good three to five years to get a staff, through attrition and hiring, to get a staff that pretty much agrees with you. I don't know how anyone can do anything in two years. Today if you have administrators that are leaders and visionaries and want to move, you have a lot of resistance, especially in the first couple of years. I convinced now that it doesn't really matter who you are. One of the problems is that the staffs don't move, but the administrators do. That's one of the reasons that you can't make the progress you would like. Every principal that has the opportunity to staff an entire school says the same thing. Even though everybody might not work out, you're only looking at a piece of paper and a short interview, but it's like night and day, because you have not inherited somebody else's philosophy in that building and that makes a difference, it makes a big difference.

\section{Ms. Elliot (Division A)}

Ms. Elliot described herself as one who is committed to making a difference in the lives of the "at risk" students who comprise the majority of her school. Two areas of emphasis were described: a) implementing developmentally appropriate practices, and b) helping to meet the basic needs of students that are often found wanting.

She described herself in these terms: "I am pretty personable, sometimes too personable. I like people. I care about kids deeply. I support my school, I love my school, I love to talk about my school and brag about it."

TQM is important to me, I see the parents as my customers too. I want them to be very, very happy and feel that their children are in a safe school where they are learning, and that I'm taking care of everything. With their help. I will take care of educating their children, I will make sure that they're fed, I'll make sure they're safe. I'll make sure that they are free from a whole lot of nagging issues, so they can concentrate on their education. I want the superintendent to see me as someone who is doing a good job, making a difference. 
Ms. Elliot's decision to become principal of her school stemmed from two factors: she empathized with the social circumstances of her students, and she had a passion to implement developmentally appropriate educational practices in her school.

I loved these kids. I had really grown to love this area. Once I understood the family structure, and the make-up, and what these children are all about, and what happens to them, what unbelievable circumstances many of them live under once they leave me.... Plus, I had this real vision-I saw things in early childhood changing to the ways I had always believed in- the floor thing, the hands-on, getting rid of board work and dittos.

Ms. Elliot's Role. When asked how she wanted to be perceived as a principal, Ms. Elliot responded:

For my staff I want them to feel- I always promised that if I left the classroom, I would never forget the trials and tribulations of being a classroom teacher. So I want to always be understanding of what they are going through. I try to be accommodating whenever possible, unless it's repeated and I'm getting suspicious. I don't want anyone to think that I'm trying to be a powerful person. However, I want everybody to know and understand about my passion for what's appropriate for children. I know that's come up over and over, and it's the number one thing.

For parents, Ms. Elliot also wants to be seen as one who is empathetic, one who listens, and one who is dealing with concerns. "When they (parents) come in angry or concerned, I've never had a parent leave out of here who did not see things more clearly and have a greater understanding, and feel that everything is fine."

Ms. Elliot's Career. Ms. Elliot traces her interest in education to her sophomore year in college, "my mother advised me to take some education courses, just in case, plus you have your summers, your Christmas and your spring break. And, I thought now that sounds great." Her first job came as a result of being recruited.

I think they needed more racial mixture with the teachers. It was very Jewish, very upper class area. The guy I was hoping to marry was going to (the same area). We went up there got married and I taught in the schools. I thought well this is fine. I like first grade, works for me. I like the kids.

She moved to another city with her husband and continued to teach, then "due to varying circumstances I ended up in (this area) with my son, as a single parent."

She then taught in a university laboratory school which she really enjoyed, "it was a very forward thinking and progressive school in the area of creativity and I really like that. I don't like a lot of rigid structured, that kind of thing with children, I believe they should be more natural, 
natural setting." However, the lab school did not provide enough support for a single parent. The next part of her career was a marked difference:

I decided to apply to the public schools. I went to a school which had very low income students. I had just come from the lab school where I had students who were professors' children, lawyers, doctors students and very, very well behaved, well dressed, come to school every day fed, two parent families. When I went to 0 in 1985 , it was like I stepped into another world. Now I thought that I could teach any child, anywhere, anyhow- and children were just children.

These children were just children, I was the problem. I was not used to children who came to school hungry. I was not used to children whose parents-not because they didn't care- but who didn't come when I asked them to come for conferences, because they were surviving, they're worried about their survival. I didn't know all that . My father was a college professor, my mother was a high school principal. I had never really been in an area that was at risk. The first year was pretty awful, although I had lots of support. I kind of thought, is this really what I want to do?

On the advice of her mother, Ms. Elliot began looking at something else, administration.

My mother saw an ad in the paper about a college orientation on administration- I do have a college degree in elementary ed., my master's degree is in early childhood- then I went to the orientation. It seemed reasonable, an advanced certificate in administration. I had admired the assistant principal at my school and I thought, I would like to be an AP, that would be a dream come true. You don't have all that final responsibility, yet you still are with children, yet you still can get away from children when you need to. I thought that I could be a part of educating every one. When I'm a teacher, nobody listened to me, but as a supervisor, you have to try things I ask you to try, sort of. That was my goal to be an AP.

Her rise to the assistant principalship came quickly. After 22 years of teaching and

completing the administration course work, she was hired as an assistant principal, split between

two schools.

I have to say I learned the most here, the principal at the other school was very nice, a good leader, but had a big school and didn't have the time to kind of show me the ropes. But, the principal here included me in everything. Every conference, every problem, every glow and glory- I was with her along the way. Then she was in an accident and out for an extended period, so I had to take over. That lasted one school year. That June the superintendent called me in, he said that he was transferring the principal here and he wanted me to take the principalship. After I came back from the faint, from the disbelief, of course I said yes. I thought that if I said no, he might not ask me again. But, I wasn't really sure that I was ready, because I had only had three days a week of training, and I was kind of nervous.

She has now been principal at the school for three years. When asked about her future career, she replied:

If I could pick what I wanted to do, it would be to stay right here, to continue to make a difference in children's lives, continue to educate teachers to the beliefs that I feel strongly about, have the same passion for what's appropriate for children that I have. And, I'm 
getting there. I feel that if I moved to another school- I'm $60 \%$ where I want the school to be- if they move me, I'm afraid it will back up and the children will not get what I want them to get. So, I hope that I get to stay here, but I know that it's probably not likely after a year or two more.

Ms. Elliot's School. The school was described as being a primary school, kindergarten through second grade only, with special education of the very young, developmentally delayed students. There are two PEP classes (primary enrichment program) for at risk students whom teachers have selected. The demographics of the school were described as:

We are a school with a lunch and breakfast program, $95 \%$ of our students are on free or reduced lunch. Our school is $99 \%$ African American and 1\% Caucasian, 1 Hispanic child and no Asian American children.

Community support is described as strong, "when we call on the community, they're always willing to help."

We've had a lot of support from Walmart. We had children who needed clothing at Christmastime, toys and what have you. All the business, some of the attorneys, are very supportive. We know that when parents come in who are hungry or need some assistance with getting their lights back on, we know what churches we can send them to for assistance. We know what social service agencies support us. We do get community support.

Ms. Elliot, also described further how the school - community relationship went both ways:

I do collect lots of clothes. Periodically I send a note to parents, we've laid everything out in the gym, help yourself to whatever you want. PTA meetings, there is always clothing. I have adult, male, female, extra large, everything. I get grocery bags and encourage them to help themselves, and they do. But they're very supportive. And it's not because the clothes are out there. It's because they love their kids and they support their kids. I haven't had a PTA meeting where I haven't had standing room only. So, they're very supportive and they don't take advantage, so far. And, I hope they won't.

When asked to describe how she would like the school to be seen, Ms. Elliot responded:

That just because we have 95\% free and reduced lunch, that our kids are not morons, they are children that can be taught. You don't have to come down here and be afraid. Yes, you see beer bottles, we've come to school and in the entry way will be condoms, you do find some paraphernalia around the yard. But, my custodian is the best in the city. She gets all of that out of the way in the dark of morning, by the time the children come here, everything is in place.

It's not a scary place, drug dealers don't come onto our property and harass us, they don't come and bother the children. It's a very safe school, and you need to be educated, and come down and visit us to see that it's not the horrible place that you think. The children are learning, and they might not have brushed their teeth that morning or had a bath, but we'll take care of that. We have bathed children in the clinic. We have combed hair. We're not afraid to hug the children, and I don't want anybody here who is. Don't be scared of us. We take care of needs that would impede leaning and then get to it. 
Ms. Elliot's compassion for meeting the basic needs of her students was highlighted by the following observation:

If I could do this I would go to year round schools or 24 hour schools. If we had the facility and parents could visit on the weekends, we would take care of everything else. Especially if there were certain things that I knew that were going on, that the child just does not need to go home and have happen to them after they leave us. So I would like to keep them, feed them a nourishing dinner, have activities for them, field trips, stay all night in a comfortable bed, all by yourself that you don't have to share with brothers and sisters. Have clean clothes ready for the next day, have people on staff that read to the children and monitor what's on TV. Make sure that they see certain things, get to the opera, get to a play, and parents could visit on the weekends. I would much rather have the parents do all that, but if they can't I would like to see the needs met somehow.

\section{Ms. Elliot's Work.}

My hours are 7:30 to 3:45, that's my contract hours. I doubt if ever in my life, unless I was very sick, did I keep those hours. The first year I think I was working harder and not smarter. So I took this training with Covey. You're supposed to stay in quadrant two which is important, but not urgent. So I started really trying to get in that mode of thinking and to prioritize important things. Also, I started giving a lot more responsibility to my assistant. That helped, and doing more delegating.

The first year I didn't know anything about school money, I'd had school finance, but you know how it is when you take courses then you get into the program and it's not at all what you thought. Another problem I had and am still working on is- I think I'm a better manager than leader- because it's very hard for me to say "the way you typed that report was pathetic, you're supposed to be a secretary, you're supposed to be able to line the paper up and not make spelling errors, and check it." I had been and still feel a part of the team. Power is not- except for making changes for appropriate activities for children, the power thing is not at all what I'm about. I want us all to work together for the goal which is the children. I've just never been good at setting people straight when they're not doing what they're supposed to be doing.

Ms. Elliot described her typical work day as follows:

Five minutes after I get here, children start coming which they're not supposed too. But I'm not the type of principals who'd say, I'm sorry you have to go back home, or I'm sorry Ma'am, you can't drop your child off now, you have to sit in the car and wait twenty minutes. They're doing the best they can rushing to get to work. I'm not going to do that.

I let the children come on in, and they sit quietly. I start getting my announcements together, make sure everybody's here, because attendance is a problem with one or two. Then at eight, the bell rings and the children start coming in. I'm always at the door to greet them. I greet every single one of them, I know almost every child by name. Sometimes parents are coming in with complaints, or with this, that and the other, the phone is ringing off the hook. I know that this is a good time to get central office to return calls. I supervise the breakfast. Children do come in late, I make sure the cafeteria manager is going to feed them.

Once everyone is fed, we start announcements at 8:30, I make sure everyone is quiet. We start our day on a real positive note, we sing a real happy friendship, happy sunshine day kind of song. I remind the children over and over that they will make choices and how proud I am with all of them and how I hope that we're all here and we come to school every day. I like to do the announcements, because I like what I tell the children. Positive climate and positive work with children is very important to me, so I constantly try 
to build their self esteem. If something wonderful has happened to a child, a teacher tells me... I'll talk about that on the speaker in the morning. We start, we say our motto, which is a very positive motto: "I believe I can learn, I can learn, I will learn. I can make the right choices, I will make the right choices."

Around nine I start my rounds, I go by every room. I walk in for thirty seconds or a minute. If the children are involved in something really exciting or if they ask me to come over- what we're really trying to do is have children really engaged in the learning. But, if they ask me to come over and look, I come over and look at what they're doing. I take a quick glance around the room and make a mental note about things, sometimes I want to leave the teacher a note. It's very positive, I like what you're doing. I visit every room, and the special ed. kids are always singing, and I love that. Sometimes I go in and sing with them because they are the same songs I taught to my first graders. The rounds take about an hour, usually it gets interrupted with "Ms. Elliot you're needed in the office." Sometimes parents are coming in and out, or important phone calls.

Then if I have paperwork, I work on that and meet with my administrative assistant. I sometimes stand in the hall and talk to children. Just the average routine of the zillion things you do, solve all the problems. This is another thing I do wrong, but I can't help it. I leave this door open (to the hall) the whole day. So they're very comfortable about stopping and saying can I have quick second which turns into a long time. But, I really believe in the open door policy. However, I can't get anything done. I feel it's really important to let the teachers know that I'm here for them. I can't decide if it's something I should wean off of or keep doing it, or maybe close the door sometimes during the day to get things done.

Children are always coming in here, "can I read you this book?". And I invite them to come in and read to me, then at the end of the day, I always acknowledge them. I encourage the teachers to send me slips with principal's proud moments. I highlight all of the classrooms that have perfect attendance and encourage them to come to school. If they had really good behavior in the cafeteria, which they usually do, then I tell them their boats have moved. We move their boat everyday if they follow the rules. I remind them to read at least two books every night, to do their homework. That I really like to do.

The rest of the day is anything, parents come in, emergencies, problems come up and I have to close the door. I've given all the discipline to the assistant. It's got to be put into the computer and certain steps have to be taken with parents. He has all the training and he does all that.

As far as yearly cycles, Ms. Elliot observed:

Getting ready for test time is a stressful and a nervous time. Let me say about testing, I understand the division's concern over high test scores, but I'm here for the children to learn so I don't have quite the feeling for the importance of test scores that the others might feel. I want the children to do well on the test because they learn the material, and they are better learners, not because it will make our city look better. That's a very stressful time.

The first year I was here, our test scores were not great. I was working harder and not smarter and didn't really understand the importance of the test scores. So we didn't do as well. Last year we had a 27 point gain from $35 \%$ tile to 60 something. The first year I didn't want to see the principal of the school where our kids go, but now I hear from her and our kids are doing great.

The beginning of the year is hectic, very hectic. Nobody knows who rides which bus. Files are coming in, registering people who didn't think you had the whole summer to register come in the morning of. The beginning of the year is the real nutsy time.

Finding time to communicate is difficult: 
For long term stuff, periodically I meet with our reading resource teacher who also has the same philosophy I have about young children and about what they should be doing. And we meet through out the summer. We take time out usually after school, when she is allowed to leave, but she stays. We have long talks after school. She and I are mostly the instructional leaders. Mostly my assistant and I talk at night on the phone, but we talk about the safety. He's more of the safety and the discipline and that sort of thing at the school. So we have those discussions.

As far as communicating with staff, it is more informal than formal:

I don't do formal observing, monthly I visit everyone and sit down for thirty minutes. I script tape. I also use green flags, red alerts which is a scale. If your room is not print rich, or if I don't see centers, then I might give a check toward the red alert. When I first go in, I turn the sheet over and script tape. Then after the lesson, I flip it back and do the little checklist. There's a place for comments. I make a copy and put it in their mailbox, if they want to come to a conference, then they're welcome to set up a time. Formally, they are observed once a year; I drop in all the time and once a month I do an informal.

Ms. Elliot's views on leadership and management.

The manager side of the job, if I had to pick, would be my least favorite side. I think it deals with all the nitty-gritty kind of things. You have to do all the stuff like make sure that the roof does not leak, and you have enough toilet paper. Even though I don't do the ordering, someone else is in charge of it, if something was not ordered, it's always my fault. I accept the blame, because the buck stops here. All those little things like that. Then a group wants to use the building after school. I have to make all the arrangements, make sure the insurance is covered. If a child is in an accident make sure everything is straight, all the paper work is filled out, time sheets are in on time. Different people may be assigned to those responsibilities, but I am ultimately the one who has to answer if something goes wrong.

Leadership would be a little different and that's what I like. That would be to develop a really good mission statement, a really good tone, to set goals that are very appropriate and to somehow get the staff to buy into what... Again, you have to be a principal that's doing it the right way. If your goal is something that's not appropriate, then I wouldn't want that, but I feel mine is right. So, to get people to buy into the goal which is, of course, getting children to achieve, to have good self esteem, to make good choices and to be successful, and to be happy and healthy and safe, to be sure that they carry out the instructional program to the best of their ability and in an appropriate way.

I see myself as a leader of leaders, we've been getting a lot of training in that from the Superintendent. He wants the teachers to have lots of autonomy, and I have no problem with that, as long as they are following things that are appropriate and following our mission. When deviations happen, I need to make sure that they are getting training and staff development, and going to conferences and going back for classes, to keep up with the research of what's going on in early childhood education, because it's changed.

Ms. Elliot described the relationship of the two constructs as follows:

My job is to manage the building, under that big umbrella of management, a huge part of that would be the instructional leadership part. The instructional leadership part is almost the whole umbrella, it's all part of how you manage your school. If you manage your school well, the instruction is gong well, the toilet paper is being ordered and you've earned your money. The ideal thing would be to separate them and I wouldn't have to worry about all that other stuff. 
Leadership is more important, but management takes up more of my time. I'll be ordering materials, just trying to do that, then stuff will happen. Those (managerial) things I have to take care of, I have to. I have to take care of the instructional part too, but Miss Jones class is not going to fall apart if I don't get right down there and do that observation that minute. It's really sad, but sometimes I have to push that part on the back burner because of the managerial part. Ideally, it would be mostly instructional with just a little bit managerial. In reality there is an urgent thing out there. I should probably ignore some things more, but I haven't gotten to that point yet.

Ms. Elliot saw the constructs as overlapping:

Ordering toilet paper, although it is still kind of part of the mission, because the mission is a safe and orderly school and the children go into the bathroom and there's no toilet paper, then that's going to cause a problem, confusion, disruption, it might get noisy, and the class next to the bathroom might be disturbed.

\section{Ms. Elliot's views on her role as a manager and a leader.}

I mostly do the leadership. The assistant does some of the management, I lean heavily on the secretaries, I lean heavily on the custodian. When a worker comes in, I immediately get the custodian and she takes care of it, but I always go back and check and ask questions. Same with reports and records, I trust that they are getting them out, but I do ask. I don't have to do those things, I just have to make sure they got done.

Leadership would be what I do most of the day: lots of reading to make sure that I'm on the right track, lots of visiting of classrooms and observations, lots of meeting with teachers one-on-one or in grade levels, asking questions of them- what's going on, interviewing children from time to time. I bring in lots of materials that I think are appropriate, I make decisions about ordering. We have choices on materials, I will choose not to have the worksheet books. I will choose to get the money so I can do something different that I think is of more benefit.

I do stay in very close touch with the children, the teachers and with the classrooms. I pretty much know everything that's going on in them and I think that's very important. Plus I bring new ideas. I attend conferences to get new ideas and new perspectives.

Ms. Elliot described the role of the central office:

There's a lot of pressure about test scores. I listen to that edict or that ruling, that test scores must go up and what have you. But, then as the leader of this building I see how I can do that so I can be successful with test scores and not compromise the children and what's appropriate for the children. Then I have to sit and figure how I'm going to get this job done, doing it in an appropriate way, that fits the needs of the kids. I hear the goal, I try to achieve the goal, but I achieve it my way. They don't really tell us how to get there, they just tell us this needs to happen.

We have a regional director who's there for us. From the littlest thing, we always contact the regional director first and he tries to trouble shoot before we go to the assistant superintendent. So any little thing, he will listen to and try to help, so we do have that support. They don't interfere a lot as long as they're seeing results, or not having lots of parent complaints, they trust that you're doing pretty well. The regional director comes and visit periodically and checks things out. 


\section{Ms. Elliot's beliefs on the role her personal educational views should play.}

They're very important. Because of my research, I believe that my views (on developmentally appropriate practices) are right, I believe that it is the way it should be. I believe very strongly those things are the right way to work with kids. Now if you go talk to principal X who doesn't feel that way, he's going to say the same thing.

When asked about the balance between her strong personal views and her efforts at being

collaborative, Ms. Elliot replied:

I talk to teachers a lot about. "I really would like you to try this. I'm there for you to help you." First of all I try to hire people that have the same beliefs that I have. When I interview, I ask questions that will carefully help me make a good decision. When I don't make a good decision, I'm not afraid to say "that wasn't good", that teacher may be more comfortable at another school.

Most of the people have the same philosophy that I have, and they're gung ho with everything I bring. They bring ideas to me too because they're going to the same conferences and reading the same journals, and have the same feelings about children that I do. Those that aren't, and are kind of set in their ways. I ask them to just try it. I'm there for them to help them. I'm not going to make them change, because it will harm the kids more if they're doing it all wrong, but I ask them to do a few things. I have seen the most hard core teachers in this building makes these little baby steps towards the goals and every now and then you hear through the grapevine, that little by little the hard core are buying into it.

We do some collaboration, but most of the people have the same philosophy. I do not want anyone to feel that their ideas are not important, and I will discuss anything with them within reason. I'm willing to be open and discuss it and entertain it, if it sounds good, I'm willing to try it too. If you want to try a new project and it sounds bizarre, but I usually give you the autonomy, because you are the leader of your students.

Ms. Elliot cited the following examples of things she feels strongly about that have been

implemented in her school:

The main thing is developmentally appropriate practices for young children. I don't know if anybody knew what that was all about before I came. I really did a lot of training and working with teachers on we're not going to sit in rows and do paper and pencil and copy off the board all day in kindergarten. We're not going to do that anymore. The next thing was dittos and worksheets, I did not see the need for 1,000 sheets a month to be copied. I couldn't even imagine why they were allowed to have that many. So we worked real hard to get the worksheets out.

The boardwork is the same way. I worked real hard to get the teachers to see that centers and play is very critical for young children. Centers can be going over and writing letters to pen pals, can be listening to tapes that you have read a book onto tape and they are listening to you, they can be buddy reading, they can be over on the computer, they can be having poems on charts and reading. So it's not a center where you say, oh just go over there and play with some puzzles while I do my reading group.

Creativity was pathetic, in the hall and I did the same thing when I taught, every single art project would be identical and look just like the teachers. The teacher would precut or predraw all the pieces and the kids would cut it out just like hers and they would put it up and I did this too, I stood back in the hallway and said, "Wow, that's just beautiful, look at it , they're all perfect!" And I didn't know that I needed to show them a bunny, I needed to show them pictures and bring a bunny in, and take them to the zoo or 
take them to the pet store. I needed to bring all sorts of pictures in and we needed to read stories about bunnies. Then I needed to just lay out tons of stuff and however they made their bunny, looked like a bunny to them. If it had an ear coming out of the bottom and an ear coming out of the top, and no tail, that is theirs. They're proud of it, they're excited about it, and that's what we hang up on the wall. "But it just looks so sloppy!" I don't care, I don't care how it looks, that's the kind of thing I want. That took two years.

Reading-Writing Workshop is a biggie. We have about a third of the teachers now doing Readers-Writers Workshop, and you can see it in their test scores. You can see it in the children as they walk down the hall going to the bathroom reading and talking about the books they've read. And as I go into the classroom and see a pile of books that they've written, stories that the students have done and the teacher has bound. The reading center is library books, but it's also their books, tons of books that they've written.

Positive climate, positive behavior management for everyone, respect that we must give the children, as well as the respect we want from them. The cafeteria, the first year I was here as an assistant, the principal was in there screaming and turning off the lights, pounding her hand on the table to get them to be quiet. Two minutes later they were doing it again. So I brought in a whole new system for dealing with the cafeteria, positive! All that happens is if they've done a good job their boat moves. They live to get that boat moved. There's no sticker, there's no pizza, there's no bribery. Their boat moves to the next day. Substitutes just can't believe it, we're always being told they can't believe how pleasant it is, and teachers now eat in there because they don't have to escape from the noise.

When asked about constraints or restraints in implementing personal views, Ms. Elliot responded:

The poverty of the children. You want them to do so many things, but they don't have the materials at home and certainly the teacher can't go out and buy a poster for every child and crayons so they can go home and do the projects. What happens to them at night and the children come in here the next day and they're not really ready to go because we don't know what happened that night.

Money is getting better, I think we were sort of the forgotten school, because we're really little. I used to think, and this was naughty, because we are predominately African American and at risk and there is not much money in the community that they thought "Let's pour money into a place where we can see a lot of success," but I was very wrong about that.

However, it was also noted that money was an issue in a different way:

Some schools have school wide projects, so they get millions. Some schools have private benefactors that pour a ton of money into the school. My kids appreciate that all I can do is punch and cookies here in the cafeteria when they have made achievements. They appreciate that, they think it's super, but I wish I could do more. And I wish I could go out and buy clothes for the kids and that sort of thing. The teachers are real good, or should I say bad because it's really not good, about spending their own money, but when they really want to do something that's important to them.

This is what aggravates me. You get a percentage of the picture money for your school, (at other schools) every parent buys the most expensive package, they end up with $\$ 3,000$ just on their pictures. I get $\$ 600$. Same thing with milk, we don't sell milk because our children are on free lunch. Their profit every semester from the milk is like $\$ 2,000$ to $\$ 3,000$. So I hear from that guy all the time, "I just don't know how to spend the money." Another principal coming back form an early childhood conference said to me, "I think I'll cash in a CD to get some books for the kids." I thought your husband 
must be generous to allow you to cash a CD to buy books for the kids. That's impressive, don't you have kids to educate through college? She said "I don't mean my CD, I meant one of the school's CDs." We don't have such a thing, we don't have CDs, she said "Well just get something from your school savings." Well that would be zero. "Well ask your PTA." When I came here our PTA had \$350. Another school in the system had $\$ 55,000$. So that's frustrating, but we do the best we can and I think it's the quality, not the quantity sometimes. But I think we're doing OK even though we don't have much money. I won't say it inhibits us at all, I will just say it frustrates me.

\section{Mr. Baker (Division B)}

Mr. Baker described himself as an innovator, a role model and a decision maker who sets

high expectations for a good school- a broad based, community supported school.

People know that I set very high standards for this school, for the staff, for me, for them. And, I think parents respect that. I want them to know that, that there are high expectations here as far as academics, as far as behavior, as far as community participation, as far as teacher performance, as far as any other staff member's performance. That's how I want to be recognized as a principal.

I am very interested in curriculum and innovation, I do a lot of studying and involve myself in a lot of reading to be aware of what is going on. I always have things that I'm looking at and sharing with staff to make sure that everybody has access to new things. We try new things. My goal as a principal is first to be an example; be an example, be a partner, be a leader in a lot of different ways, to be a decisive decision maker. Someone who's not afraid to make a decision, but to be thoughtful in those decisions and fair, whether it's a decision related to students, or to staff or to parents.

When I have new parents come in to register, if I have the opportunity with a school parent, I ask the parent or the kids to share, "What kind of school is this? Do you like having your children here?" And they'll say, "It's a good school. It's a nice place for your kids. It's the best school in the division." Those kinds of things. I think they're really serious in feeling that way, that they feel that. I think there's very few people that don't feel that this is a good school.

I think that they feel welcome. I think they know that they can send their kids over here and we'll take care of them in whatever way they need to be taken care of, whatever the need might be. That's how I want it to be seen. As a good place for kids, a good program, a broad based program, not just a math school, or language arts school, or geography school or whatever, but that it's a good broad based school that's going to set your kids up to be successful when they go on to a higher level.

Mr, Baker's Role. When asked to describe himself as a principal, Mr. Baker stated:

One of the things I'm concerned about is having a broad based instructional program. I have pretty high expectations of the children, the staff, and myself...and the parents. I tell the parents up front, you have your part to do just as well as us. I just put a sign up "Home plus school equals success." That's what I feel is important here.

As far as who I am as a principal, I would consider myself to be an innovator, a risk taker, I'm not afraid to try new things. We do a lot of things that are different to enhance our program. We have lots of opportunities for children to get up in front of other people. I think it's important and it makes a lot more children successful as they move onto middle school.

As far as working with my staff, we are doing a lot more shared decision making, and I think you do what your staff is comfortable with as far as shared decision making goes. It's been something that's taken some time to develop. Shared decision making is a 
learning process. I think it's important, it's the wave of the future. I think it will be required if principals are going to be successful to be able to share and garner all the resources that they have in their schools and not try to be the single sage on the stage.

Mr. Baker's Career. Mr. Baker has been in the division for 25 years. After serving as an officer in the military, he began teaching fourth grade and began work for a master's degree in guidance and counseling. After being an AP in two schools for three years, Mr. Baker became a principal when one of his principals was named to an assistant superintendency. Regarding this experience he stated:

Probably, it is not advisable to move from AP to principal in the same school. I think that your jobs are so different, the role perception has to change, and it's not always easy for some people. As an AP there is always the other person where the buck stops, and it stopped sooner with me, and it was difficult for some people.

After four years, he moved to another school where the principal had been promoted to a

central office position and spent 5 or 6 years there.

Then I came to this school. It was kind of tough when I came here. I knew what I had to do here. I had a couple of agenda items, one was to get the private school kids back, two was to, unfortunately, clean up the mess that a weak principal had left, as far as instruction goes. That was really difficult because some teachers did not want to change from doing their own thing to doing what's right for kids. There were a lot of teachers that left here or retired within the first five years that I was here. Then, I had the opportunity to bring aboard a lot of new, bright, eager, innovative teachers. Which has been a real delight for me because I feel it's that kind of staff now. They're very vocal, very vocal, and will say it in a heartbeat, when they have an opinion, but that's OK. We have grown from that. We feud every once in a while, but that's probably a healthy way to get it out. Some weak teachers, considered weak when I first came here, have really grown a great deal, not necessarily just from my administration and my support, but by example of others and seeing that indeed the expectation was there, and they needed to do a better job. They needed to do more. They needed to be a little more creative, they needed to work with parents a little differently.

Mr. Baker has been at this school for 13 years.

Mr. Baker reflected on the differences between the schools he has served in and made this comment

I found that staffs are very different. I think probably it would be really good if staffs were juggled a little bit as far as long term people, or people that needed a change. Sometimes some few people can cause a principal some difficulties if they are not in harmony with their approach to doing business, and they want to be on their own team instead of being a member of THE team.

As far as future career plans, Mr. Baker has no plans to leave the division, even though he has had opportunity to do so. 
I'm real happy as the principal of this school. It would have to be just the right situation for me to leave. I've been offered other jobs outside the division. There are a couple of things I would like to do in our division if I were given the opportunity. I would like to open a new school. I would like to be the first principal of a brand new school, but I don't think that that is going to happen here. The building, the staff, the furniture, everything, that would be a real highlight in my career. That would be something I would like to do. In central office, I'm interested in personnel. I'm particularly interested in training new principals, and being a leader of principals. I think I have something to offer there.

Mr. Baker's School. The community surrounding Mr. Baker's school has a long and relatively stable history and there has been a school in the general vicinity since the 1700 's. The community is "comfortable with the school". They feel it is safe and that it is "the right place for their children." The school has high academic expectations and good discipline, it provides "a bridge between what is expected at home and what is happening at school."

I don't put up with foolishness. That this is the way it is, and you should do unto others as you would want them do unto you, if you want to put it that way. I just absolutely do not tolerate disruptions, disrespect, bad discipline, but it's a caring place.

I don't think parents are really that concerned about the size of the school, some are concerned about the demographics. I think they're concerned about reputation, image. We have a very positive network. It's not something that has just happened. I've been here 13 years. There's a reason that I've been here for 13 years, and I think it's something that is missed a lot of times when principals are assigned to schools. Certain schools need certain personalities to be long term successful schools. The things that I have valued mesh with what is valued in the community.

This parental support was seen as a two-way street:

parents have something to say about what is going on in our community. They know that they have a right to say it. They are encouraged to be a part of what goes on in the schools. They value that, and I think that it's one reason why I've been here, and I think it's part of the reputation of our school.

The community is described as being close-knit and relatively stable, but the school-

community relationship was not always so:

This community is a very close knit community. There is a network out there that doesn't quit. If something's going well or if something's not going well. We have an extremely active parent organization. That was a big accomplishment for me when I came here, because there was very little cooperation between the school and the community; there was no relationship, there was angry relationship.

Economically, we run the whole spectrum from low income to very wealthy. We have a couple of subsidized housing apartment complexes, I think that this has increased. The number of children with free and reduced lunch has increased. We have more single parent arrangements and different structured kinds of families. That's had an impact on schools. There's more transience, but it is still a relatively stable community with long term families- children's, children's children come to this school. This is unusual as far as schools go. It's the most rural area in the district. It's a big area, which is kind of nice. 
For administrative organizational structure, the school has one secretary and one

administrative intern half time- shared with another school.

The half time administrative assistant does a lot of instructional things, works a great deal with ordering, paying for and accounting for materials, selecting materials, working with special remedial groups, our special needs group, does a lot with assisting teachers with their staff development. We have the one secretary for the whole school. It's a crime. The teacher assistant, the school aide does stuff for the teachers, the duplicating... The secretary does the other stuff, my personal business, she manages the office, mail coming and going, all the correspondence with teachers, records in and out, clerical kinds of things, all the books, financial records, paying bills, registrations and all the other stuff. I do all the assignment of students, I try to make a personal contact with every parent who comes in here. I think it's important to have that initial contact with parents.

Mr. Baker's Work. When asked to describe a typical day or a normal day, Mr. Baker

replied:

Every day is different. A normal day, there's no such thing as a normal day. Sort of like a routine? I get here at seven. I use that as time where I can do some reflection, do some cleaning up, do some preparing mentally for the day and some other ways as well. I write a note to my teachers every day. After that I do something that most principals don't do, I set the coffee up for the staff. I put that in the lounge I get a cup of coffee, I go talk to my cafeteria manager and the staff in there. I find out what's happening in the cafeteria for the day. I speak with my custodian and do some things there, this is usually within the 7:00 to 7:30 time range.

I try to be at the front office area to answer questions for the staff, I turn on the copier so it will be warmed up and ready to go for them as they come in. I don't mind doing some of those things, but I think it's important to be available at that time of the day and to make those personal contacts. There are lots of decisions made during that time. The principal's job is one decision right after the other and mine starts real early in the day. Parents call and have certain questions, I may even return a few calls if I've been away at a meeting in the afternoon.

At 8:00 the kids start coming in and I try on as many days as possible to be at the front of the building to be there to see kids when they come in and to let them see me. I know a lot of them by their names and their families and so forth; I know all of their faces. At 8:30 I go into the cafeteria and see what all is left in there, sometimes some late breakfasts and we try to get them along to their rooms. Sometimes we have announcements, sometimes we don't. From there it can be anything during the day, from observations of classrooms, follow-up on observations, I have a new instructional/professional development activity that I'm doing with all of my teachers this year. All kinds of instructional decisions, ordering things, making decisions on whether this should be ordered, when it should be ordered, how much we should spend on materials and so forth. Discipline is not real bad in this school, so I don't really have to deal a lot with discipline.

I am involved and sometimes too involved in a lot of central office kind of committee work. I want to be a part of change and decisions that are made in the division. I don't mind saying what I think, and sometimes you get selected because people know that they'll at least get an answer even if it's not the one they particularly want to hear.

I like to be with kids as much as I can. I can't really be with kids as much as I would like to. Last year I set as an objective to sit with every child during the year, and I met with every child. We read, looked at math, had a sharing time and it was an enormous job. I made notes on each child. It was something I wanted to do myself and maybe 
something I need to do every few years. I did accomplish it by May, but it was difficult, and I'm not sure I'd want to do it in exactly that format in the future. I eat lunch in the cafeteria almost every day.

The afternoon is committee work and working with teachers which goes through out the day. There are so many jobs as far as what's involved in a principal's day, it would be impossible to list them. And the sequence in which it takes place. e-mail, everytime it dings up on the screen, you got another job to do. Going through mail, I despise doing it, but you have to do it every day. There are things there that you have to get out to the right people and make some decisions on, order new materials, pay bills. I don't do the books, my secretary does that fortunately, she's good at it. I sign the checks. Sometimes after school, I go out to the Price Club and get things for the school. I take pictures of all the kids for good citizens each month, I get the film, take the pictures, get the film processed, pick them up, bring them back. I keep a scrapbook. That's one thing I like to do is to keep a history of some things that have happened.

When asked about yearly cycles, Mr. Baker responded, "I look at the year as a circle, I didn't realize that everybody didn't do that. I see the year as a circle. Closing the year and opening the year are the major busy times." There are some busier times but "we always have something going, so it never slows down. It used to slow down in January-February-March, but it doesn't seem like it slowed down much for the last two or three years."

Mr. Baker's Views on Management and Leadership.

Management, first involves decision making and that is what this job is-one decision right after the other-and management involves how you go about making those decisions. As a manager, I have to look at a lot of different things; the people part and the other part, which does not involve people, the money, the building, the facilities. As we talk about managing people, we talk about managing scheduling, we talk about managing their time, we talk about managing their resources of all different kinds and that is for children, for staff or parents. When we talk about the management of the other part-the non-people partmanaging the use of the facility is a big job. You have a certain facility that has certain rooms and available resources to it. I think, the principal's job is making sure that those resources are used most effectively, that includes grounds, buildings, equipment, books, materials, all those of kinds of things.

Leadership in and of itself implies being the example, but also leadership means that you can do it a lot of different ways. Using your resources and showing especially your staff people different ways to do business that would result in a more beneficial school program for children in all different kinds of ways. I think leadership should involve a little bit of risk taking. As a matter of fact, a whole lot of risking taking sometimes and showing by example that you are willing to take risks and willing to accept taking risks, even if mistakes are made. Leadership in exploring new ideas.

When asked about the relationship between leadership and management, Mr. Baker replied,

"both can be creative.," and "in no way can they be separate; I would think that leadership and management have to work together."

I think that probably leadership and management have a lot of inner-connectedness. There probably are areas of management that do not necessarily involve leadership-I think there 
is a just plain nuts and bolts kind of stuff that isn't necessary leadership, that doesn't involve other people as much; but I think that there are lots of things where leadership and management fit right together.

Creative leadership causes more overlap of the two domains. I hear thisInstructional Leader- all the time. What is an instructional leader? Everything that a principal does, somehow impacts on instruction, no matter whether it's the direct curriculum, whether it's the employment of the right kind of people, bringing the right kind of people in.

\section{Mr. Baker's views on his role as leader and manger.}

I see my work as principal as being a manager and a leader. I think that there are times during the school year that you are more of a manager. For example, during the times that the staff is not here during the summer time, I am really a manager, getting materials in and prepared for next year, getting equipment ordered, recruiting new people, cleaning up the building, hiring/firing - those are managerial kinds of things.

I think that when you bring in children, when you bring in parents, when you bring in staff, then you become more a leader. I think the very details of getting kids into school, registering children, and giving the parents the information they need to deal with the school, that is managerial kinds of stuff. As far as developing staff development programs, as far as getting new materials and figuring out how to use it, getting a few people in, developing a bi-annual plan, doing all those kinds of things, I think you show leadership when you do that and there is a managerial aspect of that as well.

I think anytime that you have kids in the building, staff in the building, you should be more a leader than a manager. I think that your emphasis is in the right place then, that it is on instruction, that it is on doing for kids, especially when they are in the building.

When asked about who was doing the leading in the school, Mr. Baker shared the following:

There are those formal leaders and there are those informal leaders. Of course, we have a structure. We have grade chairmen in our building and they are leaders. We have an assistant principal and she is a leader. I am a leader and those are formalized. We have our informal structure, of course, that are seen as leaders. These are the people that are respected as informal leaders. They are people that a lot of people respect as far as their decisions go.

When asked what keeps all of the leaders coordinated or unified, Mr. Baker responded:

I think the principal has to do that, has to serve as an impetus for leadership, informal as well as formal. They have to serve as the person who expects leadership to take place or expects things to be coordinated, expects thing to happen. Also, that allows things to happen. You have to be the person that kind of guides those things along. If you are willing to allow things to happen many times as far as leadership goes, wonderful things happen. You can do some programs that you might not even have any idea that you could have done.

Sometimes, you have to be the person that says no when the leadership is not seen as being beneficial and you have to be very careful how you handle that because sometimes the principal sits out there alone when the final buck is passed. If you are not real careful, you get to be left out on the limb. You have to watch how you say no to leadership.

When asked about the role of central office, Mr. Baker responded:

I see them more as management than as leadership and I think that our division wants to change so that it is more leadership. I see them as imparters of direction. I see them as 
evolving from that to some degree to allow more of the decision making to be done at the school, but I do see them more as management. They come up with the programs and they come up with the material recommendations and they guide the selection of materials, guide the selection of recruiting people, they guide selection of staff development opportunities and so forth. I see some leadership in the creativity in staff development, but I still see them much more as managers than I do of leaders. I think more needs to be done as far as helping teachers more as leaders, being example setters.

Mr. Baker's Beliefs on the Role of his Personal Educational Views.

I think it is important to have views and share those, but you have to share those with the understanding that there are other views as well. When you move more toward a shared decision making model, I believe you allow more of those views to enter into decisions that affect the total school program and inform instructional practices.

I think your own personal views are important. If you don't have any, then you certainly shouldn't be a principal and I think you need to be willing to state your position. You need to be willing to act on it, but you also have to listen to other people. You have to be knowledgeable. You need knowledge, but sometimes you don't have knowledge and you also need to count on those people on your staff that might have more knowledge on the topic than you do and use them as your resource, personal or otherwise.

When asked for examples of personal views that were implemented in the school, $\mathrm{Mr}$.

Baker cited a number of things.

The thing I feel the strongest about is the importance of community/parent involvement along with the teachers in the school. When I came here, it was not a good mesh and I have been really, really concerned that it be developed over the years. I think that parents are more involved in what goes on in school. There is more opportunity for them to be involved in what goes on in school and parents are better informed.

I think probably the second thing has to do with kids in that I believe we have a right to expect a lot of kids and that maybe at times we don't expect a lot of kids and that many kids have not had the opportunity to show what they can do because they have not been expected to do a whole lot because of their background. I really have stressed expecting a lot of kids, expecting a lot of them academically, expecting a lot of them as far as their behavior, expecting a lot of them in every way possible. They have a responsibility and they are accountable for that.

The third thing has to do with behavior. I feel that there are certain behaviors that do not allow children to progress to a point where they will be successful in society. So, I think it is important that we establish from day one entering school that even if they have no expectations as far as their behavior goes anywhere else, they will have them in school, when they are here. And that we be consistent about that. One thing I tell my teachers when they come here, if you can't administer good discipline and I mean positive caring discipline, this is not the place for you. Don't come here. The teachers, the parents want it, I expect it and, if you don't have it, don't even talk to me any more.

The fourth thing, I want our kids when they leave this building to be able to get up in front of people and show what they have to offer. I want them to have those experiences during the time they are here. We do a lot of things to make that happen. We have programs for every child in the school and everybody participates in one or two programs during the year. Leadership kinds of opportunities, we have those in the classes and the teachers have a lot of things that kids get up and demonstrate. They don't just write it. They don't just put it down in a way that does not allow children to say and do it in front of other people. So, I think there is a self-confidence that is developed by doing that. 
I think probably another thing and I would like to add, a cultural appreciation and I am talking about it in two different ways. One, I am talking about it as far as an appreciation for the arts because I believe that people who have an appreciation, not necessarily an involvement in, but an appreciation of music, dance, and art, graphics, that kind of stuff - I believe that those people have a sensitivity and I believe it enriches them as human beings. And a second way has to do with an appreciation of other people, whoever they are, whatever country's culture, ethnic background, religious belief that they may have and I feel very, very strongly about that. Those are some of things that I think that are really important and I see it happened. I have been here and it could not have happened if I had been here on a short-time basis.

When asked about constraints or restraints, Mr. Baker replied:

I think that are lots of external constraints and I think there are a lot of internal constraints. At times if you are not doing what every other school in the division is doing, then you are seen as not doing your job. I think that probably more and more the central office folks are beginning to accept the fact that different schools have different needs, a different clientele, the population expects different things. More and more we are getting the opportunity to select our own materials and use our scheduling the way we want to and make things happen, to use our staff the way we want to use it.

Consuming our time when it is not time well spent, meetings that are unnecessary, I think that is a constraint. I think sometimes lack of funding, is a constraint when we have a special need. The fact that sometimes things are put into such tight little boxes as far as expenditure of funds, that you can't use funds the way your school would best want to use them and could use the money most effectively. Of course, time is always a constraint as far as staff goes and I think the day itself is a constraint many times. We don't have enough time where we can be together here to talk about the plans for those things that affect us. That is a big problem sometimes.

Sometimes we constrain ourselves as far as what we should or should not be doing. This group has these expectations and those have those expectations and these have those expectations. Dealing with that takes time and sometimes it takes energy and sometimes it takes away the desire to innovate.

The paperwork is a constraint. It is a monster. Dealing with the e-mail is a monster. Every time that thing comes up it is a task. I have had three or four today and they were not on the administrative level that I am on, they are clerical people who have asked me this moming: send me the number of, get this report to, have teachers bring, that is taxing and no matter what, that is a constraint on my time and I do not know how to get by it. People without skills internally, it is a restraint of being able to implement what you need and want to do in the building. It is very time consuming to do what needs to be done to make the changes that need to be made to make sure you have a person with skills. That happens a lot.

\section{Mrs. McGrath (Division B)}

Mrs. McGrath described herself as a teaching principal who leads by example. She is very concerned about curriculum and instruction issues, and also is addressing some of the larger issues that face her at-risk school community. She has a concern for collaborative leadership and empowering the stakeholders of the school by listening to the "voices" of students, parents and teachers. 
I'm an advocate of children first, that's the bottom line with everything I do. I feel like even though some people perceive elementary children as not being ready to have a voice, that they have a voice, and I listen. I have a structure in place so that I can listen to what they have to say about things. I also feel as though teachers deserve a strong voice in the school. Although our school system has not gone to total shared leadership or complete site based management, I do try to operate my school as a shared leadership school.

She described her school community in this way:

Many single parents and absent fathers. Low socio-economic level. Some of their parents are in jail, their fathers are in jail. Lots of drug issues. One family had to get their power from the family upstairs with an extension cord. That's very consistent here. That was vary hard for me to deal with, only because it was so foreign to me. I had never experienced that before, going into homes and seeing what I see in homes is not at all what I grew up with or what I live with now. So, that was a real eye opener for me and very emotionally draining. But the kids when they come here, they know what to expect.

They know that we will do anything we can to take care of them and our job is to open up possibilities to them and we tell them that kind of thing all the time. They're happy to be here, they're really happy to be here. I try not to allow kids to be here until 8 o'clock. I've got kids who are here at 7:30, walkers that live nearby because they want to get to school, a safe haven.

Leading by example and being a teaching principal is important to Mrs. McGrath:

I don't expect anything out of anybody that I'm not willing to do myself first, and teachers know that. I try to attend workshops so that I know what is going on too, and not so I can police their efforts, but so that when I attend their team meetings, I can be part of the discussion. I even go in and team teach with teachers and do demonstration lessons. That kind of thing is important, I would say that I was a teaching principal.

Mrs, McGrath's Role. When asked how she would like to be seen as a principal, Mrs.

McGrath responded:

First thing always is that kids are first, kids are definitely first. I hope they see me as somebody who is fair and has a plan and a vision, is focused in a certain direction. I want to be perceived as a risk taker, somebody who is not necessarily creative or innovative for it's own sake, but can see possibilities, and doesn't do something just because it's always been done, or because it's been recommended that way. Willing to see insights or a different perspective on things- I've had parents tell me they feel as though they can come in and talk, and I'll listen to them, teachers have said the same thing. I try to be collaborative. I try to look at anything we decide, "What impact will it have on all of the stakeholders?"

Mrs. McGrath described a specific structure she has implemented to move more toward collaborative decision making:

I have a steering committee, where representatives from each grade level serve on the committee. Together we make decisions that impact on the school. There are instructional decisions, scheduling decisions, budget decisions, we have a pot of money to spend, how will it be best spent. I set the stage up front, ultimately the responsibility for the decision rests with me, but I value input and I value the role of the teacher in making that decision. If there should ever come a time where there might be discrepancies or controversy in the 
decision, they need to understand, that since I'm the sole responsibility for downtown, there might be a time when I have to step in and make a decision, but if I have to do that, I certainly communicate why that decision was made. But, I believe in shared leadership too. The teachers are beginning to get more and more comfortable with it.

Two examples of decisions by this group were cited, hiring new staff and using the profits from the vending machines:

I've hired four or five new people and we've always done it by committee, and it's worked really well. They're becoming more comfortable with it, even something as-to me it's kind of trivial, but for a teacher who's never had a voice in that arena, it's not trivial-our soda and snack machine, the profits that the school makes. We now have an outline of exactly how we're going to spend that money. The first thing was the purchase of a new microwave. That sounds kind of silly, but I feel like, I have to build some trust. If I build that trust to know that for the small things I want people involved, then I know when we get to bigger issues like using instructional time most effectively or how are we using the technology lab, when we're ready to talk about those kinds of things, I'll have built that confidence level. They'll know that I want to know what they think and feel and we'll make the decision together. It's been fun for me to watch and see that growth take place. I know that in the long run it's very important.

Mrs. McGrath's Career. Mrs. McGrath stated, "I never ever had a real strong desire to be a principal." Her teaching career began in third grade for eight years, then she went into gifted and taught gifted for eight years, and from there to staff development as "I wanted to impact teachers." She sought out a degree program in curriculum and instruction, but because of travel constraints ended up in an administrative program at a local university during her two and a half years at central office as a staff developer. She described a realization she came to at that time:

With our program, we worked with teachers for four or five days during the year. As part of that I would go in and observe the teachers. I found that, I'd teach my heart out, and not just lecture, I'd involve people, hands-on, group activity, everything good teaching should be, and I'd go in the classroom and I wouldn't see it implemented. It was so frustrating. I'm a reflective type of person, so I would sit back and say why isn't this happening. I think part of the problem was there was no expectations at a building level that what the school division had deemed as critical learning in a staff development program would be implemented in a classroom. So I thought well we need to look back and change our evaluation tool. Then I thought even more importantly than that, the principal needs to know what is going on. I know we have this thing called instructional leadership, but if I don't know the instruction, the strategies and philosophies deeply, into it's deepest depth, I can't give teachers feedback. I can't talk to teachers about what's going on. So that's where things started turning. And, I thought I could have a better, a greater impact on kids by being in a building as an administrator. I never feel like I' $m$ in charge of a building, but being in a building and working with teachers, and seeing the daily impact on kids.

Her rise to the principalship was somewhat serendipitous as a principal got sick halfway through a year and an assistant principal was tapped to fill that position leaving an assistant 
principalship open. "They asked me to step in, and the next year I was a principal. I finished my degree in the meantime." This is her second year as principal. She related how she came to her particular school:

After I was deemed a possible candidate for a principalship, I was placed here by the superintendent. He explained to me that he thought some of the skills that I had would best be served at this school. It is considered a challenging school, because of its population, the transiency and the socio-economic level. I feel like I would have been better prepared for a school where the children were at a higher SES because that had been my experience, I'd worked with a school like that, and in the gifted program, typically you don't have a lot of gifted kids who fall in this...but we've found gifted kids here. I felt like when I first came in here, I was ill prepared to deal with the clientele, but I have been told that I have strong interpersonal skills and that got me through a lot I think.

As far as future career plans, Mrs. McGrath sees a couple of possibilities, but they are more long range ideas:

I initially looked at this job as a stepping stone to become a professor at a college. I don't have the time to do a doctoral program right now. At this point, this job is all consuming. I'd really like to teach the teachers, and teach teachers who are going into the profession rather than those that are in the profession, and some are just so stuck in the way that they have been doing things, that it's frustrating.

At the central office level, Mrs. McGrath also mentioned the possibility of becoming an administrator in staff development and maybe a director of instruction but not Superintendent or Assistant Superintendent. She would like getting into personnel, possibly in staffing and recruiting.

Mrs. McGrath's School. Mrs. McGrath characterized her school as being a true neighborhood school. Because of the conditions of the roads, with no sidewalks, most students are bussed; however most students all live within a mile. "We are really a neighborhood school and self contained. As a result, there is that feeling of being a neighborhood school. Everybody knows everybody."

The vast majority of the students live in apartment complexes or in public housing, section 8 homes. Two thirds of the children are on free and reduced lunches (the highest number in the division). The school population is also very transient. "In years past we were the number one school with entering and withdrawing students after the year began. I would guess that a third of our population leaves during the school year and we get a third." Contrary to what might be 
expected from the influence of these factors, the students in the school are achieving well which

Mrs. McGrath credits to hardworking teachers and parental involvement.

Because of the at-risk nature of the school population, there is some extra money that is to be used to keep class sizes down. There is also a lot of resource help available. "We've got a lot of resource help at this school, and it's not just for those kids that are having difficulties, but we do an inclusion model where the teacher goes into the class and everybody benefits."

Organizationally, there is just Mrs. McGrath, "no administrative intern, no assistant principal. I have me and I have my secretary, that's it. That's why I work on Saturdays." There are some teaching assistants, and Mrs. McGrath is working to get more help administratively. "Basically, my secretary works very hard, really hard. I have said that those schools that have a transient population really need more help in the office, so there is some money in the budget for next year."

When asked to describe how the she would like the school to be seen, Mrs. McGrath responded:

One of our goals is to create an environment where everybody has an opportunity to learn. When you come into the office you're greeted by a friendly person. We're open. I have trouble with parents sometimes who had negative experiences with school. Parents are valued, we want to hear what they have to say. I want children to feel that they have a voice. We have a structure in place for them to give input on school issues and they talk about bathrooms and toilet paper and being inside or outside for breaks.

Mrs. McGrath's Work. When asked about her work, Mrs. McGrath responded:

I battle with my daily work, because every day I come in and have a plan of what I want to do. One of the things I told my self from the beginning, there are a lot of things that need to be done just to run a school, you've got to work with custodians if the floors are not clean or the bathrooms are not clean and there's always budget and the line going into the cafeteria. There's always things like that to deal with, and if you're not careful, those kinds of things can just take over your day completely. Discipline issues too, if you're not careful you can spend all your time on those kinds of things, management things.

I have focused myself to try to include something with leadership at least two or three times a week. I worked out a schedule, the teachers and I did, where every other week each grade level team has an opportunity to plan together. I'm always part of those meetings with them, and I consider that a leadership function. I set a block of time each day where I'm in a grade level for an hour or an hour and a half each morning. I'm always visible that way. I try to do at least two formal observations of teachers every week.

The relationship that I set up with staff and kids and parents here at this school, if I'm here in my office and I'm not here very much, my door is always open. So I have kids that come in and talk to me, I have parents, some on a regular basis who come in and talk. I'm always open for teachers. 
Another big part of my day is I have children whose parents have no phone numbers or whose numbers are disconnected, and I do a lot of visits to home on a weekly basis, during a week I bet I go three or four times.

Mrs. McGrath related two stories about her becoming involved with social/family issues of her students. One involved missing students who were dealing with abuse issues and the other involved a transportation issue with an inebriated parent. Mrs. McGrath has had to reactively deal with these issues, but she has also begun to proactively address them with the formation of a neighborhood center that operates out of her school:

I deal with those kind of issues a lot. I have contact with Child Protective Services, neglect, some abuse issues. I've had several children in homeless shelters. Through our neighborhood center we offer parenthood classes, we have social services working over here. I have a social worker who's assigned to this school by the city, and she's here two days a week. She works with parents. Right now it's only a community center on Thursdays, Fridays and Saturdays. It's a start. Right now we have a $\$ 100,000$ grant to make it happen. What I'm working on now is getting future funding from the city because it's a city service as well as a school service.

Mrs. McGrath's typical day starts at around 7:00 by touching base with her custodian.

From 7:20 to 8:20, she is at the front desk for teachers, then at the front for bus duty.

I like to be seen. I like the kids to see me, I like the teachers to know- they got bus duty, I can do it too. I do it every day. I know just about all the kids names, but it's tough because they come and go.

The kids come in at 8:20, till 8:25-30 and Mrs. McGrath "takes a trip around." At 8:35 every morning, there are announcements and they sing a song. She characterized the morning time as follows:

I kind of have a general rule that from 8:00 until after announcements I don't get bothered by phone calls or by parents unless the Superintendent calls. Generally that's my time to be there for teachers and kids. Then starts my day more or less, my block of time to go into classrooms is 9:00 to 10:30, I spend at least an hour in the cafeteria at lunch time. I have two monitors that serve in there, but with the younger kids I need to spend some time in the cafeteria. My older ones are great, but I'm still working on the younger ones.

After lunch, Mrs. McGrath often returns to classrooms:

When I do my observations, new teacher require four, all teachers get one formal, I might go in and step in another class. If I did a morning observation I might do an afternoon one. So I go and visit classrooms. When I go in the morning, I always leave a note for the teacher and I also leave notes for kids, if I saw something special. In the afternoon sometimes, I'll just go into a classroom and do my work. I'll take a pile of paperwork or an observation to analyze or write up. I'm really not in here (the office) very often, you can tell by the piles. That's what I do on the weekend, I go through the piles. 
At 2:20, I'm outside for afternoon bus duty, I assigned myself a bus. I have teachers who go on each bus and get on with the bus driver and make sure the kids are calm and seated before it takes off. For the early bus duty, I have a bus assigned to me, at 3:00, I'm outside, just to be outside, I don't have a bus assigned to me. After 3:00 when the kids leave, I'm usually here for teachers. I usually have teachers who just want to come in and talk, and we talk about so many different things. I usually stay until about seven trying to get paperwork done and I try to get feedback to the teachers quickly. Once I conference, I try to get it to them the next day. I spend a lot of time on those, those are real important to me.

Mrs. McGrath also has evening and weekend responsibilities, that have been increased by the neighborhood outreach project:

The neighborhood center when we started it I was out two times a week from September to January. Now I'm out about twice a month. And on Thursdays I teach a family computer class at the center. I come in on Saturday because the neighborhood center is open. I feel like it's important for me to be here for this too. I spend a lot of time at work, luckily I have a husband that's supportive of this.

As far as yearly cycles, Mrs. McGrath specifically highlighted summers, testing time, and the opening and closing of school.

Initially I thought that summertime would be a time to just lay back, but it's not. There's a lot of work to be done in the summer, update brochures for parents, setting some goals. I always try to get my steering committee together in June, and then they're even willing to come in in the summer. The summer time is less stressful than during the school year, but I do a lot of work in the summertime. Central office also involves us in lots of things in the summer.

The start of the school year is a big impact, then things calm down then new initiatives come from SACS. Right before ITBS seems to be a time where work picks up. Lots of practice testing in preparation for the ITBS teachers get stressed. And the kids get stressed, so I spend a lot of time talking to people, students and teachers. I don't feel as if the standardized tests capture what the children can do. I know that we need something to report to parents and it's certainly something we grew up with and have done for years. I would like to see individualized tests administered, but that's not going to happen. I tell that to teachers too, politically, we have to do what we can to make sure that our kids do the best that they can do.

The end of the year, trying to close things out is a busy, busy time. Last year I took two weeks in July, and one day in the fall and that was it. I know I should be doing better for myself in that and that's one of my personal goals. I make up for lost sleep on the weekends.

Mrs. McGrath's views on management and leadership. Mrs. McGrath stated, "I think management is, can almost be defined as, just the everyday administering of school functions. I look at it as completing tasks, as maintaining the building, for example." She listed planning, organizing and controlling as management functions. For her, management is 
basically, just a function of making sure that the school is running as it should. There is an efficiency factor with managing. I think when you go into leadership, you are looking more at quality, but for managing you are looking more at just the efficiency.

Management was seen to often interact with leadership:

Even holding faculty meetings with teachers, because scheduling of those faculty meetings and ensuring that you do have those meetings is a management task. I believe that leadership comes into what happens at those faculty meetings, but the management is just making sure that they are scheduled, making sure that you set up a way to ensure communication between the staff and the principal.

In contrast, leadership was described as influencing people:

I think you have to influence people and the influence has to be based on goals that the whole community sets. I think teachers have to have a strong voice in that and I think parents deserve a voice, kids deserve a voice and then, of course, you have the central office voice that has to be considered.

Vision was described as being important to leadership:

I feel like a big part of being a leader, though, is making sure that you have a vision and that you clearly articulate that vision. And, again, that vision should come from a group of people. These are mutually agreed upon goals and, therefore, out of that comes an idea of where we are going. I feel like everybody in the school then is a leader because if our goal is clearly articulated, we have a mission. We know where we are going. Then teachers can make decisions along those same lines and we know that we will always be together. That is the role of the administrator, too, to make sure that there is a clear understanding of what our mission and then allowing teachers to make their own decisions regarding that mission.

Leadership was also linked with new ideas:

The leader has to look at new approaches and new opportunities for things. I think sometimes we have to create opportunities for teachers to reflect on what they are doing in their classrooms. Kind of do a little nudging through observation and conferencing and offering staff development opportunities for teachers to learn new things. As a leader, you have to create that environment for taking a risk. You have got to provide opportunities for teachers to learn something new and in some cases you have to kind of heighten awareness so that the teachers themselves recognize that there is a need for something. Our children are changing. Instruction is changing. Content is changing, so let us look at new ways of doing things and that is what a leader does.

When asked to describe the relationship of the two constructs, it was emphasized that management and leadership are often intertwined, but that management should be under leadership as far as importance.

I think leadership is the big umbrella and I think that management comes under leadership. I feel like there is a lot of inner personal functions that even take place under management, that's where the leadership qualities come in. That is why I think they are related in lots of ways; the two of them are very integrated and very interrelated. Sometimes you have to be a manager and request things of people in order to get leadership activities in place, too. 
Mrs. McGrath related that her view of the relation of the two constructs has changed:

It was almost as though the management end of it was more important than the leadership end of it. And that was my perception, from my course work and my readings and now I believe just the opposite. I think that you have got to have that leadership and even though it may be tough to define what leadership is.

So, I think initially I thought that the thing called instructional leadership doesn't really exist. The job in school is mostly management, but it is not. The management can be the most time consuming only that it happens day-to-day. A lot the time during the day is managing things, but it is the leadership that is most important.

I believe also that if a leader is not a good manager then that person is not going to be effective as a building administrator. I believe the other is true, too. I think years ago a lot of principals, particularly in this system, went up through the ranks as basketball coaches or football coaches and they became administrators. They were good managers and I am not sure that many of them were good leaders.

Mrs. McGrath's view on her own role as leader and manager. In her own context, Mrs.

McGrath described the roles as having to be integrated because of a lack of administrative assistants, "In (our division) where there is one person at the helm in most elementary schools, I feel as though the principal has to not only be a good manager but also has to be a good leader."

I see a lot of it is management and I think that the school year that we have, the fact that we have no time during the week that our children are not in school, I think that it is almost a system that mandates that my job must be mostly management. To try and build that leadership in, means that I do a lot of work before school, after school, and on the weekends so that I can spend my time during the day doing things that I consider leadership type things and not just do managing. It would very easy to just manage.

As far as delegating management tasks, Mrs. McGrath explains that there is just not the staff to be able to do that, but she also recognized that the integrated nature of management and leadership might make it difficult.

In contrast, leadership is seen by Mrs. McGrath as something that is definitely shared in her situation:

I have team leaders in the building and I see them responsible for leadership on their grade level and in the group of teachers they work with. I have my SCA officers have student leadership roles in our schools. I don't see myself as being solely responsible for leadership in the school. And that is because we know where we are going. We know what we are all about. Our whole school knows that. Therefore, people can make decisions. They can do things amongst their grade levels or cross-grade levels. They are not always generated directly here from this office and I want that to happen. I feel like that is what a true leader is all about to encourage people to take a close look at what they are doing and come up with a different way of doing things and me making sure that there is a climate here that we can take risks.

When asked about the role of central office, Mrs. McGrath responded: 
My central office here is changing. I see it becoming more of a support role. I feel like in that past, the role of the central office was one of evaluation, one of getting phone calls from parents if there is any disagreement or any conflict and central office would get the phone call and you never wanted a parent to call down at central office. That type of thingit is changing to one of more support.

Mrs. McGrath's beliefs on the role her personal views should play.

I think I could be a hypocrite and say that they don't impact at all, but they do. They have got to. My personal views are faimess, integrity, the fact that I believe that people are inherently good. I believe that all children can succeed. There are some people that would think that because our children lack the experiences at homes because of their poor, socioeconomic level, that they can't succeed. I firmly believe that some children need more time, but that every child can be successful. And those views are very important to me.

Mrs. McGrath also described her views being balanced by the views of others because she

functions in the role of a facilitator:

I believe as a facilitator and as an educator, we can't ever forget that we are the ones that have more knowledge about that particular thing than the regular, average person walking down the street does. We are the ones that have been to school to learn how to teach. I hope that we keep abreast of new practices and new theories with education, so it is our role to tell people and keep them informed. If we want the community at large to be part of the decision making, then they have to be knowledgeable, so our job is somehow to make them knowledgeable through discussion groups, newsletters or whatever we decide to do. And in making decisions as what knowledge is shared, then we are going to go into personal beliefs.

I am not the only one that can bring things to the table. We can all bring things to the table. We try to do that. One of the things that we do here is if anybody finds an article in a joumal that they think is interesting, I copy it, give it to faculty members, and I find articles that I think are important, too. We have discussion groups. I guess the collaborative end of it comes from the fact that we have this system in place and anybody can contribute to it who wants to.

Communication and discussion is seen by Mrs. McGrath as a very important part of her

job:

I had a principal, a mentor, who told me one time that I was spending too much time evaluating teachers. I should be able to go in and do an observation, write it up, conference with teacher, and write up a formal evaluation and all that together should not take more than an hour or an hour and a half, max. The whole process. I can't do that, because that is a big role for me as a leader in my school-instruction. And, how do you get at instruction if you don't talk about it?

When asked about constraints or restraints on implementing views, Mrs. McGrath

responded:

We have a new superintendent that has brought in a lot of changes. He has given us, as principals and as teachers, not a free reign, but he has created a climate where it is okay for us to try something new. If you are not successful, that is okay, too. He has given us the opportunity to takes those risks. It wasn't there before. 
A few restraints were mentioned. One was not having enough time to do things. Another was

that,

sometimes there may be a constraint that teachers are entrenched in the way that they have been doing things and change is hard to come about. With my school and my staff I am lucky I have many almost brand new teachers. So, I think it easier sometimes to work with the fresher minds and they are more willing to try new things.

If I didn't have the staff development training that I have, I would see that money was a problem, because I think many of the new practices require lots of training, lots of staff development, and money would be an issue. But I can do a lot of that.

In management issues, there is a lot of bureaucracy, custodial functions for example. That is a huge bureaucracy there that I have yet to work my way through. Budget, that is a bureaucracy there. We don't have a whole lot of flexibility with combining accounts, for example, in spending money. That kind of thing. But instructionally, our superintendent, I feel, has just paved the way for there to be no constraints.

\section{Mrs. Tanner (Division B)}

Mrs. Tanner described herself as a very active, hands-on, kid-centered principal of a

specialized school that emphasizes school-parent collaboration and high expectations for behavior and achievement. Describing herself and her school, she stated:

I know that my main focus is the kids and every decision that I make is based on what is best for kids. Often times, if a teacher wants to see me and I am talking with a kid, that has priority. I think that everybody knows that. I am real hard to catch up with. I am very rarely in my office. They know that I am in the classrooms and they know that I am with kids. That is exactly what I am like and that is what I need to be-that is what is fulfilling. I try not to shortchange the teachers. I try not to do that, but we can get together after school, we can get together before school and often times do. They know how to catch up with me and walk with me as I am going.

(Our) school requires an awful lot of active participation from the parent. It doesn't mean that you have to be here in school to be a volunteer. That would be nice, but we do have a contract that speaks to the parent's responsibility, the child's responsibility and the school's responsibility. What that really boils down to is a lot of open communication between the school and the home, to make that connection, to reinforce what we are doing here, and for us to try to reinforce what they are doing there. I really do think that we achieve that as a school. I think it reflects itself in the demeanor of our kids. They are very well-mannered which shows discipline at home and discipline here. And, our test scores are terrific, they really are.

Mrs. Tanner's Role. When asked how she would like to be perceived, Mrs. Tanner

responded:

Accessible, warm, caring, that they can tell me whatever they need to tell me and it won't reflect on them, per se. That I do have their child's interest in my mind. That I do know what I am talking about and I know kids and I know curriculum. That I am not above you, but I am a source to help you because I do know kids and I do know curriculum. I can help you with whatever you have to bring to me. 
When asked to describe herself, she stated:

Curriculum, kids, instruction is really my forte' and my background. If the floor isn't swept within the last half an hour, I am not that concerned about it. I will be concerned about buses, I will be concerned about the cafeteria. I do all that, but that is not my main focus. It is my last priority. My first priority is the kids and that is in direct relation to the teachers because if I am so concerned about kids, then I want the teachers to do the best they can.

Mrs. Tanner's Career. Mrs. Tanner emphasized the serendipitous nature of her career

choices:

You know how people always set goals. I never did do that. I think I was really one of those free-spirited people, but because of some of the jobs and some of the tasks I had, I became much more rooted and settled. I don't know when that happened or how that happened because I think I really would like to still be out there being a free spirit. But when I was a teacher, that was all I ever wanted to do. In fact, I never wanted to become a teacher. I didn't set goals.

I happened to take an education course one summer as an elective to get a few more hours and "Oh, this is pretty cool, I will major in this." Lots of thought in that. I will major in that because I liked the course. Sure enough, that is what happened. I had a wonderful experience with it and I think sometimes your cooperating teacher makes or breaks how you feel about teaching. She is still a good friend today. It was really just a terrific experience and I got a job right away in a wonderful school, in a wonderful environment and thought I had died and gone to heaven.

Mrs. Tanner's teaching career began at the fourth grade level, and the school she was in went through four principals in four years. At the beginning of her fourth year, her new principal assigned her to first grade with the only other option being to transfer schools. She decided to stay in the school as she was very comfortable and loved the parents and kids. She taught first grade for ten years. During that time, the seeds of her administrative career were sown:

During that time, I got involved. I changed to another school and my principal and I had a real good relationship. He passed around something one day and said you want to go to a Madeline Hunter workshop. I said, "who is that?" He signed me up for it. I went and just thoroughly enjoyed myself and then the assistant superintendent was charged with the responsibility of getting in a program that would make teachers more effective. I got signed up for it again by the same principal, which led to a staff development position. Because of my background in Madeline Hunter, I was asked to apply. I told you I don't have the goals. I would have just been happy in first grade and still I was doing some training in the summer, and I loved it. I had some people that I was responsible for, to make sure they were keeping up their skills. I had first grade full time and then I had this other job full time. But it was wonderful. I thought it was terrific.

The assistant superintendent came in and said, "you are going to apply for that staff development job" and I said, "I am." I did and I worked there for four years and as I was working there, I went to all the schools, high schools, middle schools and elementary, and worked with teachers on being more effective and saw climates of schools, had direct interaction with teachers and principals on some improvement teams to help improve that person to either make or break that person. I saw a lot of ins and outs and really some of 
the more negative things of being a principal because a lot of my job was working with those who were not doing their job. I thought if I am doing all this and I can do all this and I think I can at least do it as well as so-and-so can do, why don't I go ahead and get the money for it too?

I was still on ten months, even though I was doing training sessions in the summer and that same assistant superintendent said "I think you ought to apply for an elementary principalship." I said, "the one thing I don't want is an elementary principalship. So much for those die statements- always, never-anyway, I went back and got my second degree, got my Ed.S. and got a principalship right after that. This is my fifth year.

When asked about future plans, Mrs. Tanner stated:

I know that this is not what I want to do until I die. I know that, but I love training, but I got out of the training because I wanted to be with kids again. I was around kids in a way, but very indirectly, and I really wasn't supposed to interact with them and help them, I was supposed to help that teacher. It was almost like clenching my fists or grabbing my hands so I wouldn't do anything to interfere with what she was doing because I was supposed to observe her and give her feedback. I was trying to be real objective and it was awful. I just couldn't wait to be around kids again. It really is what makes my day and I truly thoroughly enjoy it. I love training and I would love somehow to combine the two which means teaching. I have been there, done that, so I don't know.

Working at the university level was ruled out because "that is not kids", and central office was not appealing because of political games.

I think central administration, not just ours, just in general, is a lot of politics and I don't know how to play those games. I am not good at games. I can't keep up with it. I don't want to. I don't think that is me. Now, I will probably eat my words one of these days again, but I don't know.

I also know that I need a real challenge in my life and I not saying that I have mastered this job by any degree, but having been here for as long as I have been here I really do know the parents and I know the kids and I know the teachers and I know how to get things done without ruffling feathers. I think I do. So some of the challenge is not there.

Mrs. Tanner's School. Mrs. Tanner's school is a specialized one that scores very well on

standardized tests. The school emphasizes school-home collaboration and it this aspect that Mrs.

Tanner cites as the reason for the high test scores contrary to some people's perceptions:

We seem to have a perception out there of the general public that we have very, very smart kids. We certainly do, but we teach whoever comes in that door. We don't screen kids for their intelligence or whether they are well-disciplined or well-mannered. That is what we want, but the application just has name, date of birth, address, that kind of thing, so it is not a screening out process at all. But because of what we expect of kids, the high expectations as well as the close home-school connection, we have very successful children. We have super, super dedicated teachers that are going to make that happen for kids because we really care about kids.

This particular specialized school movement started a few decades ago by focusing on

"back to basics" education, reading, writing, arithmetic with no frills. 
You were supposed just to stick to the basic books and reading, writing and arithmetic. No fluff and stuff. It has emerged from that and I am thankful for that. Because if we really stuck to that tradition, we wouldn't have the computers or anything else and I think we need to compete in education with television and videos and you can't just expect it to get everything from the main source. So we have evolved from that, but the contract has remained exactly the same that the parents sign that they will adhere to that upon entering their child in school.

For the school it says the school will provide an orderly instruction environment. For the parent responsibility it said, we will provide a place for the child to do homework, we will monitor television viewing, we will enforce the discipline that the school will enforce and recommendations that are in the best interest of the child; and for the students, that we will finish class assignments, we will do homework and turn it in in a prompt manner, those kinds of things.

In theory, the school would draw students from all over whose parents chose to send them to this type of school, but in reality, the school is more of a neighborhood one because it is a zoned school for kindergarten and those kindergartners get first priority in continuing on. Also siblings of students in the school get priority in being admitted. The school is so popular with the zoned population that last year only eleven students were accepted off of the waiting list and those students were all siblings.

The school is one of the larger ones in the division. The school is $35 \%$ minority with a "very low, low percentage of free lunch." Administratively there is the principal and one secretary. Parental support helps in some of the administration and it is also cited as a major financial plus. There is a very active PTA.

Our fund raisers do extremely well. You would be very impressed. We are talking a lot, and it goes all toward children's programs and I think that is why people are willing to commit that energy and go out and help that because they know that is what it is going to go to.

When asked about the atmosphere of her school, Mrs. Tanner stated:

Most people who come in here, I would like to say that they can just feel that it is a very special place that the teachers care about the kids. It is bright. It is friendly. It is open. It is inviting. We have got a lot of stuff hanging on the walls to show what our kids can do and make it more inviting. Teachers are very respectful of kids and vice versa. You really can feel it.

We have high expectations and terrific parent cooperation and teachers who like their jobs and like kids. Any research will tell you that high expectations and parent reinforcement are the two biggies with kids succeeding in school. We expect that homework will be done. That if we assign it, it is going to be done. It is going to come back and come back neat. And parents who want to send their kid to (this type of specialized) school want to because they are committed to that child's education. 
Parents who come by and are here a little early to pick up their child ask, "any help you need in the office?", and I will name some things and some of them will come by in the summer, "do you want me to help you staple something? Just call me if you need me. Just call me whenever you want." Every classroom has room mothers and that probably is true with every school, but I think probably six would like to be room mothers rather than just "won't you please be my room mother" kind of idea. The field trips- when we need chaperones, "why don't I ride in my car behind the bus and meet you there." They do that. I think it goes back to that we have more parents who are committed to their child's education and want to be active in the entire process because of the nature of how they perceive (this type of specialized) school.

That is what they want. They want their children to know "I am interested in every aspect of your education, whether that is a PE demonstration team, whether it is coming to the classroom for a conference, whether that is going on a field trip, I will be there for you."

Mrs. Tanner's Work, When asked to describe her daily work, Mrs. Tanner responded:

I feel like a very large part of my responsibility is making sure and not that I am checking up on people, but looking for good instruction so the more feedback that I can give the teachers on their instruction, constructive feedback I hope, the better that is going to be. I also feel that teachers feel very comfortable with me in talking about a particular student because I do know him. I pride myself on that. We talk a lot about kids around here. An awful lot about kids and I think they respect my opinion because I do know the kids and can understand what they are saying sometimes. Just plain old understanding, so a lot of my job is communication, feedback to teachers, but again having a lot of time with kids.

When asked to describe her routine, Mrs. Tanner stated that she usually comes in a 7:30,

checks her e-mail and then supervises the breakfast program until school starts at 8:30. Then she

describes herself as being in and out of classrooms:

I go into classrooms usually and then after a few classroom visits, then I am checking incoming mail. See if that needs any answers and back into the classrooms. Some of it is formal and some of it is not. One of my goals this year is to try leave more positive notes rather than just the verbal. On Sunday, for instance, I was here and I left a note on each teacher's desk with a little treat about something that had happened the week beforepersonal to them-so that it is not just something that is fleeting, that it something that they can keep and look back on.

I try to stop in the cafeteria at lunch time. I eat in there every day. It is a chance to talk to kids. I bring my own lunch. I hate cafeteria food and kids ask me, like I know that my next turn Monday is with Mrs. Winslow's class. They ask me in advance. And they just do. Larry said today they had a lesson on friendly letters and so they wrote them to me. You should see them. They are real cute. But one of the things was I wish you would sit next to me at lunch Monday. They are used to my doing that and I try to take turns.

Mrs. Tanner spends her afternoon much the same way, and she has mostly informal contact with people. including staff, parents and students. There are two dismissals and Mrs. Tanner is around for them.

Sometimes it is just helpful to the patrols for me help them so they don't have the burden all the time and they like it too that I am out there to support them. And then we have the three 
o'clock dismissal and I always make sure that nobody is left by themselves. I will not leave until that last person is picked up. I don't care what time it is.

Mrs. Tanner uses the late afternoon when things quiet down to do paperwork and she "will come in on weekends sometimes just to clear off the desk or get some quiet time where I can do something uninterrupted." She does not schedule a particular time to be with teachers because,

they know they can generally catch up. I am usually in the outer office so they can catch up with me. If they need to speak with me privately, they will just say can they come in the office. They know where I am. They know where to get me.

As far as yearly cycles, Mrs. Tanner cited some parental events that she tries to sponsor every other month. Because of the low student turnover, Mrs. Tanner's summers were not cited as being too hectic, but she does try to keep busy.

I try not to let it calm down in the summer. Usually, summer, I try to have a giant summer project and this sounds like a dumb one. But last year, I painted all the doors on the primary hallway. The first grades are yellow doors, real bright colors. The second grades are blue and I have a red door and a green door and four that are all four colors. I have gotten better about taking off some time in the summer. The first year I think I just took off a week or so and last year I took off two whole weeks and did nothing. It was hard. It was hard. I realized at the end of that two week period I had all these things I was going to do and hadn't done any of them. I thought, gosh, I have got to be productive somehow. I do not sew. I have a sewing machine. I bought a pattern and made a dress.

Mrs. Tanner's Views on Leadership and Management. When asked to discuss

management, Mrs. Tanner responded:

I think more in terms of the physical stuff. Perhaps even tasking out things to people. Management is about organization and how you are going to go about whatever it is, whether it is the cleanliness of the building or whether it's-we have something coming up in May-I have to kiss that pig.

(Mrs. Tanner has developed a reading incentive program for this year with her kissing a pig as the "reward" for the students' hard work.)

I am working on getting all of that organized in terms of a whole school project. To me, that is the epitome of management if you can pull something for the parents, all the kids and the staff and get a whole day of activities planned and have it come off. It is management.

Management, too, I think is scheduling and stuff like that. I don't have to do a whole lot on this level. I know high school and middle school have a time with trying to maintain its flexibility of scheduling so that kids can move about. I don't have to worry about that as much and we have a PE schedule, a music schedule and teachers hand in their schedules to me because we have blocks of time that we like to devote to subjects, but I don't have to set them all up.

To me, leadership is getting people to go with you and I think that is where maybe that ed-psych gets in there because you have really got to know people, kids, community, to be able to lead them in a direction; somebody has got to follow you. We have got an 
awful lot of people who are very talented, but they say something that falls on deaf ears because they don't have the leadership things. I think it is that you really do know what you are talking about and that you are not just going to take a lead because it is the thing to do plus the fact that you know who you are dealing with and that you can work with them in increments and not take them too far out of their comfort zone because then they are not going to follow.

When asked if leadership and management are related, Mrs. Tanner replied:

I definitely do see that within a school. I think it is also hard. I have seen people-a wonderful guy who was a principal for awhile that had no management skills. After awhile, he didn't show up to this meeting because he just frankly didn't know what was going on. There were things scheduled at his school and he forgot. It was on the calendar, but he never looked at the calendar. Those kinds of things. He had the leadership qualities but no management and it did him in because you have got to have both to keep up with all the demands that are within a school. I don't think leadership is enough.

I have also seen wonderfully clean schools. Everybody is doing what they are supposed to be doing, but it is just kind of stagnant because the leadership isn't there. It just stays status quo. Things are clicking, but it just stays status quo and you can tell that. You don't see the exuberance maybe in people, the enthusiasm. They are just going through the routine, just kind of a little shuffle "okay I am supposed to be there and I am doing this and the kids are working," but there is no real joy or enthusiasm, the morale, the whole climate, you can really feel that that is just not there.

Even though Mrs. Tanner stated that both are needed, she also indicated that they were of different importance: "leadership would be number one and management would be maybe up and down a list of things, like maybe number five." One area that was delineated as being mostly management was overseeing the cleaning of the building.

I really do count on the day custodians that I am not going to come back at nine o'clock at night to see what the night custodians are doing about this. I don't just let it run because we have had some problems in the past and one guy is no longer here and I have a new guy this year who is wonderful. I am not going to be as on top of it as I was. I am not going to come back at nine o'clock, whereas some educational programs that I have going on, I am going to be right in there looking to see how it is going.

They have a schedule where they are going to clean the bathrooms here and do the cafeteria here and if they are going down to the kindergarten rooms because we have a morning and afternoon shift and they wanted it cleaned up before there are any new kids. So there are certain times during the day they are relegated and delegated to certain things, but if I say, gosh, there is graffiti on the marquee, I ask can I have some cleaning fluid and I am just going to go out there real quickly, and they say, no, we'll do that. We will take care of it. Don't worry about it and it is just done.

\section{Mrs. Tanners View of Her Work as a Manager and Leader.}

Again, I think there has to be a mix. If you were so busy leading all day long and that was as a majority what you did, then things are going to fall apart because you are not managing what you are leading and vice versa. If you are just managing, then those visionary things that cause that excitement in your building are not going to happen. So it is just going to go back to status quo because you are not. I think it has got to be a mixture of the two. 
Mrs. Tanner related how she endeavors to keep the two balanced:

If you don't give yourself some time to think where am I, where do I want to go, you could very easily get swallowed up in management because there is so much to do and there is only one person to do it. One of the things that I do, is I have teams within the building, like quality circles in total quality management, that kind of thing. I can get more of a perspective rather than just sink in the mire and get with those three people and we meet and we talk about things and where are things going and how is it happening and how is it evolving. To keep a perspective. That is one of the ways. The other is that I don't think you ever leave the job even though you physically go home. I don't anyway. It is on my mind a lot and I can get a little perspective when I move away from it and I am a total processor all the time. I am processing. It is just constantly going and going on the weekends. It is not all consuming, but I do process a lot and rethink things a lot.

Mrs. Tanner also tries to balance management and leadership by putting people with differing skills together to work on projects: "sometimes if you get all those creative people, it all sounds wonderful but a lot of creative people don't know how to implement things. They have a wonderful idea, but I try to get a real mixture because you need to see the other side too." Mrs.

Tanner also talked about the difficulty of trying to develop shared leadership:

They look to me as being the primary source. But I am not the primary source. They are coming to me with the ideas and hopefully I have some too. I had a really, really hard time trying to develop the idea of shared decision making. There was a tremendously traditional principal here before I was , and before that was an even more traditional one, and before that there was a principal who was here for fifteen years. I am only the fourth in the line. I think they are used to the boss and then there is us. I really worked hard at trying to change that. I am not there, but I have really worked hard.

I also know that I can go to them with some ideas and get some honest feedback where they are not going to say what I want them to say. I don't have to be the number one right person and know all the answers because I can't be and I won't be and I will never be. They have also had some problems with image. I am not-you don't have to salute me. You don't have to say, yes ma'am. It is okay if you do, but you don't have to. We are working on perhaps a more casual side as opposed to a more structured relationship-I am principal, you're the Indians. That is evolving in a nice way I think.

When asked about the role of central office, Mrs. Tanner responded:

I feel so positive about the central office this year. I really see them as a support to all that we do. I also see it somewhat as a bigger version of the principal. That central office should have the leadership and management division, that here's where we are going, here's the five-year plan, and here is how we are going to accomplish it. What do you all think about this. I see it just as a bigger version of what a principal does in his or her school.

This is seen as a very different thing to the way things were done before:

I think it was very much authoritarian. You do it because I said to do it and I am the boss. It is going to get done now, yesterday. The change is just so drastic and dramatic and it has definitely permeated the people who work at central administration because I think they are very aware of what our superintendent stands for. And it is for kids, how can we make 
it best for kids. That it is to support people who are supporting kids. I did not feel that way before he came in.

Mrs. Tanners Beliefs on the Role of her Personal Views.

One of the things that we taught in staff development was that you modeled in your lesson, that kids learn from your model. Even if you don't voice your philosophy, the modeling that you do comes out loud and clear. Like I was saying with our superintendent. Even if he doesn't say it all the time, you can tell by what he is doing and what he is showing and he supports that philosophy in every single thing he does and every single thing he says. That is why the support he is giving us, even though he is not saying I support you, it shows. I think we underplay how powerful modeling is. That is to say that even if the philosophies aren't verbalized, I think they are extremely evident.

I think sometimes my personal views are not always what I embody here. Because I think anytime you are in a public perspective I don't think your views can always be what you want them to be. I can't tell every kid you have got to go to church. I can't tell every kid vote Republican or tell your parents to vote Republican, those kinds of things. I think you supersede your own person sometimes to make it the best for kids. You can't always have those middle class values that there should be two parents in every home and they should be working and they should help kids with homework. Even though that's what I believe personally, that is not reality and I know it won't be, so how can I make it better for that kid when there is a single parent and they are in poverty and teach them survival skills .

When asked to cite examples of her personal views being implemented, Mrs. Tanner

responded:

What really has hit me going in classrooms and working with teachers is that we can't teach kids all that we need to teach them. It is just impossible because of the technology. We can't teach them everything that they need to know because the world is changing so rapidly. Whoever would have thought of Internet five years ago? We didn't teach that because we didn't know about that. I think it is more important or equally as important to teach thinking skills, problem solving as well as content. I am not saying to throw the content out, but the way we prepare kids for the future is to teach them how to think. We have really worked hard on that here at our school. That is kind of what we have been working on as well as technology.

We were real backwards here. Computers were in teachers classrooms, but there weren't very many computers at all and they really weren't being utilized. "Oh, let me put this book on top of this computer, it is a good shelf." We had a change of personnel in the library and were able to establish a computer lab right next to the library. And that was not acceptable with the personnel who were here before. We have got two or three people, you see again, where your committees kind of shift. Terrific people who are just computer whiz kids. They have done an in-service. We just had a real fun one on one of our half days. We were in a little circuit and went to each station and "when a computer doesn't do, what are you going to do". Like problem solving with the computer and one was to introduce us to new programs. One was a camera that takes pictures although it is not really using film and you can import it into programs. It was really fun. The trouble was it was too short and we all have asked for another one.

Again, that enthusiasm and not just being status quo has really enlivened us, but I think the key was to get people comfortable with the computer. We started low. We really did and have worked up since then. Every time I have been able to allocate any money, it is going to go to thinking skills because money talks too and it is going to go to computers. We got to enforce it with your resources too and not just with your mouth. 
When asked to identify any constraints or restraints to implementing things, Mrs. Tanner replied:

I think there is always resistance no matter how powerful your views are, how right they are, how wrong they are, whatever, I think there always is resistance. I talked about looping, for instance, with second and third grade teachers and they said, yeah, but not really. The other thing I worked on for five years is back-to-back planning time so that there is more time to team plan. "All my breaks will be gone in the same day," but if you are perceiving them as breaks rather than planning time, then you have got the wrong perception of what $\mathrm{PE}$ and music are allowing you to do. And you are telling me that you don't have enough planning time, so what do you do? I did a needs assessment at the beginning of the school year with them and that is the thing they said right here on this chart. More planning time. There it is. Got 20 points on it. But, I can't sell them on that.

The role of the superintendent in fostering an atmosphere allowing new things was emphasized:

Again, our superintendent has said that he wants people to take a risk. In fact, he is developing an entire evaluation system based on taking a risk and it is called pay for performance. You get a third of your salary raise if you just exist, two-thirds if you develop a project, and three-thirds if it is a successful one. Sometimes if you are going to take a risk, you may fail at it, but it doesn't mean that the risk wasn't a good one. We will see what happens with that. I think those words were said before, but your risk better be successful and it better be the right risk. And I don't feel that way now. I don't. If I fall on my face, I think that would be okay, "well at least you tried."

When asked if there was any problems with dealing with a bureaucracy, Mrs. Tanner replied that it was there, but that she thought that people could see their way through it.

Mrs. Allen (Division C)

Mrs. Allen described herself as a long term principal in a very stable school community

who has had the opportunity to mentor an educational culture to maturity. The culture values

having both high achievement and positive affective climate for students and staff.

I want to be seen as someone who has created a school where children can not only learn but love learning and where teachers not only teach but can love to teach. I think I am very conscious of the school climate. I think it is real important that the students and teachers do well, but in order to do well, they need to be comfortable and happy in their situation. At the end of the visitation when the chairman was leaving, she paid me a high compliment of what my values are. She said, "Your children's achievement is high, your children are happy, your teachers are happy, what else do you want?"

Mrs. Allen credits her success to having a long term relationship with her school community:

I am lucky as a principal. I have a wonderful staff and have a rather unique position because I was once a member of the staff that I have now served for twelve years. And, it is in a small town so we do not trade or move from school to school. I have been able to 
stay with the same group and grow with them and work with them. It is a unique situation for a school administrator.

I am in a position where I know my staff very, very well. They are either people that I have worked with or who were friends with or the ones that I have hired. I have been able to continue working with them for many years and there is a real bonding among the staff and with me and I think that makes the job much easier. Also, because I have been in the same community for so long, and not moved around like so many other principals are, I get to know the families pretty well and sometimes we have a lot of high school students who volunteer and work here and we get to see the kids that we taught in first and second grade and they cycle back as high schoolers and now some of them are actually coming in and registering their children. There is that continuity which I like and it is very helpful in working with families. We have that kind of knowledge of them.

Mrs. Allen's Role. Mrs. Allen sees herself in the role of a facilitator:

I would like to think that I have been someone who has fostered other teachers and maybe sometimes inspired some of them to try things they wouldn't have tried and introduce them to things that they might not have looked at. I really see my role more as a facilitator for teachers. I want to have a building and a place that they have everything they need to teach and a schedule that is the best for them to teach and colleagues that are most supportive. My whole program as a principal is to make sure everything is there in place and ready and accessible so that they can do the very, very best job they can.

Mrs. Allen's Career. Mrs. Allen came into education as a second career. She began as a researcher for an encyclopedia company and was doing a lot of research in educational areas.

When her husband was transferred to this area, she decided to get certified and become a teacher.

Most of her educational career has been in a single school system. She began as a reading specialist in the elementary school. She traced her going into administration to two factors. "As a reading specialist, I started to realize that you could have more impact in administration as far as setting policies and impact on a lot of children. It was more effective to be in an administrative role." Also, she was encouraged by her colleagues, "when the existing principal started thinking about retirement, she approached me and said she wished that I would consider going into administration." When asked why this happened, Mrs. Allen responded:

I think because in a position as a reading specialist I had people coming to me frequently and I was able to help them out and was starting to act in an administrative role while I was still being a teacher. I did a lot of work with parents and the special education people and was just kind of selected for faculty spokesman. People were coming to me for help and answers.

Mrs. Allen already had a master's in elementary education and almost the equivalent of a master's in reading, she did need to take four additional course in administration to get certified. She was the assistant principal for three years and when the principal retired the teachers requested 
her to be the new head, "the teachers actually drew up a petition and presented it to the school board." She was principal of the elementary school for seven years, then the elementary school was split into two schools by grade creating a new primary school. She was chosen to be the principal of this "new" school. "I came up here with all of the teachers who were in the kindergarten, first and second grades. We brought everyone that was within those grade levels."

She has been in this position for seven years. Reflecting on her career, Mrs. Allen stated:

I don't know if I would have sought out this job someplace else, but because this community is so supportive of education and I knew the staff that I would be working with and I knew they would be easy to work with and I felt that I had already gained their respect. I moved into it that way, but it wasn't originally a goal I started out with at all. In fact, I didn't take my first education course until I was in my thirties.

When asked about future career plans, Mrs. Allen responded: "This is where I want to be

until I retire." She related a comment one of her professors had made regarding the elementary school principalship:

"Some people don't realize that it is the best job in education, bar none. You get the most satisfaction out of it. You get the hugs. You can see the impact that you made, you can take children at a very young age and within a couple of years accomplish and see a big difference with them. They are still enthusiastic. The teachers that you work with at that level tend to be very humanistic and very easy to approach." Now that I have been in it and I look at other education jobs, I can see he was right. I would not trade mine for any other job in education. I have been asked several times, didn't I want to move on into central office kind of positions? As far as I am concerned, they involve meetings and writing reports which are the two things I don't like about this job and I would miss the children and the teachers and the satisfaction which is the part I like. As far as I am concerned, this is the ideal.

When asked if she felt she could have greater influence on the field in a position in a university or

in central office, Mrs. Allen replied no and cited these reasons:

We have had over the years many student teachers and I feel that we have been able to work with them and have an impact on them. Even after they have been hired in other school systems, they still come back if they are having a problem and say how this didn't happen here, what would I do. So, I feel that I can be having impact more by having them here and modeling what a good school should be like and what their classrooms should be, than by lecturing them in a classroom setting. I would rather work with them in real life situations.

There are only three professional people in our central office and they end up having to just take care of so many things- buses, grant reports and that sort of thing, that we are really very much site based and so as far as curriculum and policies that affect the children, we are able to pretty much enact them here at our level. Any new ideas, if you can present them and justify them and they don't cost too much, we usually can go with them. 
Mrs. Allen's School. When asked to sum up how she would like her school to be known, Mrs. Allen stated it up very succinctly, "It is a good place for children to live and learn and love." She expanded on this more when asked to relate school information that she might share with parents:

It is an effective school where their children always do quite well in standardized and different types of tests, etc., that we usually are able to have academic goals met and we are fairly vigorous in our academic approach. But even more than that, I think the fact that we are able to still have our children be very happy, enjoy being at school, and usually if I take them on a tour of the school, they can see the children's faces and that is something that you can't fake and they can see the excitement just going into the classrooms, that is very active learning environment.

A very child-oriented school, partly because of the age that we have but also the philosophy of teachers that I select are very much wanting to do things that are appropriate for children-so we have a rigorous academic program, but we try and walk that fine line so the children don't feel that pressured or stressed, yet they are excited about learning.

Mrs. Allen's school includes all of the children in the division from preschool through grade two. Racially it is about three percent minority with more Asian American than African American children. "That is a function of the community. It is not because there has been any gerrymandering, we just take everybody in the town and that is what it is." About $10 \%$ of the students are enrolled in the free or reduced lunch program. The school population is described as being bipolar:

We have one very sophisticated, very well traveled, very educated group and on the other hand, we have some trailer parks and some low income housing and a lot of older homes in old (city), where children tend to be very isolated and rarely leave the peninsula. We have a bipolar group that we need to work with and that goes as far as educational levels, economic levels, and just access and experiences.

Organizationally, there is one half time administrative assistant and two secretaries.

Mrs. Allen's Work. When asked to characterize her day, she stated:

I don't think there is ever a typical day. I am sure you have heard that from most of the people that you interview. I think the hard part about this job is time management because there are so many routine things that you have to take care of. If you don't take care of it, things just don't run smoothly and my goal has always been to have things run so smoothly that the teachers don't have to stop and even think about having supplies or is the assistance going to be here. Everything just needs to be there and be there automatically.

In order to keep those things going, you get involved with a lot of detail work and you have to take care of those things. On the other hand, every five minutes there is somebody at the door with a question-there were two or three crises today. So there is always the unexpected, especially when you work with little children and you just expect that. 
It is a juggling act as far as being able to handle all the routine, regular things you need to do. Do the reports and the ordering and interviews and at the same time handle all these little mini crises that just keep popping up. I think you can very easily get caught in that you are just running around putting out fires and you forget the long term planning. You got to have a vision of where you are going and you have to have both- a very cerebral type approach, but then you've got to be able to get down to the real nitty gritty.

When asked to describe her routine, Mrs. Allen replied that she usually arrived about 7:30 and checked the e-mail to see what is going on. She then has a relatively quiet half hour to do some writing of reports or longer conferences with teachers. The teachers start arriving at eight and the students arrive at nine.

Once the teachers are here from eight to nine, I usually try to be available to them and we frequently have meetings. We have faculty meetings, grade level meetings, teacher assistance team, the whole routine. And the days that we don't have meetings, I will work on something right at the counter so I am accessible as the teachers come in for quick things they want to talk about or get straight. So I just try and be available around them until school starts. At nine o'clock all the children come in and I greet them at the door when they are coming in and there are always a couple of little crises to solve.

I try sometime each morning and sometime each afternoon to do what I call walkarounds for supervision type things. Sometimes it amounts to nothing more than just walking the route and going by the classrooms. Sometimes I will go in for five minutes just to do a quick survey. I think very often you can tell more what is going on a day-today basis by those walk-around, informal type things than when you schedule with a teacher an observation and they know you are coming and you see their best. I have a good staff so the best is very good, but I also want to make sure that the quality is there on a day-to-day basis. Also, they have got questions and they are wondering about things and they will grab me when I am going around.

By the time I get back, there is usually phone calls to answer, curriculum to work on and as I say, I try to take care of the routine things and then just handle all the things that keep coming up. We are a small system so we develop all of our own curriculum, we do all our own in-service training here, we do our own text book selection. All of the things that sometimes in a larger system are done by a committee. We have to do it all here. I have to get much more involved in that type of instructional supervision than probably some principals do. But I like it.

The parts that I am most responsible for are being aware of new research, new trends, new ideas, to be able to introduce them to my staff and to know where to go and get speakers to bring in so they can keep up with it. It is easy in a small system, especially if you are doing well, to get complacent and not continue to be on that growing edge, to be pushing for growth and I have made a real conscious effort that we don't settle in and we need to keep trying to see what's going on. That is the kind of thing that takes time, looking it up, researching it, being presented to the staff, talking to the staff about it, deciding where we want to go. I feel strongly that we identify our values and our vision and go out and get materials and things to incorporate with them rather than oh, that's cute, let's try it type thing.

When asked if she ate in the cafeteria, Mrs. Allen responded:

I don't. I eat with the teachers. I know of principals that eat with the students as well, but I feel my job is more supporting the teachers and the teachers are supporting the children. I feel that I need to have more contact with them and a lot of things do get discussed over a 
lunch table and I try to be in there as they come in and just discussing things as they come up at the time and again they can ask questions if there is any need. It is easy to pick up on their trends or concerns they are having that aren't being addressed. You sometimes hear about them first in the lunch room and you can go ahead and set up meetings and look into them more formally.

The aftemoon goes pretty much the same, often it is when the parents come by or call or I have parent conferences, that type of thing. I also spend a lot of time (as a computer) troubleshooter and it is not unusual for me to get a note saying my printer won't work, help, and go down and work with that sort of thing. A lot of times in the afternoons I get pulled into working on that type of thing.

When I first started, I used to be here until five or six o'clock and I don't know whether partly it is because some of the things I have mechanized and enabled them to become more routine, partly I let go of some of the control I tended to have when I first started by letting other people do more of it. I will try to get out of here by about 3:30. If not, it usually is 4:00 or 4:30 that I am able to get out. As I said in the earlier years, it was not unusual to put in 12 hour days. Now, I have really tried to work the schedule, but occasionally it will happen.

When asked about yearly cycles, Mrs. Allen responded:

The first and the last month are always very, very time consuming. The first month just because we usually have a lot of new children in school, often new staff members that need more orientation and explanations and if we are having to readjust class schedules and bus schedules, so the first month is always very difficult. The last month just gets very busy with all the conflicts and you are going to have children being retained and you meet with parents and there is just a lot of things. Usually the first and last months are the most strenuous.

Summers are interesting. People always say well what do you there all summer long. My staff is very dedicated and it is unusual for there to be a day when I don't have at least one or two teachers that are in looking at things. And that is the time when they just want to come talk and brainstorm and reflect. It is also the time that we write curriculum. If I am hiring teachers, I do a lot of interviewing, because the staff is so cohesive that you need to make sure who is coming, who is going to fit in with that staff. I don't want to say they are cliquish because it is the whole faculty that is involved in it. Probably most of them are best friends with somebody else on the staff. Because of that, hiring takes a long time.

And then ordering, again, because we are a small school system, we don't have a purchasing department. I have got to shop. Also, setting up the computers. It is busy. It is a different type of pressure, but it still is quite busy.

\section{Mrs. Allen's Views on Management and Leadership. When asked to describe}

management, Mrs. Allen responded:

I think it is mainly organization, making sure that the people and the resources are where they need to be at the right time to get the job done. In a school setting, of course, it means having staff in place, trained and ready to go. Overall, I think it is a form of organization and under that comes a lot of human skills, motivating people, getting them involved by certain procedures. I think it is, what you need is there when you need it.

Leadership is drawing forth the best in everyone. I am talking about children and staff, effective leaders can get people to perform at their highest level. That would include training, motivation and getting them involved with the decision making.

I think as management as more the nitty gritty, the day-to-day type thing. Leadership often takes on, or should take on, more of a visionary aspect. Ordering work 
books and making sure the paper is here and the contract is signed, that type of thing is management. The leadership is more developing curriculum and doing training sessions with teachers and involving them in decision making; that to me is more of leadership.

I think that there are some principals that are leaders and some are managers and hopefully some combine both. I think that you could get lost in either one and you have to keep a balance of the two going.

Mrs. Allen's View on her Role as Leader and Manager. When asked to characterize her

work in terms of the two constructs, Mrs. Allen responded:

I am combining them, and I contradict myself because I spend more time in management, but I think leadership is the more important one. If you were to go around with a stop watch and have what I'm doing classified, I think the management takes up probably more time. The leadership takes more thinking and more creativity.

I concentrate on not letting the management take over. I am very much aware that you can get caught into a situation where you can't see the forest for the trees because you get so involved in things that have to be done, reports have to be turned in, books to be counted and it is easy to get bogged down in strictly management things.

I am very conscious of setting aside a time to look at the new research that has come out. evaluate the programs, talk with the people, having time to pull teachers together and do some brainstorming. The day-to-day time is more management oriented. The importance is the leadership and I try very much not to let management take over. Because when you walk out the door and sometimes, there is ten people sitting there, "But okay, I am focused on vision." It's hard to ignore.

When asked if she could delegate things, Mrs. Allen replied, "Yes, I think that is one of the beauties of being with a staff for a long time. I have tried to get the school to the point where I can step out." She also stated:

I think that many schools do well based on the single dynamic personality that goes okay for awhile, but then when that person leaves, it begins to fall apart. So I was very conscious that could happen here and I hope that when I leave the teachers here would not let somebody come in to make decisions that would undermine what we have worked so hard to establish. I don't think they would ever select anybody in the first place with a contrary philosophy, but the teachers could almost take over, and run this school without me, so that wouldn't be a problem.

The ability to use distributed leadership and shared decision making was also tied to a strong, unified culture:

The bottom line if there is a problem it still comes back to the principal. But, I think here we work very much as a total staff and people of the community see that. I think because it is a small community and we have a core of teachers who went to school and lived here, so that forms a very strong core. There is not a lot of turnover, and when we select staff, they are philosophically on the same wavelength that we are so we don't have to constantly battle out ideas.

Purposely I very often will seek out ones who are involved in the military because the school can be a very insular community. We are trying to bring in new ideas and people in university programs. We try consciously to try to bring in a lot of new, fresh ideas, but the basic values in approach to children, we respect children to gain their 
respect, that core has to be there. If you have the people with the skills and the maturity, you can turn things over to them. At this point, the school has that.

I am more of a facilitator. I still feel responsible for bringing things before them because so much of their job involves being in the classroom and it is hard for them to see trends - so a lot of it is making them aware of things, being observant, bringing ideas to them, research to them. I'm more information gatherer and distributor to them.

We don't fall into things. We make a lot of conscious decisions of this is where we are going to go and I think that is one of the jobs of leaders, is to force those decisions to be made and get people to look at, "Here's something we need to look at, here is some data on it, information on it, let's talk about it.," facilitating that process and coming to a decision.

When asked about the role of central office, Mrs. Allen responded,

For the most part, they have been able to support us in every way whenever we need it. Except finances, of course, that is the bottom line. This is a community that doesn't have a wide tax base and doesn't have any commercial or industrial zones.

However, because of the small size of the division, there is flexibility in spending finances:

In fact, they laughed when we first started hearing about site based management. "'Oh, that is what you call it." We've been doing it all along from necessity more than anything else and so I don't think we're like those other places who are just getting into determining their own staff, budgets and so forth. We've done that for years.

The budget is decided by group decision making in the school. However, there were times

when Mrs. Allen felt that group decision making was not appropriate:

So there are times when and they have indicated it to me just for practicality, it is like "Okay I am not going to bother to do a survey on this one. I think this is the best way to go with this." Especially on the more minor things, that I will take over just because it is easier.

I think there was a stage in my administration that I wouldn't turn a decision over to the teachers until I was sure that they were going to make the right one. I think that is one of the first steps when you start doing distributed decision making is choosing which ones you can feel comfortable with and it usually is the ones you know the decision they are going to make and you can live with it. I think we have gotten beyond that and I think there are times that they make a decision that isn't a decision that I would make. If it were really something that went against my principles and I thought it would harm children, then I would step in.

\section{Mrs. Allen's Beliefs on the Role her Personal Educational Views Should Play.}

I think in order to be successful someone has to live their philosophy and from that standpoint I think your personal philosophy should be what you live by. I think one selects teachers to try and find a match. I am not asking teachers to go against their principles.

I think you need to be careful about identifying as a principle something that really is more technique, more method. I think we need to be open so they can change. But if you are actually talking about principles, you have to look at peoples' principles. I hope that all my teachers are living their principles. I think also in education we really are role models. You don't want the children in the building picking up things that are contrary to what you think or believe in. 
Mrs. Allen cited a number of things that she believed were evidence of her views being implemented:

I think that the tone of the school and the way people talk to and treat children when I first came to the elementary school, it reflected the former principal and it was a loud burly kind of thing. A lot of sarcasm and humor that sometimes was hurtful to the students. That doesn't happen any more and I think that's because I am a quieter person. I talk to the children with respect to get respect, and I think the teachers have gone along with that.

The other is becoming more active in learning styles and not rigid and not text book based. I have tried to open them up to some new ideas, that there's two or three ways to each everything and at least two or three kids who need different ways. I think they have become much more creative in their teaching, much more flexible and much more aware of things. It has been one of my goals and now technology is included in that too.

We have become very child centered and that the enjoyment and love of learning is as important as doing it. It doesn't do any good to teach a child to read, if they don't read. They are no better than someone who can't read so we try and make it a pleasant atmosphere. I think there is success in that parents of children see that it is very, very positive. Just walking down the hall today a child said, "I am sure glad we are back in school I have really missed it. It is boring at home." That to me is a success, that the children want to be here.

When asked about any constraints and restraints, Mrs. Allen cited political pressure from a vocal minority that sometimes over-rides sound educational practice and finances.

\section{Dialectic Analysis}

The distillation of the principal's stories from the interview transcriptions was a first level reduction and display of the data. A second level reduction and display was accomplished by creating four matrices dealing with contextual factors and the three sub areas of the investigation. Analyses of the data were then organized into four sections: a) trends and commonalities that emerged from each of areas represented by the matrices were noted, analyzed and commented on;

b) themes and issues that emerged from the reduction and analyses of the data were discussed; c) cross-case comparisons were made; and d) items and issues discussed in the third interview member checks were noted and commented on.

\section{Second Level Data Reduction and Display}

Four matrices were created to further reduce the data from the principals' stories and aid in identifying emerging trends, issues and themes. 
Matrix One: Contextual Factors.

\begin{tabular}{|c|c|c|c|c|c|c|c|}
\hline & Type of School & Size & Div. & Assts & Race & Career & $\begin{array}{l}\text { Ten- } \\
\text { ure }\end{array}$ \\
\hline $\begin{array}{l}\text { Mr. } \\
\text { Lexus }\end{array}$ & $\begin{array}{l}\text { Specialized, K-5, } \\
\text { New (1st year) } \\
\text { Two Programs }\end{array}$ & $\begin{array}{l}\text { Large } \\
700+\end{array}$ & A & 2 & C & $\begin{array}{l}\text { Teacher: } 5 \text { years } \\
\text { AP: } 1 \text { year } \\
\text { Principal: } 15 \text { years }\end{array}$ & $\begin{array}{c}1 \\
\text { year }\end{array}$ \\
\hline $\begin{array}{l}\text { Mrs. } \\
\text { Parker }\end{array}$ & $\begin{array}{l}\text { Neighborhood, K-5, } \\
\text { Middle Class }\end{array}$ & $\begin{array}{l}\text { Large } \\
700+\end{array}$ & A & 1 & C & $\begin{array}{l}\text { Teacher: } 6 \text { years } \\
\text { AP: } 1 \text { year } \\
\text { Principal: } 5 \text { years }\end{array}$ & $\begin{array}{c}5 \\
\text { years }\end{array}$ \\
\hline $\begin{array}{l}\text { Mrs. } \\
\text { Kaplan }\end{array}$ & $\begin{array}{l}\text { Specialized, preK-5, } \\
\text { Two Programs, } \\
\text { Lots of Bussing } \\
\end{array}$ & $\begin{array}{c}\text { Mid } \\
450+\end{array}$ & A & 2 & C & $\begin{array}{l}\text { Teacher: } 14 \text { years } \\
\text { AP: } 1 \text { year } \\
\text { Principal: } 20 \text { years }\end{array}$ & $\begin{array}{c}5 \\
\text { years }\end{array}$ \\
\hline $\begin{array}{l}\text { Ms. } \\
\text { Elliot }\end{array}$ & $\begin{array}{l}\text { At-Risk, K-2, } \\
\text { Urban, Low SES }\end{array}$ & $\begin{array}{c}\text { Mid } \\
400+\end{array}$ & A & 1 & $\mathrm{AA}$ & $\begin{array}{l}\text { Teacher: } 22 \text { years } \\
\text { AP: } 1 \text { year } \\
\text { Principal: } 3 \text { years }\end{array}$ & $\begin{array}{c}3 \\
\text { years }\end{array}$ \\
\hline $\begin{array}{l}\text { Mr. } \\
\text { Baker }\end{array}$ & $\begin{array}{l}\text { Community, K-5 } \\
\text { Stable, Rural }\end{array}$ & $\begin{array}{l}\text { Large } \\
600+\end{array}$ & B & 0 & $\mathrm{C}$ & $\begin{array}{l}\text { Military: } \\
\text { Teacher: } 3 \text { years } \\
\text { AP: } 3 \text { year } \\
\text { Principal: } 19 \text { years }\end{array}$ & $\begin{array}{c}13 \\
\text { years }\end{array}$ \\
\hline $\begin{array}{l}\text { Mrs. } \\
\text { McGrath }\end{array}$ & $\begin{array}{l}\text { Neighborhood, K-5, } \\
\text { At Risk, Low SES, } \\
\text { Transient }\end{array}$ & $\begin{array}{c}\text { Mid } \\
500\end{array}$ & B & 0 & C & $\begin{array}{l}\text { Teacher: } 16 \text { years } \\
\text { Staff Dev. } 3 \text { years } \\
\text { AP: } 1 / 2 \text { year } \\
\text { Principal: } 2 \text { years }\end{array}$ & $\begin{array}{c}2 \\
\text { years }\end{array}$ \\
\hline $\begin{array}{l}\text { Mrs. } \\
\text { Tanner }\end{array}$ & $\begin{array}{l}\text { Specialized, K-5, } \\
\text { Special Program, but } \\
\text { like Neighborhood }\end{array}$ & $\begin{array}{c}\text { Mid } \\
500\end{array}$ & B & 0 & C & $\begin{array}{l}\text { Teacher: } 14 \text { years } \\
\text { Staff Dev.: } 4 \text { years } \\
\text { Principal: } 5 \text { years } \\
\end{array}$ & $\begin{array}{c}5 \\
\text { years }\end{array}$ \\
\hline $\begin{array}{l}\text { Mrs. } \\
\text { Allen }\end{array}$ & $\begin{array}{l}\text { Community, K-2, } \\
\text { Middle Class }\end{array}$ & $\begin{array}{c}\text { Mid } \\
500\end{array}$ & $\mathrm{C}$ & $1 / 2$ & $\mathrm{C}$ & $\begin{array}{l}\text { Researcher: } \\
\text { Specialist: } 3 \text { years } \\
\text { AP: } 3 \text { years } \\
\text { Principal: } 14 \text { years }\end{array}$ & $\begin{array}{c}14 \\
\text { years }\end{array}$ \\
\hline
\end{tabular}

School factors noted include: a) type of school which attempts to capture the character or essential elements of the school, b) size- number of students, c) school division, d) number of administrative assistants. Personal factors noted include: a) race (Caucasian or African American), b) career history, and c) tenure (number of years as principal at the present school). 
Matrix Two: Management and Leadership (Sub Area One).

\begin{tabular}{|c|c|c|c|c|}
\hline & Management & Leadership & Relation of Them & Own Work \\
\hline $\begin{array}{l}\text { Mr. } \\
\text { Lexus }\end{array}$ & $\begin{array}{l}\text { Physical plant, } \\
\text { people in time and } \\
\text { space, money } \\
\text { materials, organize }\end{array}$ & $\begin{array}{l}\text { Leader of Leaders, } \\
\text { develop leaders, } \\
\text { don't give } \\
\text { answers, proactive, } \\
\text { begin with end in } \\
\text { mind }\end{array}$ & $\begin{array}{l}\text { Have to have both, } \\
\text { overlapped, } \\
\text { management part of } \\
\text { leadership }\end{array}$ & $\begin{array}{l}\text { Evolved from } \\
\text { manager to leader } \\
\text { to leader of leaders, } \\
\text { provide focus, } \\
\text { interaction with } \\
\text { internal and } \\
\text { external }\end{array}$ \\
\hline $\begin{array}{l}\text { Mrs. } \\
\text { Parker }\end{array}$ & $\begin{array}{l}\text { Logistics, making } \\
\text { it work, status quo, } \\
\text { urgent things }\end{array}$ & $\begin{array}{l}\text { Vision, goals, } \\
\text { direction }\end{array}$ & $\begin{array}{l}\text { Need a balance of } \\
\text { both, actual is } \\
\text { overlapped, ideal is } \\
\text { management part of } \\
\text { leadership. }\end{array}$ & $\begin{array}{l}\text { Leader more than } \\
\text { manager, AP is } \\
\text { more manager, } \\
\text { collaborator and } \\
\text { communicator }\end{array}$ \\
\hline $\begin{array}{l}\text { Mrs. } \\
\text { Kaplan }\end{array}$ & $\begin{array}{l}\text { Rules, regulations, } \\
\text { schedules, } \\
\text { procedures, } \\
\text { mechanics, } \\
\text { directive }\end{array}$ & $\begin{array}{l}\text { Vision, } \\
\text { communication, } \\
\text { collaboration, team } \\
\text { building, new ideas }\end{array}$ & $\begin{array}{l}\text { Need a balance of } \\
\text { both, overlapping }\end{array}$ & $\begin{array}{l}\text { Evolved, was more } \\
\text { authoritarian, } \\
\text { difficult to } \\
\text { empower others, } \\
\text { lots of crises and } \\
\text { issues to manage }\end{array}$ \\
\hline $\begin{array}{l}\text { Ms. } \\
\text { Elliot }\end{array}$ & $\begin{array}{l}\text { Nitty-gritty details, } \\
\text { paperwork, } \\
\text { ordering }\end{array}$ & $\begin{array}{l}\text { Mission, tone, } \\
\text { goals }\end{array}$ & $\begin{array}{l}\text { Leadership more } \\
\text { important, more } \\
\text { time in managing, } \\
\text { overlapped, } \\
\text { leadership part of } \\
\text { management }\end{array}$ & $\begin{array}{l}\text { Trying to lead, but } \\
\text { often pulled into } \\
\text { management }\end{array}$ \\
\hline $\begin{array}{l}\text { Mr. } \\
\text { Baker }\end{array}$ & $\begin{array}{l}\text { Decision making } \\
\text { for people, } \\
\text { facilities, money, } \\
\text { scheduling- using } \\
\text { resources } \\
\text { effectively }\end{array}$ & $\begin{array}{l}\text { Being an example, } \\
\text { trying new things, } \\
\text { bringing focus or } \\
\text { unity }\end{array}$ & $\begin{array}{l}\text { Inter-connected, } \\
\text { overlapped }\end{array}$ & $\begin{array}{l}\text { Both leader and } \\
\text { manager, with } \\
\text { people around- } \\
\text { leader, when alone- } \\
\text { manager }\end{array}$ \\
\hline $\begin{array}{l}\text { Mrs. } \\
\text { McGrath }\end{array}$ & $\begin{array}{l}\text { Everyday school } \\
\text { functions, tasks, } \\
\text { building, } \\
\text { schedules, } \\
\text { planning, } \\
\text { organizing, } \\
\text { controlling }\end{array}$ & $\begin{array}{l}\text { Influencing people, } \\
\text { goals, vision, } \\
\text { mission, new ideas }\end{array}$ & $\begin{array}{l}\text { Intertwined, need } \\
\text { both, leadership } \\
\text { most important, } \\
\text { management more } \\
\text { visible and time } \\
\text { consuming }\end{array}$ & $\begin{array}{l}\text { Integrated, does } \\
\text { both, system } \\
\text { favors management } \\
\text { so leadership time } \\
\text { needs to be built in }\end{array}$ \\
\hline $\begin{array}{l}\text { Mrs. } \\
\text { Tanner }\end{array}$ & $\begin{array}{l}\text { Physical stuff, } \\
\text { tasks, organizing, } \\
\text { scheduling, } \\
\text { planning }\end{array}$ & $\begin{array}{l}\text { Influencing people, } \\
\text { direction, vision, } \\
\text { getting followers }\end{array}$ & $\begin{array}{l}\text { Need both, } \\
\text { leadership most } \\
\text { important }\end{array}$ & $\begin{array}{l}\text { Mix and balance of } \\
\text { both, collaborative } \\
\text { not authoritarian }\end{array}$ \\
\hline $\begin{array}{l}\text { Mrs. } \\
\text { Allen }\end{array}$ & $\begin{array}{l}\text { Day to day } \\
\text { organizing mesh of } \\
\text { people and } \\
\text { resources }\end{array}$ & $\begin{array}{l}\text { Drawing forth the } \\
\text { best and involving } \\
\text { people, vision, } \\
\text { new ideas, } \\
\text { developing culture }\end{array}$ & $\begin{array}{l}\text { Need a balance of } \\
\text { both }\end{array}$ & $\begin{array}{l}\text { More time in } \\
\text { management, but } \\
\text { leadership is more } \\
\text { important, need to } \\
\text { protect time for } \\
\text { leadership }\end{array}$ \\
\hline
\end{tabular}


Matrix Three: Role of Personal Views (Sub Area Two).

\begin{tabular}{|c|c|c|c|}
\hline & $\begin{array}{c}\text { Participant Conceptions of } \\
\text { Role of Views }\end{array}$ & $\begin{array}{c}\text { Effect or Examples of } \\
\text { Views }\end{array}$ & Constraints or Restraints \\
\hline $\begin{array}{l}\text { Mr. } \\
\text { Lexus }\end{array}$ & $\begin{array}{l}\text { Share own views, but } \\
\text { listen to others. } \\
\text { Disagreements are OK as } \\
\text { long as kids are } \\
\text { progressing and being } \\
\text { successful. A trailblazer, } \\
\text { but with others along side. }\end{array}$ & $\begin{array}{l}\text { High expectations, choice, } \\
\text { empowerment. }\end{array}$ & $\begin{array}{l}\text { None, constraints are more } \\
\text { in one's head. Need to } \\
\text { push and it helps to know } \\
\text { the system. A way can be } \\
\text { found if there's a will. } \\
\text { Need to work with people. }\end{array}$ \\
\hline $\begin{array}{l}\text { Mrs. } \\
\text { Parker }\end{array}$ & $\begin{array}{l}\text { Bounded by laws, but } \\
\text { beliefs guide vision and } \\
\text { culture. Expectation and } \\
\text { time to be the main source. } \\
\text { Marketing not selling-not } \\
\text { pushing own ideas too far. }\end{array}$ & $\begin{array}{l}\text { The screen is "Is it good } \\
\text { for kids?" }\end{array}$ & $\begin{array}{l}\text { Direction of state } \\
\text { politicians, standardized } \\
\text { tests, lack of respect for } \\
\text { educators as a profession, } \\
\text { lack of flexibility in } \\
\text { spending. }\end{array}$ \\
\hline $\begin{array}{l}\text { Mrs. } \\
\text { Kaplan }\end{array}$ & $\begin{array}{l}\text { Leader means having a } \\
\text { vision, but need to respect } \\
\text { others too. It takes } \\
\text { everybody. }\end{array}$ & $\begin{array}{l}\text { Teaching the whole child, } \\
\text { kids are important, kids } \\
\text { want to be here and love } \\
\text { learning. }\end{array}$ & $\begin{array}{l}\text { Lack of flexibility in } \\
\text { spending, too much due } \\
\text { process, not enough } \\
\text { flexibility in staffing. }\end{array}$ \\
\hline $\begin{array}{l}\text { Ms. } \\
\text { Elliot }\end{array}$ & $\begin{array}{l}\text { Own views very important } \\
\text { because they're right for } \\
\text { kids. Will discuss and } \\
\text { talk, but has faith in own } \\
\text { views. }\end{array}$ & $\begin{array}{l}\text { Developmentally } \\
\text { appropriate practices for } \\
\text { young children: no more } \\
\text { drill and kill, positive } \\
\text { discipline. }\end{array}$ & $\begin{array}{l}\text { Poverty of children, lack } \\
\text { of "extra" money from } \\
\text { fundraising, pictures, } \\
\text { PTA, partnerships or } \\
\text { grants. }\end{array}$ \\
\hline $\begin{array}{l}\text { Mr. } \\
\text { Baker }\end{array}$ & $\begin{array}{l}\text { Has and shares views, but } \\
\text { recognizes that there are } \\
\text { other views too. More } \\
\text { shared decision making } \\
\text { means more views. }\end{array}$ & $\begin{array}{l}\text { Parent involvement, high } \\
\text { expectations in academics } \\
\text { and for behavior, active } \\
\text { demonstration by oral } \\
\text { presentation, cultural } \\
\text { appreciation. }\end{array}$ & $\begin{array}{l}\text { Beginning to be less } \\
\text { expectation of uniformity, } \\
\text { but lack of flexibility in } \\
\text { spending, time consuming } \\
\text { meetings, paperwork, e- } \\
\text { mail tasks, self limiting. }\end{array}$ \\
\hline $\begin{array}{l}\text { Mrs. } \\
\text { McGrath }\end{array}$ & $\begin{array}{l}\text { Own views are important, } \\
\text { but balanced by others, all } \\
\text { can bring things to the } \\
\text { table. Communication is } \\
\text { important. }\end{array}$ & $\begin{array}{l}\text { High expectations, kids } \\
\text { from dis-advantaged } \\
\text { background can and do } \\
\text { succeed. }\end{array}$ & $\begin{array}{l}\text { New opportunity to begin } \\
\text { to take risks and try new } \\
\text { things, but there are } \\
\text { entrenched attitudes and } \\
\text { lack of money. }\end{array}$ \\
\hline $\begin{array}{l}\text { Mrs. } \\
\text { Tanner }\end{array}$ & $\begin{array}{l}\text { Modeling, views come } \\
\text { through without being } \\
\text { stated. Limits some } \\
\text { personal views (religious, } \\
\text { middle class values). }\end{array}$ & $\begin{array}{l}\text { Increased use of } \\
\text { technology and emphasis } \\
\text { on thinking. }\end{array}$ & $\begin{array}{l}\text { Resistance to change, } \\
\text { superintendent is } \\
\text { encouraging change and } \\
\text { ability to take risks. }\end{array}$ \\
\hline $\begin{array}{l}\text { Mrs. } \\
\text { Allen }\end{array}$ & $\begin{array}{l}\text { Live by philosophy and } \\
\text { principles (being role } \\
\text { models and building a } \\
\text { culture), but flexible on } \\
\text { methods or style. }\end{array}$ & $\begin{array}{l}\text { Child centered, respect for } \\
\text { kids, appropriate practices, } \\
\text { kids like school, deal with } \\
\text { the whole child. }\end{array}$ & $\begin{array}{l}\text { Political pressure from a } \\
\text { vocal minority, and lack of } \\
\text { funding (flexibility is } \\
\text { there). }\end{array}$ \\
\hline
\end{tabular}


Matrix Four: Descriptions of Role, School and Work (Sub Area Three)

\begin{tabular}{|c|c|c|c|}
\hline & Role & School & Work \\
\hline $\begin{array}{l}\text { Mr. } \\
\text { Lexus }\end{array}$ & \begin{tabular}{|l|} 
Leader of leaders \\
emphasizing choice and \\
distributed decision \\
making. Begin with end in \\
mind, supporter, \\
encourager, empowerer. \\
\end{tabular} & $\begin{array}{l}\text { Ist year, specialized with } \\
\text { two programs and lots of } \\
\text { resources, open, friendly, } \\
\text { professional. }\end{array}$ & $\begin{array}{l}\text { Contact with kids, teachers } \\
\text { and outside people. } \\
\text { Management by Walking } \\
\text { Around (MBWA). }\end{array}$ \\
\hline $\begin{array}{l}\text { Mrs. } \\
\text { Parker }\end{array}$ & $\begin{array}{l}\text { Innovative, collaborative, } \\
\text { distributed decision } \\
\text { making, change agent, } \\
\text { service mentality, people } \\
\text { person, support, } \\
\text { encourage, prod, asks } \\
\text { "why not?" } \\
\end{array}$ & $\begin{array}{l}\text { Comfortable, but with an } \\
\text { academic focus. Great } \\
\text { community involvement. }\end{array}$ & $\begin{array}{l}\text { Not a lot of putting out } \\
\text { fires. Monitor and adjust, } \\
\text { MBWA-tours of the } \\
\text { school, communicate with } \\
\text { students and teachers, time } \\
\text { to plan, communicate and } \\
\text { organize. }\end{array}$ \\
\hline $\begin{array}{l}\text { Mrs. } \\
\text { Kaplan }\end{array}$ & $\begin{array}{l}\text { Business like, but } \\
\text { compassionate, empowers } \\
\text { others when possible, } \\
\text { encourages, leader in } \\
\text { curriculum and instruction. }\end{array}$ & \begin{tabular}{|l|} 
Lots of special programs, \\
develop and encourage the \\
whole child, encourage all \\
to be involved, a place for \\
elementary kids.
\end{tabular} & $\begin{array}{l}\text { Handling crises, lots more } \\
\text { stress and increased } \\
\text { demands from society of } \\
\text { everyone in schools, } \\
\text { walking building, MBWA. }\end{array}$ \\
\hline $\begin{array}{l}\text { Ms. } \\
\text { Elliot }\end{array}$ & $\begin{array}{l}\text { Insisting on appropriate } \\
\text { practices for children and } \\
\text { helping with the many } \\
\text { needs of her students and } \\
\text { families. }\end{array}$ & $\begin{array}{l}\text { Urban, low SES, 99\% } \\
\text { African American, kids are } \\
\text { succeeding and happy in } \\
\text { school, "safe haven". }\end{array}$ & $\begin{array}{l}\text { Attempting to be hands-on } \\
\text { and model instruction, but } \\
\text { being pulled to handle } \\
\text { details, communication and } \\
\text { open door policy, MBWA }\end{array}$ \\
\hline $\begin{array}{l}\text { Mr. } \\
\text { Baker }\end{array}$ & $\begin{array}{l}\text { Decision maker, role } \\
\text { model, innovator, no } \\
\text { nonsense, high } \\
\text { expectations, risk taker. }\end{array}$ & \begin{tabular}{|l|} 
Community supported, \\
broad based instructional \\
program, high expectations \\
in academics and behavior.
\end{tabular} & $\begin{array}{l}\text { No normal or typical day, } \\
\text { being there for teachers } \\
\text { and kids, making } \\
\text { decisions, attending to } \\
\text { details, doing committee } \\
\text { work. }\end{array}$ \\
\hline $\begin{array}{l}\text { Mrs. } \\
\text { McGrath }\end{array}$ & $\begin{array}{l}\text { Facilitator, empowerer, } \\
\text { collaborator, teacher, leads } \\
\text { by example, listens, has } \\
\text { vision, takes risks. }\end{array}$ & $\begin{array}{l}\text { Kids are first, } \\
\text { neighborhood school, low } \\
\text { SES, transient, a safe } \\
\text { haven, friendly, open, } \\
\text { willing to listen to all. } \\
\end{array}$ & $\begin{array}{l}\text { Planned time to be in } \\
\text { classrooms, being there- } \\
\text { open door, home visits- } \\
\text { dealing with family issues. }\end{array}$ \\
\hline $\begin{array}{l}\text { Mrs. } \\
\text { Tanner }\end{array}$ & $\begin{array}{l}\text { Hands-on, kid centered, } \\
\text { expert on curriculum and } \\
\text { kids, accessible, caring. }\end{array}$ & $\begin{array}{l}\text { Specialized featuring } \\
\text { parent support, high } \\
\text { expectations, more like a } \\
\text { neighborhood school in } \\
\text { practice, open friendly, } \\
\text { inviting. } \\
\end{array}$ & $\begin{array}{l}\text { Contact with kids and } \\
\text { teachers, giving feedback } \\
\text { on instruction, purposely } \\
\text { unplanned and informal. }\end{array}$ \\
\hline $\begin{array}{l}\text { Mrs. } \\
\text { Allen }\end{array}$ & $\begin{array}{l}\text { Facilitator of teachers, } \\
\text { overseeing mesh of staff } \\
\text { and resources, supply } \\
\text { needs and support, } \\
\text { building a culture. }\end{array}$ & $\begin{array}{l}\text { Community school, child } \\
\text { centered having both high } \\
\text { achievement and children } \\
\text { who are happy and } \\
\text { positive about school, } \\
\text { learning and loving } \\
\text { learning. }\end{array}$ & $\begin{array}{l}\text { Handle details and mini } \\
\text { crises, being there for staff } \\
\text { and students, making sure } \\
\text { resources are available, } \\
\text { MBWA- for daily quality. } \\
\text { Research and curriculum } \\
\text { decisions. }\end{array}$ \\
\hline
\end{tabular}




\section{Analysis of Contextual Factors}

Data on eight contextual factors were collected. School factors included type of school, size of school, divisional affiliation and administrative organizational structure (number of assistant principal type professionals). Personal factors included, race, gender, career history and tenure (the number of years as principal at the present school).

Type and size of school. Each of the participants' schools were unique. There were three specialized schools that offered specific programs designed to make those schools distinctive and these schools had programmatic elements involving parental choice. There were two community schools that served all of the children in a large given area. There were three schools that were described as more "neighborhood." School communities ranged from very rural to very urban and from very low SES to middle to upper middle class, from a very stable population that had attended the same school for generations to a very transient population where each school year saw one third of the student body turn over. Two of the schools were designated as primary-serving grades $k-2$, five were elementary- $k-5$, and one served a population ranging from pre-school to grade five.

Each school served a unique population and those populations often had very different needs. Many of the principals talked about the importance of fit between their role as principal and the culture and expectations of their school communities. They also talked about the importance of the system being flexible enough to allow each school to best be able to serve the diverse and possibly unique needs of its specific community.

Divisional affiliation and administrative organization. Principals from schools in three different divisions participated in this study. The role of the superintendent in shaping the culture of the school system was emphasized by a number of participants. Administrative structure was split along division lines, schools from Division A had assistant principals or administrative assistants, in Division B the principals worked alone, and in Division C there was a half time assistant. 
Race and gender. The race and gender of participants was noted; but with the small number of participants, any analysis concerning these factors was very tentative at best. There were two males in the group of eight participants and one African American female.

Career and tenure factors. For two of the participants, education was a second career. Most participants began as teachers at the elementary level, moved through an assistant principalship or a central office staff development position and then became a principal. None of the principals had concrete plans for extending their careers beyond the principalship. Many expressed the desire to stay at that level, while others thought that a central office position or a higher education position might be nice, but for the present, the elementary principalship was it. Reasons given for preferring the principalship were, a) working with kids; b) wanting to avoid the political gamesmanship of central office; and c) the perception that the principal could have a direct and important impact on the practice of education, whereas other positions had only attenuated effects.

Three career factors were noted as possibly important: 1) Time spent teaching in the classroom-there were those who spent 3-6 years in the classroom and those that spent 14-22 years as a classroom teacher before going into administration. 2) Tenure as principal and the ability to form a culture- tenures ranged from 1 to 14 years. Many principals noted that it took from three to seven years to begin to build a school culture if a school had been inherited (if it was a new school or a restructured one where a lot of staff was recently hired, then this time would be lessened). Some of the principals expressed apprehension that they would be moved before they could finish some of the things that they were trying to accomplish. 3) The role of chance in careers- many principals described situations where they were promoted because they were in the right place at the right time as openings suddenly happened due to illness or other factors.

There did not seem to be a well developed career ladder for the elementary principalship. Six of the participants spent a year or less as an assistant principal before becoming a principal, and no principal spent more than three years in that position. Some of participants entered the principalship from staff positions rather than from line administrative positions. All of the 
participants had master's degrees, but many had degrees in fields other than administration (e.g., curriculum and instruction, early childhood education, counseling). None of the participants had plans to further their careers in administration. Thus, the elementary principalship was not generally viewed as a rung on an administrative career ladder, but rather it was viewed as a terminal job, important in and of itself. Many participants described not having an identifiable early desire to become a principal, but instead became a principal through a series of incidents (often encouraged by mentors) because it was seen as an effective way to affect positive changes for elementary students.

\section{Analysis of Sub Area One: Participant Conceptions of Management and Leadership}

This sub area of the investigation asked participants to directly discuss the constructs of leadership and management and the relationship of the two constructs. Also, participants were asked to describe their own functioning according to the constructs as they had described or defined them.

Management. Descriptions of management by the participants contained the following themes: a) it was a daily function, b) it was directive or authoritarian, c) it was more of a solitary function and could be done by the principal acting alone or it could be delegated to others who acted alone, d) it was not innovative and more concerned with the status quo, e) it was concerned with "nitty gritty" details, and $\mathrm{f}$ ) it was concerned with a mix of resources and people. Participants talked about managing things like the physical plant, time, space, money and schedules; also, rules, regulations, tasks and procedures were emphasized. It was described as the logistics, or making things work and run smoothly by organizing the mesh of people and resources.

Leadership. Descriptions of leadership emphasized: a) vision, goals, mission, tone and direction, b) it was seen as a collaborative or an influence relationship, c) essential elements included new ideas and the ability to take risks, d) it emphasized interaction with people. The participants emphasized the importance of communication as a leader provided focus or unity in an organization. 
Relationship of management and leadership. All the participants stated that both constructs were important, and that a proper balance of both was needed. Many described problems that could happen if an administrator acted too much as a manager or did not exercise enough management. The two constructs were seen as overlapping, there is a large area where both constructs must be exercised effectively in order for things to work well. Many participants stated that the management was more pressing and tended to take up a larger share of their time, but that the leadership was seen as being more important. This idea was expressed in another way when a few participants stated that the ideal would be for management to be contained in leadership, but that the reality was that they overlapped. Only one participant described leadership as being a part of management.

Principals as managers and leaders. When asked to describe their own work in terms of the leadership and management constructs as they had defined them, many participants described a balance. Even participants who did have assistants stated that it was not possible or desirable to split the management and leadership functions into two different job roles. This was because it was believed that there was too much overlap between the two constructs, often leadership was perceived as being refined or perfected in the details of management and the two could not be easily separated. The other reason given for approaching a balance was that many participants felt that they needed to give their assistants leadership responsibility in order to develop them for a future principalship position. Thus, even if delegation were possible, it was not often done by delineating leadership or management areas, but rather by holistic task or responsibility. Thus, it was more likely that each administrator would be responsible for both the management and leadership of a particular area, instead of one being responsible for the leadership and the other for the management of the same area.

Some of the principals spoke of evolving in their job role from a manager to more of a leader. For some, maturity in the career brought the ability to be less authoritarian and more collaborative. Also, it was emphasized that it took a while (from three to seven years) to build a school culture or climate that allowed more leadership type administration to develop. A few 
participants stated that it was difficult to empower others because many do not want to be empowered or that the system had been more management oriented and was just beginning to evolve into more of a distributed leadership or site based management model.

One observation was that the schedule and other systemic factors almost favored a management approach. Leadership takes time for communication, and there was little time that participants had with their staffs when the staff was not responsible for students. Thus, participants described their time when school was in session as being leadership time and of trying to be available during that time. Many described working long hours outside of school time doing the management tasks so that leadership could be done while students and staff were available. Many described that it was a constant struggle to stay focused on leadership as the management functions were often more pressing and urgent and demanding of time. It was also noted that management functions might take up more actual time, but that leadership functions were seen as more important.

Contradictions and issues. Analysis of participant conceptions of management and leadership produced an apparent contradiction: When asked to define the terms directly, the terms were described as two conceptually distinct things, almost as opposites; but when asked to describe the relationship of the terms and to describe their own functioning according to the self defined terms, then significant overlap was described. Three possible explanations for this apparent contradiction were postulated: a) it was an instrument effect, the specific interview questions prompted certain answers; b) the terms management and leadership are not conceptually distinct; and c) the terms are conceptually distinct, but not distinct functions in practice.

It was possible that the contradiction noted was an instrument effect. Appendix A contains the Second Interview Guide in which this sub area was addressed. The first questions was "describe management" and the second question was "describe leadership". By having two separate questions, participants might have inferred that they were supposed to provide two separate and distinct definitions, and they may have highlighted the differences between the two constructs more than if they had been asked one question of "describe management and 
leadership." The third question asked how the constructs were related by using a graphic organizer. None of the participants chose the "separate" choice. The most common choice was overlap, with the comment that the two were much more overlapped than the graphic depicted. Perhaps participants perceived that the first two questions had a response set (an implied "correct" answer), and answered the definitional questions by citing definitions that they had encountered, but not really internalized.

It is possible that the terms are not conceptually distinct. However, when asked to describe the terms, two distinct definitional clusters did emerge. Perhaps, the participants were repeating definitional concepts that they had learned, and were not really describing the constructs as they actually believed them to be; if the two were conceptually distinct, then the "separate" choice should have been chosen in question three of the second interview.

A third possible explanation of the contradiction was that the terms are conceptually distinct, but are not distinct functions in practice. Perhaps participants answered the definitional questions of the second interview by citing conceptual knowledge, but answered questions three and four out of contextual or perceptual knowledge. In other words, in theory the terms are distinct; but in the actual practice of being a principal, the terms are not distinct or separate, but instead are overlapped. The researcher believed that this last explanation was the best interpretation of the apparent contradiction.

Analysis of Sub Area Two: Participants Beliefs About the Role of Their Personal Views

This sub area of the investigation indirectly approached the participants view of the principalship in terms of leadership and management by probing the role that personal vision, values or goals should play. This area of the investigation also probed examples of implemented vision or values and constraints or restraints on implementation of personal views.

Role of personal views. All of the participants stated that their personal views were very important in their practice. Many talked of modeling or of being an example. Although the role of the principal's views was seen as important, the views of others were also important. Many of the principals felt that they needed to state their own views, but also needed to recognize that others 
might have different views and that these views must also be listened to, respected and included in the discussion.

Most of the participants believed that their views or philosophy could not be hidden. Even if their views were not articulated, they would be obvious in the culture and tone that the principal would set in a school. Some principals noted that they consciously limited their own views especially in areas of religious matters or in cultural values. However, the principal was also seen as the main shaper of culture in the school and that views that were markedly or radically different than the culture of the school would not be encouraged. Some participants differentiated between differences in style or methodology and differences in core values or beliefs. Divergent views were allowed and sometimes even encouraged in methodological or style areas, but not in more central values. The importance of a principal meshing with the philosophy or culture of the school community was emphasized by many participants. However, the principal was also seen as the primary force in shaping that school culture.

Many participants expressed that all stakeholders could bring views to the discussion, but the principal had more time and resources to do so. Also, there was an expectation that the principal would be a primary source of ideas. Sometimes this expectation had to be challenged as principals sought to distribute decision making and empower teachers. Most of the participants felt that they were expected to bring forth their personal education views, but that this expectation was not without limitations. They were expected to be a primary force in shaping vision, mission, values or culture, but they were also expected to respect that they were part of community that would form these things together.

Examples of implemented views. Almost all of the participants emphasized that their main educational view was doing what is best for kids. Elements of what is best for kids included: a) high expectations in academics and behavior, b) teaching the whole child, c) developmentally appropriate practices, and d) encouraging high achievement while making school a pleasant place to be. The focus of all of the participants was on the students. 
Constraints or restraints to implementing views. Many of the participants indicated that there were system restraints in trying to implement what they thought as being best for kids. One constraint cited was a lack of flexibility in spending money. Categorical spending by central office limited some of the curricular innovations that some schools were trying to accomplish. A few participants cited a lack of flexibility in personnel issues and the difficulty of building a culture with an inherited staff. Many cited resistance to change or entrenched attitudes as being a constraint, but it was also noted that some of the divisions had been more encouraging of positive risk taking behavior. Lack of time and resources was mentioned as a constraint. Political and community expectations were mentioned as being constraining as schools were being pushed and pulled by increasing demands. A couple participants noted that constraints and restraints were more self imposed than actual, and that if they really wanted to implement something, then a way could and would be found to do it.

Money was mentioned as a constraint by some, and the two participants from the at-risk schools described the problem or constraint of not having "extra-money" from private fundraising sources. These schools with low SES school populations were not able to raise much money from the percentages received from school picture sales or the sale of milk. Also, PTA fundraising and community partnerships were described as yielding much less than in other schools. This extra money was often used by other schools to provide computer resources, reading books and other classroom resources. One participant even implied that the division had come to rely on this "extra money" and may not have increased the appropriations for materials as much as it should have been. Thus, some schools were definitely more constrained by a lack of financial resources than other schools.

\section{Analysis of Sub Area Three: Descriptions of Work, Roles and Schools}

This sub area explored how the participants described their work, their roles and their schools. These descriptions were analyzed in relation to the constructs of leadership and management as described by the participants. 
Descriptions of work. The dominant theme in work descriptions was leadership oriented, emphasizing contact and communication with kids, teachers, parents and others. The idea of Management By Walking Around (MBWA, ) was described by many. Participants often had a lot of informal contact that was initiated either by "being there" for people (being free to converse with people during arrival, departure and other free times) and by "walking around" (gathering data about the functioning of the school by taking tours or walk abouts and by doing a lot of informal observing). Many participants described themselves as having an open door policy, so that even when they were in their office, they were available for contact.

Some participants focused their attention on the teachers, while others focused more on the students. Each participant had contact with both groups, but there were definite differences in emphasis. The direct contact principals thought of themselves as leaders by example, while the teacher supporters saw themselves as having a greater effect on students and instruction by being a facilitator of the teachers. Almost all of the principals stated that contact with the larger community, especially parents, was a very important part of their job.

Another dominant theme was more management oriented, dealing with details and making decisions. Some participants described their work as being constantly reacting to situations and crises while others described being able to set aside time to concentrate on longer term issues. Most participants stated that there was always variety, that there was no such thing as a typical or a normal day; but many did have a sort of routine.

Descriptions of role. All of the participants described their role with language similar to the way the leadership construct had been defined. The vision of "doing what is best for kids" emerged over and over as a goal. Many participants described their role as making sure that good decisions were made. The more detail oriented decisions were often made by principals, while larger decisions were made more collaboratively. In collaborative decision making times, the role of the principals was seen as being a gather and disseminator of information and a facilitator of the group decision making process. 
Most of the participants described that "what's best for kids" was often used to evaluate decisions. Collaborative decision making was often qualified by this caveat; the principal would allow distributed decision making as long as the result was according to this vision or mission. Some participants seemed truly committed to empowering others in decision making, while others seemed more authoritarian even when describing group processes. The participants' descriptions of their role tended to emphasize leadership attributes, but also contained elements of management. They were not purely leaders, but were more of a mix with leadership dominating. No participant described their role in dominantly managerial terms or language.

Descriptions of schools. The factual, contextual descriptions of the schools were more different than similar, but the affective descriptions of the schools were definitely convergent. Most participants stated that they would like their schools to be seen as a friendly, open and inviting places- places where children like to come. Achievement was seen as important, but positive affective climate was also very important. Many participants implied that there was a dual mission, to have kids learning and to have them enjoy learning.

Many principals felt that standardized testing did not really access all that the children were learning, but almost all of the principals stated that it was important for their students to do well on the tests. Many lamented the fact that affective climate was not measured as much as achievement because they felt that it was a worthy goal and one that was often overlooked, especially when schools were compared.

Emergent Themes and Issues

During the reduction and analysis of the data, themes and issues emerged as the researcher sifted through the responses of the participants and attempted to distill meaning from the various sub areas of the investigation. These emerging themes and issues were related to the primary purpose of the investigation (How do the participating elementary school principals describe or define their work in terms of leadership and management?) and were examined further during cross-case analysis and the third interview member checks. 
An oxymoronic role. The researcher coined the term "Middle Leader" to describe the principal's role as described by the participants. Participants definitely characterized themselves as leaders within their own school communities, but also identified systemic and divisional influences that constrained them to act more like middle managers. Participants felt that their primary goal was to meet student needs and it was very apparent that needs of students (academic, social, basic survival) varied widely across different contexts. Elementary schools were definitely individualized and in many cases unique, thus the leaders of those schools often had very different visions or missions of how to best meet the needs of their students. Many participants noted that the "fit" between a principal and the school community or culture was very important. However, many participants also described divisional control processes (e.g., testing and spending) that were not flexible enough to allow the specialization desired to meet the specific contextual needs of their students. Many principals also described the importance of the superintendent in setting the tone and mission of the school division. Knowing the superintendent and being known by him was seen as an important part of being a principal. Meshing with the divisional culture and the superintendent while at the same time meeting the distinct and specialized needs of their particular school community was of primary important to the participants in this study.

The oxymoronic nature of the role was also evident in descriptions of the participants work. The participants described being proactively reactive by scheduling unscheduled time and by planning to have unplanned time. This was needed because the participants saw a lot of their job as being contact with people and most of this contact was informal and unplanned. Participants described expectations for them to be the primary shaper of collaborative, communal cultures. The participants felt that they needed to "be there" for their school community and recognized that a lot of their job was responding to the things of the day as they arose so that their was no such thing as a typical or normal day.

Being a principal. The participants described their role more as a "state of being" rather than a "state of doing or acting." Many participants talked of modeling or of being a role model for the school. The principal existed as the focal point of the school and embodied mission, values 
and ideals while making decisions or facilitating group decisions to be made. Participants described the concept of "being there" for the school community and this involved being available to lead and to manage as needed. Supervision was mostly done informally with "walk-abouts" and feeling the pulse of the school by observation and conversation during informal contacts.

The mixing of management and leadership in the principals' roles was implied in that many principals saw themselves as a focal point in the school for both ideas and for resources. Almost all stated that "what's best for kids" was the glue that held their complex and diverse organizations together and it was the principal's role to embody this view and to constantly remind the school community of the ultimate goal of everything. The concept of what's best for kids often included appropriate practices, high expectations for behavior and academics, and making school a pleasant place to be where students could both learn and enjoy learning. Many principals also described being the focal point for distribution of materials and other resources. Often this role was described as a gathering and obtaining, then disseminating and distributing materials and information.

Evolving from managers to leaders. All of the participants indicated that their present role was a mix of leadership and management, and many also stated that this was a result of an evolutionary process both personal and systemic from a more management to a more leadership orientation. Many participants indicated that they felt leadership to be more important, but they also felt that management was more pressing and often took up more time.

Personal evolutions from manager to leader were possibly related to a number of factors. One of the factors was learning how to do the management part of the job better. An issue mentioned by a number of participants was the stress and burn out associated with being a principal. Taking vacation time and time off for exercise and personal pursuits was something that increased with maturity. Young or new principals often worked unusually long hours in order to accomplish the job. However, participants talked of working smarter and not harder as time went on. Part of this evolution was learning how and being able to delegate more to others by letting go 
of some of the control of the details. This loosening of control indicates an evolution from management to leadership as the constructs were defined by participants.

Being able to delegate was linked to time, maturity and the ability to build a school culture. Many participants talked about the need to build a culture that would allow effective delegation. Without a strong culture, delegation would detract too much from the focus. Building a culture was related to selecting staff. Principals of new or restructured schools were able to build a cohesive culture much quicker than those who had inherited staffs. Principals were described as much more mobile than staffs and this was sometimes seen as problematic. It was difficult to lead by building a culture when the tenure of the leader was less then the tenure of the staff.

Two issues involved with being a principal that might be part of the evolutionary development towards leadership were a) amount of direct contact with students verses indirect contact with students through teachers and b) type of and content of decisions made collaboratively. All of the participants described contact with both students and teachers and also described participating in some distributed or shared leadership, but there were differences between participants in these areas. Cross case analysis was done to explore if these differences were more stylistic or if they were related more to contextual factors.

Some participants described a systemic evolution from management oriented to more leadership friendly organizational patterns. Distributed or collaborative decision making as part of $\mathrm{TQM}$ or site based management was alluded to, but the system was also seen to be changing very slowly and the changes toward leadership were sometimes seen as mere language changes only, more word than deed. Resistance to change and the inertia of a large system were seen as constraints in the evolution toward a more leadership oriented principalship. Participants described being given more flexibility and encouragement to be risk takers in some areas, but they also described control processes that tended to maintain the status quo. The inflated importance of standardized testing and a lack of flexibility in spending were possible holdovers from a system that was in the process of changing from being very top-down to being more distributed or site based. 
One of the problems that principals faced in this evolving system was a lack of quality contact time. Principals were expected to be leaders and collaborative decision makers, but the time to do this was not always available. Management could be done alone and decisions imposed, but leadership took lots of communication. The present system was seen as almost requiring management because there was precious little time that principals and staff could spend together when there were not students around or when there were not details or pressing needs to attend to, and these pressing needs often involved mandates from above.

Principals could mange things, time, money and people without contact, but they could only lead by sharing ideas through communication and contact. Thus, the principals were often involved in "being there" because they were fitting themselves around the more tightly scheduled students and teachers. The school community needed to be able to catch the principals and the principal needed to be available to be caught. This meant that many principals spent their work day in informal, unplanned contacts, and saved the management of details for times when the building emptied out and quieted down. Summer time was seen as problematic because there was time available to do long term planning and thinking in terms of vision or mission, but the staff was not available to be led. Many principals described that leadership was possible in the summer only because their staffs were dedicated and often came into the school on their own time.

\section{Cross-Case Comparisons}

Cross case comparisons were made by focusing more on the differences between participant contexts and responses. Previous analysis had focused on identifying commonalties in the form of trends and themes. The cross case analysis focused more on differences and attempted to explore possible connections between identified differences and contextual factors.

The most striking feature of both the participating principals and their schools was the uniqueness and individuality; there were more rich contextual differences than this study was able to access. Related to this, the themes of specialization and fit emerged. Each school was specialized according to the unique needs of its school community, and this specialization demanded more attention to the fit between the principal and the community. There was a definite 
feeling that "one size does not fit all", and it was not believed that any principal could be a successful leader of any school. Three contextual factors that might help explain cross case differences were identified: a) divisional differences, b) school community differences, and c) career and tenure factors.

Divisional differences. The contextual factor that caused the most differences between participant responses was the divisional affiliation. This investigation focused exclusively on the principal, but the participants definitely indicated that their job and work was greatly impacted by divisional influences. Beyond different organizational patterns, like the number of assistants, the tone and mission set by the superintendent was very obvious. In the third interview member check, some participants indicated that they were very apprehensive because there were rumors that the present superintendent was leaving. These participants were concerned about having the programs they were working on being supported by a possible new person. Also, they felt apprehensive about getting to know and getting known by a possible new superintendent.

School community differences. The types of communities served by participant's schools varied widely from urban at risk, to suburban middle class, to rural whole community. Because of the small sample size it was difficult to make any generalizations according to these differences as it was difficult to determine if differences were be attributed to the individual context of a particular school or to the type of school it was classified as. There were definite differences between schools according to the wealth of the community and according to parental support. These differences impacted how a school was operated. The principals of the two at risk schools in this study felt that it was part of their mission to improve conditions in the community and to support the families of students, many of whom were struggling with survival. Other participants described the relationship with the community as one where the school was well supported by the community in the form of donations of time, money and other resources. However, differences in approaches by participants to management and leadership could not be specifically tied to school type. 
Career and tenure factors. There seemed to be two distinct types of careers for principals. Some participants described spending six years or less as a teacher before beginning an administrative career, other participants were teachers for 14 to 22 years before getting into administration. The principals who spent longer time in the classroom tended to be more focused on the details of curriculum and instruction, whereas the more "career" administrators focused more on developing teachers. Also, principals who had longer tenures or were in schools that they had established seemed to be more collaborative and less directive, possibly because they had been able to build stronger school cultures.

Items and Issues from the Third Interview Member Check

The third interview member check was conceptualized as being part of both data gathering and data analysis. The member check interview had three purposes a) to review each principal's story with the participant to allow further clarification or comment, b) to debrief the participants and ask questions about their experience of participating in the research process; and c) to discuss emerging themes as part of the ongoing data analysis. The Third Interview Guide in Appendix A contains the questions asked in this part of the investigation. The third interview was not taped, instead participant responses were noted by the researcher.

Review of the principal's stories. Each participant accepted their story as an adequate representation of their views. Many were concerned that the syntax and grammar in the quotes of their oral communication did not look right in print; but after being assured that the text was supposed to represent oral, not written communication; they accepted them without reservation. Some participants requested some minor stylistic changes and these were made. None of the participants had anything significant to add to their stories.

Debriefing of the research process. Most participants responded that they often reflected, but that this research project had caused them to reflect on a deeper level and had been useful to them in that respect. Most participants stated that they had enjoyed the interviews and all participants were very interested in seeing the rest of the results beyond their own stories. 
Participants were asked if there was a particular theorist, book or idea that had particularly influenced them. Most replied that they read widely, and that they were eclectic in choosing educational ideas. They picked and chose bits and pieces from various places and adapted those to fit their own school contexts. Many participants mentioned that things from The Association for Supervision and Curriculum Development (ASCD) were particularly useful. Two of the participants from Division A specifically mentioned the work of Schlecty, a consultant with whom the division had been doing a lot of staff development. Only one participant, Mrs. Elliot, identified a specific movement, the National Association for the Education of Young Children as a primary source of ideas and resources for her work.

Discussion of emerging themes. As part of the analysis process, participants were asked to comment on some items presented as emerging themes of the analysis in progress. Four areas were discussed: a) changes that the participants had experienced in the principalship during their tenure and possible future directions of the job role, b) identification of the primary stakeholders of the school, c) discussion of the preferred method of impacting students-through direct contact or indirectly through the teachers, and d) identification of the factors considered when deciding what type of decision making to use-collaborative or authoritarian. All of the participants named the students as the primary stakeholders, but emphasized that parents and teachers were very important in reaching students. Responses from the other areas are presented in Matrix Five 
Matrix Five: Third Interview Responses Regarding Emerging Themes.

\begin{tabular}{|c|c|c|c|}
\hline & Changes & Student Contact & Decision Making Factors \\
\hline $\begin{array}{l}\text { Mr. } \\
\text { Lexus }\end{array}$ & $\begin{array}{l}\text { More collaboration } \\
\text { throughout system, more } \\
\text { diversity, less uniformity, } \\
\text { increased technology }\end{array}$ & $\begin{array}{l}\text { No illusion of direct } \\
\text { contact }\end{array}$ & $\begin{array}{l}\text { Safety is authoritarian, } \\
\text { instruction is collaborative, } \\
\text { Is it good for kids is the } \\
\text { measure }\end{array}$ \\
\hline $\begin{array}{l}\text { Mrs. } \\
\text { Parker }\end{array}$ & $\begin{array}{l}\text { Less of a middle man, } \\
\text { more site based with less } \\
\text { control processes from } \\
\text { above, becoming more } \\
\text { specialized }\end{array}$ & $\begin{array}{l}\text { Implement programs } \\
\text { through teachers, but } \\
\text { monitor through students }\end{array}$ & Time \\
\hline $\begin{array}{l}\text { Mrs. } \\
\text { Kaplan }\end{array}$ & $\begin{array}{l}\text { Increased regulations, } \\
\text { paper work, demands, } \\
\text { more stress and burnout, } \\
\text { more social problems in } \\
\text { schools }\end{array}$ & $\begin{array}{l}\text { Indirect because of day, no } \\
\text { time to be with kids }\end{array}$ & $\begin{array}{l}\text { Issue: authoritarian for } \\
\text { safety, collaborative for } \\
\text { instruction if culture is } \\
\text { developed enough }\end{array}$ \\
\hline $\begin{array}{l}\text { Ms. } \\
\text { Elliot }\end{array}$ & $\begin{array}{l}\text { Increased pressure and } \\
\text { stress, lack of job security } \\
\text { especially with new } \\
\text { superintendent coming, } \\
\text { lots of changes }\end{array}$ & $\begin{array}{l}\text { Very involved directly with } \\
\text { students. does a lot of } \\
\text { things for them }\end{array}$ & $\begin{array}{l}\text { Issue, authoritative when it } \\
\text { involves what's right for } \\
\text { kids }\end{array}$ \\
\hline $\begin{array}{l}\text { Mr. } \\
\text { Baker }\end{array}$ & $\begin{array}{l}\text { From autocratic to } \\
\text { democratic, but reverts in } \\
\text { crises. Increase in tasks, } \\
\text { more community input }\end{array}$ & $\begin{array}{l}\text { Impossible to have much } \\
\text { contact with kids because } \\
\text { of lack of time }\end{array}$ & Issue, time and history \\
\hline $\begin{array}{l}\text { Mrs. } \\
\text { McGrath }\end{array}$ & $\begin{array}{l}\text { Moving toward site based, } \\
\text { more responsibility placed } \\
\text { in schools, increased } \\
\text { technology, more use of } \\
\text { schools, less staff support } \\
\text { from central office }\end{array}$ & $\begin{array}{l}\text { Impact students indirectly } \\
\text { through teachers, but a } \\
\text { little each day impact } \\
\text { individual students directly }\end{array}$ & $\begin{array}{l}\text { Time, involve people who } \\
\text { will be impacted, level of } \\
\text { support or ownership } \\
\text { needed }\end{array}$ \\
\hline $\begin{array}{l}\text { Mrs. } \\
\text { Tanner }\end{array}$ & $\begin{array}{l}\text { More shared decision } \\
\text { making and acceptance of } \\
\text { risk taking, change is } \\
\text { constant }\end{array}$ & $\begin{array}{l}\text { Work through teachers, } \\
\text { but look at the product of } \\
\text { teaching, not the teachers } \\
\text { themselves, monitor } \\
\text { through contact with kids }\end{array}$ & $\begin{array}{l}\text { Issue- serious is } \\
\text { collaborative, trivial is } \\
\text { authoritarian, free staff up } \\
\text { for big decisions by } \\
\text { making little ones. }\end{array}$ \\
\hline $\begin{array}{l}\text { Mrs. } \\
\text { Allen }\end{array}$ & $\begin{array}{l}\text { State and politicians have } \\
\text { taken a more active role, } \\
\text { school system more } \\
\text { distributed, but larger } \\
\text { system has more } \\
\text { mandates, } \\
\text { more expected of schools }\end{array}$ & $\begin{array}{l}\text { Focus on working with the } \\
\text { teachers, but the students } \\
\text { are the ultimate goal. }\end{array}$ & $\begin{array}{l}\text { Time, importance of issue- } \\
\text { minor authoritarian, } \\
\text { expertise and the need to } \\
\text { build consensus }\end{array}$ \\
\hline
\end{tabular}

Summary regarding the emerging themes. The changes in the principalship identified by the participants are that the job has had increased demands. Society has asked schools to do more, 
and the political community has increased its demands and mandates. Also, the principals are expected to oversee these increased responsibilities in a more collaborative and less directive way. These two factors have combined to increase the stress and burn out associated with the job. There are more tasks, and many of these tasks are supposed to be performed in the more time consuming, collaborative way, but there hasn't been much change in system scheduling to provide for more contact time between the principal and the staff.

Contact with students has decreased, but focus on them has increased. Many participants indicated that they impact students through teachers, but monitor the work of teachers through students. Thus, the focus is on the products of good instruction and not necessarily on observing the instruction itself. System wide, there is less of a feeling that there is one best way to do things and more of an attitude of if it is working, as indicated by student progress, then it is good.

In deciding how to make decisions principals looked at a variety of factors like time, impact, the need for buy-in and the importance of the issue. Many participants stated that unimportant, detail oriented issues were done more authoritatively, whereas more important, curriculum related issues were handled more collaboratively. However, all decisions were evaluated by "What is best for kids?", and curriculum decisions would be made authoritatively if certain core values were sensed to be violated.

The stronger the culture that the principal had been able to collectively build, then the less likely that any distributed decision would go against the core values, so time to establish this culture was seen as very important to principals. Early in the analysis, it was postulated that principals with longer tenures seemed more willing to delegate decisions even when those decisions would not be made exactly as the principal would have made them. However, by the end of the analysis process, this had been rejected. Participant commitment to true collaboration and empowerment could not be tied to specific career factors. It was difficult to separate the systemic and personal evolution for more experienced principals; had some of the more experienced principals evolved into more a more collaborative leadership style because of maturity, or because they were accommodating to systemic change in that direction? 
The most important factor in operating collaboratively was the establishment of a strong school culture. However, this brought up the question of the change toward collaborative decision making being real. Perhaps distributed decision making was true more in word than in deed as principals were still being quite directive, but using the indirect method of culture building. Most participants described the importance of the fit between the principal and the school culture, but they also implied that the principal was a primary force in forming and sustaining that same culture. The yardstick of "What is best for kids?" was often used, but whose conception of what is best was not addressed. Some participants seemed truly committed to empowerment, collaboration and shared decision making, some participants seemed committed to a particular vision and would allow these things only if the resulting decisions fit that particular mission, and with some participants it was difficult to tell if they truly bought into the concepts or if they were just accommodating themselves to systemic changes that were emphasizing these things. Systemic change toward shared decision making was definitely identified, but the researcher was not able to relate individual reaction to this change to any specific contextual factors. 
Chapter 5: Discussion

The primary purpose of this study was to explore how selected elementary school principals described their work in terms of leadership and management. There were three subareas of investigation under this primary purpose: a) exploring the principal's conceptions about the constructs of leadership and management, b) exploring the principals' beliefs about the role of their personal philosophies, goals, or values in relation to their practice; and c) using content analysis to explore the language that principals use to describe themselves, their work and their schools. The theoretical perspective adopted for this study was that organizations are constructed human social entities, and the focus of this study was to describe the role of the elementary school principal from the perspective and voice of the participants. Results were presented as narrative description, the principals' stories (hermeneutic representation) and analysis (dialectic) where the stories distilled from the transcriptions of the interviews were content analyzed for common themes or patterns.

This chapter (discussion) focused on reviewing the results of the study (from chapter four) and comparing them with the literature on leadership, management and the elementary school principalship (from chapter two). It concludes with discussion of a) changes in the researcher's conceptions as a result of the investigation, b) personal implications for training and educating future principals, and c) new questions and directions for future research arising from this investigation.

All discussion and interpretation of the results of this study should be considered in light of the following limitations:

1. Only elementary school principals participated so generalization to middle or high school principals is limited.

2. The small, purposive sample drawn from three school divisions in the Tidewater Virginia area may not be representative of other contexts and this limits generalizeability. 
3. The views of participating principals were solicited during three interviews held in the Spring of 1996, and no observational data or views of other stakeholders were included in this study; the relatively short contact time and the focus exclusively on principal's views as expressed to an interviewer are limiting to generalizeability.

\section{Review of Results}

The results of this investigation were presented in two sections in chapter four. One of the purposes of this investigation was to present the perspective of the participating principals in their own voice. Thus, the bulk of chapter four is comprised of the principals' stories. These stories were edited by the researcher, but contain extensive, unaltered quotes from the interviews with the participants. This thick description contains much rich, contextual information, and it was difficult to summarize this data without stripping it of meaning. The reader is encouraged to explore these stories as a re-presentation of the participating principals' views.

Review of Sub Area Analysis

The researcher's analysis of the principals stories was presented in the second section of results in chapter four. This analysis was designed to help answer the grand question: How do the participating elementary school principals describe and/or define their work in terms of leadership and management? This analysis was organized using the stated sub areas of the investigation and was briefly summarized below for this discussion section.

What conceptions do the principals have regarding the constructs of leadership and management?. There was remarkable convergence of participant definitional conceptions regarding management and leadership. Management was described as directive, involved with technical and detail oriented aspects, concerned with the status quo and involving a mix of people and resources. Leadership was described as collaborative; involved with vision, goals, mission, tone and direction; involving risk taking and change; and emphasized interaction with people.

However, there was an apparent contradiction between these distinct defintional clusters for management and leadership and participant descriptions of the two being overlapping when asked for descriptions of the relationship of the two constructs or asked for descriptions of their own 
functioning in terms of the self defined concepts. It was postulated that this contradiction could be explained by a) an instrument effect; b) the two terms not being conceptually distinct; or c) the two terms being conceptually distinct, but not being distinct functions in practice. The researcher maintained that this last explanation was the best interpretation of the apparent contradiction.

All the participants stated that both leadership and management were very important and described aspects of their work that fit both constructs. Many participants stated that the ideal would be to have management in leadership, with leadership driving management decisions; but that in reality, the two overlapped. Many stated that leadership was more important, but that management often took up more time; or that it was a constant struggle to be on top of the management in order to be able to focus on leadership.

Participants described their own work to be a balance of management and leadership. Delegation was often done by tasks rather than according to management or leadership responsibilities. Some of the participants described an evolution, both systemic and personal, from more manager oriented to more leadership oriented functioning. Also, the divisional, or central school system structure was described as being more management oriented than the building level structure; many participants felt that there were increased top down mandates, and also an increased pressure to function more collaboratively at the building level.

What do the principals believe about the role of their personal views in relation to their practice? All participants stated that their personal views were important because principals function as role models; but that the views of others balanced their own. Many principals expressed the feeling that they felt that others expected them to be the primary shaper and exemplar of the school's culture, but they were also supposed to respect the communal aspect of developing the culture. Almost all of the participants emphasized "Doing what is best for kids" which often included high expectations, appropriate practices and encouraging learning and the love of learning simultaneously. When asked about constraints or restraints in implementing views, many participants cited lack of system flexibility, lack of resources, lack of time and other factors, but no real consensus emerged about this area. 
What language do the principals use to describe their work. roles and schools?.

Participants described much of their work as "being there" or Management By Walking Around, which involved interacting with a variety of people informally. Work descriptions also involved a lot of dealing with details and reacting to the issues of the day. Many stated that there might be a routine, but there was no such thing as a typical day.

Participants described their roles both in management and leadership terms. The principal was often seen as being responsible for overseeing the scheduling of materials, resources and personnel; and the role was conceptualized as being a gatherer and disseminator of ideas and a facilitator of the group decision making process. Participants described themselves as being a mix of manager and leader, and there was mixed receptivity to collaborative decision making.

Collaborative decision making or empowerment were mentioned by many, but some participants were much more committed to the concept while others seemed to be talking about using school culture to exercise indirect control.

Descriptions of schools were remarkably divergent as many schools were designated as specialized to fit unique community needs. With this specialization, the importance of fit between the principals and the school was emphasized. However there was much convergence on affective issues, many stated that school should be a friendly, warm and open place where kids both learn and love learning.

\section{Principals as Leaders and Mangers: Themes and Issues.}

The grand question of this investigation was: How do the participating elementary school principals describe and/or define their work in terms of leadership and management? A number of themes and issues related to this central purpose emerged during the analysis of the data in this investigation and were discussed in chapter four. The more salient of these are reviewed below.

Enacting an oxymoronic role. The participants definitely perceived themselves to be leaders within their schools, but also were under the influence of central office. They felt their primary goal was to meet the often unique needs of their school communities, and this called for specialization and individualization of schools. However, participants also talked about increased 
control processes, especially expectations involving standardized testing. The principal was sort of a "middle leader," one who had to mesh with the divisional culture, especially the superintendent, while at the same time identifying with and meeting the distinct and specialized needs of their specific school community. Participants felt that they had been called to enact more top down mandates, and that they were expected to do this more collaboratively. Participants also indicated an oxymoronic role when they described being proactively reactive by scheduling unscheduled time and planning for unplanned contacts and issues. They also described expectations to be the primary shaper of a communal culture.

"Being there". Participants often indicated that much of their function was "being there" for various stakeholders. The principals existed as the focal point of the school and had to fit around the other more tightly scheduled people in the building. Supervision was described as being done more informally and taking walk arounds or short tours of the building was common. Many participants described trying to impact students through teachers, but monitoring teaching through observing and interacting with students rather than by directly observing instruction.

Evolving from managers to leaders. Many participants commented that both they and the system had evolved from more management orientation to more leadership orientation over time. It was difficult to separate the systemic and personal evolution, but that the system was seen as evolving slower. Many mentioned increased support and flexibility, but still there was a problem of quality contact time with staff. Many participants felt that they were trying to lead in a system that was historically set up for management.

Balancing culture and distributed decision making. Being able to delegate more was linked to the ability to build a school culture. Principals of new or restructured schools were able to build school cultures quicker because of choice in staffing. Some participants seemed truly committed to distributed decision making, while others seemed to be exercising indirect control through the development of a strong school culture. All participants evaluated decisions using "What's best for kids?" as a standard, but it was unclear whose conception of "what's best" was used. It was clear 
that if certain core values were threatened, then decisions would be made more authoritatively rather than collaboratively.

\section{Relation of Results to the Literature}

In this investigation, the field data were collected and analyzed prior to accessing the literature in depth because the experiences of the participating principals were the primary focus. A review and synthesis of published literature regarding the elementary school principalship, leadership and management was conducted after field work was completed and was presented in chapter two. In this section, the results of this study, excerpted from chapter four, were compared to the published literature, as reviewed in chapter two.

\section{Enacting an Oxymoronic Role}

Many writers have noted that the principal's role is a mix of management and leadership and have commented on the difficulties inherent in balancing the two orientations (Richardson, Short \& Prickett, 1993; Bookbinder, 1992; Robbins \& Alvy, 1995; Hickman, 1990). Stronge (1990, 1993) maintained that the two roles are overlapping and "to view instructional leadership as segregated from management is a misconception of the role, and does injustice to the principalship" (1990, p. 3). Similarly, Howe (1994) stated that there is no agreement on "whether or not leadership, administration, and management are conceptually distinct terms. For the most part, scholars in educational administration use leadership, administration and management indiscriminately and accept these terms unquestioningly as institutionalized synonyms" (p. 7).

Deal and Peterson (1994) maintained that leadership and management are two distinct constructs, but that principals must function in both simultaneously. They posited that the solution is "to accept the seemingly contradictory approaches as a paradox to be embraced" (p. 9). They appealed to eastern philosophy as this type of approach was seen as counter to western dualist thinking. Deal and Peterson's conception of the role as paradoxical was similar to the oxymoronic role described in this investigation.

It is very easy to describe the role as a mix of management and leadership without understanding the complexities involved with trying to enact that mix. Some of the participants in 
this study managed the details of schooling so that they could practice collaborative leadership with the larger issues. Other participants insisted that even the details needed to be acted on collaboratively so that trust for true shared decision making could be established. Most principals described leading and managing in all areas; they did not manage the building and lead instruction, but instead managed and led both. Building decisions affected instructional ones and vice versa, so it was impossible to separate these issues out. Thus, describing the role as a mix of management and leadership does not really capture the paradoxical and oxymoronic nature of the role.

The conflict between managing and leading by principals in schools has been heightened by the reform movements of the 1980s. Farrar (1990) characterized the first wave of reform as being the top down imposition of higher standards, more mandates and increased inspection and testing. Petrie (1990) characterized the second wave of reform as empowering teachers as professionals. Hallinger and Hausman (1994) commented that these two reform efforts have brought the principalship more responsibility with less authority. Reform has meant more management functions are being done at the school level, and there is less time for the principals to devote to instruction. At the same time, principals are being urged to develop bottom-up, empowering, collaborative leadership structures in a system that remains top-down. Participants in this study indicated that they often found themselves squeezed between these contradictory demands.

\section{"Being There"}

In this investigation, participants often described their role as "being there" for various stakeholders. Smith and Andrews (1989) described the instructional leader role as it emerged from the effective schools research to be composed of four parts: a) resource provider, b) instructional resource, c) communicator, and d) visible presence. Participants in this study definitely enacted all four of these role descriptions but really focused on communication and being available and being seen.

Mitchell (1990) in commenting on the evolution of leadership theory postulated three eras: a) born leaders emphasizing trait theories, b) becoming leaders emphasizing behavioral theories, 
and c) being leaders emphasizing phenomenological reflection. Mitchell asserted that this last era concentrates on the "is-ness" of being a leader. In the analysis of this study, neither traits or behaviors emerged as significant factors, but rather the participants seemed to be more phenomenological practitioners. However, it must also be noted that this study used a phenomenological methodology rather than a behavioral or observational one, and the "is-ness" of being a leader may have been highlighted by the way the study was designed and executed. The researcher believes that the phenomenological lens has added to the view of the principalship, but also recognizes that this perspective is not the only view, nor does he prescribe it as a more valid or correct view.

Sergiovanni (1995) postulated a similar type of phenomenological role for principals when he envisioned it as reflective practice. The focus in this conception is on the interaction of action and reflection.

Theory and research are only one source of knowledge, and this knowledge is always subordinate to the principal, teacher, or other professional, serving to inform but not to prescribe practice. Indeed, professional knowledge is created in use as principals and teachers think, reflect, decide and do....Reflective practice is based on the reality that professional knowledge is different from scientific knowledge. Professional knowledge is created in use as professionals who face ill-defined, unique, and changing problems decide on courses of action" (p. 32).

Many participants in this study conceptualized their roles similarly. Often when discussing new programs, participants stated that they did not have to have a lot of formal research data to be convinced, but that they had to be convinced by more "common sense" reasoning. Most participants did not ascribe to particular theories, but instead read widely and adopted an eclectic mix of ideas and practices, ones that particularly suited their contextual situations. Many participants stated that one of their main strengths was that they knew their kids or that they knew their school, focusing in on the particular, concrete, contextual situation. They knew their situations and adapted outside knowledge to their situations, and not vice versa, much like the reflective practitioners described by Sergiovanni. 


\section{Evolving from Mangers to Leaders}

In this study evolutionary change from more management to more leadership both personal and systemic was identified. This systemic evolution fits with the historical evolution of the role outlined by Richardson, Short and Prickett (1993) and Bookbinder (1992) from head teacher to school manager/ supervisor to instructional leader. Smith and Andrews (1989) noted that the instructional leader was added to the role on top of the building manager/ supervisory role so that this management often dominated. These authors and the participants in this study often noted that the management functions were not as important as the leadership functions, but often took up more time. This systemic evolution can also be traced to the first and second wave reform movements with the first wave being more management oriented and the second wave being more leadership oriented.

In this study, it was noted that many participants described a personal evolution from management oriented to more leadership oriented administrative styles. It was also noted that it was difficult to separate the systemic and personal evolution for more experienced principals: Had some of the more experienced people evolved into more collaborative leadership style because of maturity or were they accommodating systemic change in that direction?

Early in the analysis, the researcher hypothesized that maturity was positively correlated with more leadership type behavior, but when this was investigated further in the study, it was found not to be warranted. Some of the newer principals were very much proponents of site based, collaborative decision making, as were some of the more mature ones. Some of the participants seemed truly committed to the collaborative concept, while others seemed to be more reacting to and accommodating the systemic move in the that direction without really buying into it themselves.

Sergiovanni (1995) described stages of development in leadership from bartering, to building, to bonding and binding. This evolution proceeds from more traditional, management focused practice to more leadership focused based on ideas, values and commitments. This evolutionary development was tied to culture building. Sergiovanni postulates that this evolution is 
good because it brings about extraordinary commitment from stakeholders leading to superlative schools, but that there is also a possible problem with this concept.

The inescapable moral nature of administrative work and in particular seeking to establish moral authority embodied in the form of purposing and shared values and expressed as "cultural leadership: raises important questions of manipulation and control. Cultural leadership can provide principals with levers to manipulate others that are more powerful than the levers associated with bureaucratic and psychological authority. (p. 316)

\section{Balancing Culture and Distributed Decision Making}

A number of writers have called for or noted the use of culture in leading organizations (Leithwood, Begley, \& Cousins, 1994: Hodgkinson, 1991; Sergiovanni, 1990, 1992, 1995; Greenfield and Ribbons, 1993; Mitchell, 1990; Deal; 1987; Robbins \& Alvy, 1995; Sheive \& Schonheit, 1987). Reitzug (1994) and Maxcy (1991) noted a problem inherent with leading organizations by culture when those organizations are espousing goals of empowerment. They proposed that the use of culture by leaders can be a form of indirect and manipulative control.

The differences between empowerment and manipulation can be subtle. Owens (1991) analyzing Argyris (1971) work described Type A Soft manager behavior that employs good human relations skills to get employees to buy into company goals and is often confused with true Type B leader behavior that emphasizes shared objectives, trust and respect. Similarly Burns (1978) contrasted transactional and transforming leadership, where the former gains compliance through positive or negative rewards, while the latter appeals to and ultimately develops higher values of both leaders and followers. Couto (1993) noted that Burns' transforming leadership has been mutated into transformational leadership which is more like indirect, manipulative control.

In this study it was obvious that school culture played an important role in participants conceptions of leadership, but it was sometimes difficult to ascertain how this culture related to shared decision making. Some participants seemed truly committed to distributed decision making, while others seemed to be exercising indirect, directive control by developing a strong school culture that drove all shared decisions. 


\section{Concluding Thoughts}

Wolcott (1990) in a text on writing up qualitative research asks and answers a question regarding conclusions:

How do you conclude a qualitative study? You don't. Give serious thought to dropping the idea that your final chapter must lead to a conclusion or that the account must build toward a dramatic climax.... I do not want to work toward a grand flourish that might tempt me beyond the boundaries of the material I have been presenting or detract from the power (and exceed the limitations) of an individual case. Qualitative researchers seem particularly vulnerable to the tendency-and urge- to go beyond reporting what is and to use their studies as platforms for making pronouncements of what ought to be.... There is nothing wrong with offering your personal opinions or professional judgments-but be sure to label them as such, and to search out and acknowledge their origins in your thinking.... My advice is to work toward a conservative closing statement that reviews succinctly what has been attempted, what has been learned, and what new questions have been raised. ( $p$. 55)

Following this advice, concluding thoughts of the researcher were presented in three sections below: a) "Changes" addressed what the researcher has learned and how his conceptions have changed during the course of the investigation, b) "Implications" explored how this study might influence the researcher's chosen future profession of educating and training principals as a professor of educational administration and leadership, and c) "New Questions" explored possible new directions and questions for further research arising out of this investigation.

\section{Changes}

In order to assess how the researcher's conceptions changed during the course of the investigation, Chapter One (The Problem Statement) and Appendix B (the researcher's own story) were reviewed as representing his views at the start of the investigation. Prior to the investigation, the researcher's primary personal experience was in private schools where a concept of visionary leadership was developed. His contact with public school administration was limited, but a vague characterization of public school principals as mostly middle mangers was present. Thus, in chapter one, concepts of visionary leadership and technical management were contrasted and discussed.

At the end of this investigation, the researcher has an increased respect for and admiration of the craft of public school administration. The dualist, either/ or conception of principals being 
managers or leaders has been modified by seeing practitioners who creatively balance the paradoxes and contradictions inherent in enacting both roles simultaneously.

Coming from private schools, where stakeholder groups tend to be more homogenous, the researcher felt that school leaders should be directive, philosophic, visionary leaders- people who articulate a specific vision and help the organization rally around that vision. However, now, the researcher feels that public schools may not be best served by visionary leadership, but rather by democratic leadership. Public schools serve a much more heterogeneous community and the leaders of these schools must be aware of balancing their own visions of what public education ought to be like with the visions of others. This balancing is needed in any organization, but the researcher has come to believe that public schools with their great diversity and mission of serving the whole public, require leadership that is decidedly more democratic than visionary. Being reflective and knowing how one's actions will possibly affect others is more important than being visionary and prescriptive.

In chapter one, the researcher questioned if a leader could function without being philosophic, or if that would really entail being a group facilitator rather than a leader. Now, the researcher feels that articulating a specific vision or philosophy may not be the best way to lead a public school, but rather articulating a philosophy that espouses democratic values and respects the rights of all stakeholders in the public school to have input into the formation of vision, missions and values may be a better way to lead.

Sergiovanni (1995) discussing Greenleaf's (1977) servant leadership stated,

Servant leadership describes well what it means to be a principal. Principals are responsible for "ministering" to the needs of the schools they serve. The needs are defined by the shared values and purposes of the school's covenant. They minister by providing leadership in a way that encourages others to be leaders in their own right. They minister by highlighting and protecting the values of the school. The principal as minister is one who is devoted to a cause, mission, or set of ideas and accepts the duty and obligation to serve this cause.... the principal is at the same time a leader of leaders, a follower of ideas, a minister of values, and servant to the followership. (p. 320)

The distinction between the charismatic, heroic, visionary leader and the empowering, collaborative, democratic leader may be subtle, but important. As a result of this study, the researcher has a greater appreciation for this difference. 


\section{Implications}

The researcher's chosen future career is to become a professor of educational administration and to help train and educate future principals, and this study has generated a number of implications for that practice. Primarily, aspiring administrators need to be both trained and educated, they need to have technical, rational managerial expertise and to grapple with the larger philosophic issues and questions surrounding the field of education. They need to be competent managers, but also prepared to be leaders.

Jacobson (1990) stated it well by observing that the "is" and the "ought" of educational administration need to be reconnected- "aspiring administrators should be encouraged to study the art and science of administration in order to improve the craft of administration" (p. 41). Both theory and practice need to be accessed in preparation programs. At the present time it may be important to emphasize the art aspect of administration to counteract the imbalances of the theory movement, but one must not over-react and lose the positive contribution of theory.

Sergiovanni (1995) captured the needed balance well in his conception of administration as reflective practice. He maintained that because schools face nonlinear, loosely structured conditions and because they require extraordinary commitment and performance from workers, traditional management theories emphasizing coercion or reward are inadequate and a new theory emphasizing cooperation, empowerment, responsibility, accountability, and meaningfulness is needed. The school needs to be seen not as an organization, but as a community.

To function well in this community, Sergiovanni maintains that one must be a "scruffie". In contrast, "Mystics" see administration as an art and scientific principles are useless, everything is relative and only personal, contextual knowledge is valid. "Neats" view administration as an applied science, where research should prescribe practice.

Scruffies hold the view that educational administration resembles a craftlike science within which practice is characterized by interacting reflection and action episodes. Theory and research are only one source of knowledge, which is subordinate to the principal and which is designed to inform but not to prescribe practice. (p. 30)

This is similar to Kessels and Korthagen's (1996) conception of administration as phronesis where the universal is subject to the particular situation. 
In balancing the manager-leader, theory-practice continua, this researcher has found Bolman and Deal's (1991) reframing concepts to be particularly promising and useful. These authors propose that a successful leader needs to be able to reframe, to view situations from different lenses-at times the technical and rational is useful; and at other times, the symbolic or moral is more appropriate. These different views or lenses allow leaders to gain perspective and be reflective about situations and issues. In this sense, the use of theory is not prescriptive or even situational, but rather descriptive. The theory does not prescribe practice, but instead, it is used as a tool to view situations and perhaps to change the frame of view of the situation.

\section{New Questions and Directions}

In this investigation, the researcher was critical of earlier research that used a scientific, rational perspective to study the principalship. Thus, a phenomenological perspective was used as the basis of this study. However, now the researcher must question whether the phenomenological lens constrained his vision of the principalship, and the answer is yes.

Any theory supports inquiry-the stronger the theory, the more support it provides-at the expense of imposing a structure on the problem that cannot, in any important sense, be said to be "there." The important thing is to be aware of the trade-offs we have made in selecting a particular theory as a "lens" to look at a particular phenomenon. As long as we consider the possibility that our view through the lens is distorted or filtered in some way, then one should be OK. (D. William, personal communication, January 3, 1996)

This researcher definitely recognizes that the phenomenological lens chosen for this investigation was constraining, but it did provide an interesting view of the principalship.

For this researcher, future research on the principalship could be enhanced by changing theoretical lenses. One possible direction for new research building on this investigation would be to perform a larger, more empirical study to see if the types of trends and themes identified for this small sample generalized to a larger group. A second direction would be to explore similar questions from a critical theory lens instead of a phenomenological lens.

Critical theory is more concerned with power relationships, and in order to further illuminate the power relationships surrounding the principalship it would be necessary to study the role from more of a systemic perspective including the views of the other stakeholder groupssuperintendents, teachers, students and parents. There are three specific areas that intrigue the 
researcher that might be explored using case study methodology and a critical theory perspective: a) exploring the role of the central office, specifically the superintendent, in restructured schools that are emphasizing empowerment and exploring how this relates to the principal's role, b) exploring perspectives of different stakeholder groups regarding the conceptions of the principal as manager and leader, and c) exploring possible differences between true collaborative, empowering leadership and the more manipulative, indirect influence through strong culture building. Comparing the differences between how leadership is intended to be enacted and how it is perceived by different stakeholder groups would be particularly interesting for this researcher.

A third possible direction for future research would be to engage in action research with the goal of transforming. In this study, the researcher's primary purpose was to explore the stated questions, but a secondary effect for the participants was growth through reflection on their practice. Miles and Huberman (1994) describing collaborative action research stated: "The aim is to transform the social environment through a process of critical inquiry-to act on the world, rather than being acted on" (p. 9). Using research as a purposeful, transformative process for the participants is also an intriguing concept for this researcher; participating in contextualized, action research that empowers principals to be more effective, reflective practitioners is a future pedagogical and elucidatory possibility. 
Appendix A: Interview Guides and Forms

Reproduced with permission of the copyright owner. Further reproduction prohibited without permission. 


\section{Contact Visit Guide}

Who am I? My name is Dean S.T. Cascadden (565-6355, dscasc@mail.wm.edu). I am studying to obtain my Ed. D. in educational administration at the College of William and Mary. My advisor overseeing this project is Dr. Robert Hanny (221-2334). I am doing research for my dissertation which is a qualitative study of the perspectives elementary school principals have about their work, primarily focused on the topics of leadership and management.

What is the purpose of the study? The primary purpose of this proposed study is to explore how selected elementary school principals (nominated by superintendents) describe and define their work in terms of leadership and management. There are three sub-areas of investigation under this primary purpose: a) exploring the principal's conceptions about the constructs of leadership and management, b) exploring the principals' beliefs about the role of their personal philosophies, goals, or values in relation to their practice; and c) exploring the language that principals use to describe themselves, their work and their schools.

What will the results be used for? The results will primarily be used in my doctoral dissertation which I must complete to obtain my degree. Beyond that, I do hope to publish and/or present papers from this work. It is hoped that the descriptions and analysis provided by this study will be used to inform practice especially for those involved with the training and education of administrators.

Theoretical Perspective. The perspective adopted for this study is that organizations are constructed human social entities. The focus of this study is to describe the principalship from the perspective and voice of the participants. My goal is to provide a rich description of the participating principals' stories. This description and my analysis of it will then be compared to the existing literature on leadership, management and the elementary school principalship. 
How will data be collected and analyzed? The data collection will be accomplished using a series of three 90-minute interviews (scheduled approximately a week apart) with selected principals. The interviews will be tape recorded and transcriptions of the interviews will be content analyzed for common themes or patterns. Similarities and differences will be explored and conceptions and conclusions generated from this analysis will be compared with the literature. All names of places, schools and people will be known only to me, the researcher, and possibly to my dissertation chairperson, Dr. Hanny. Pseudonyms will be used in all writing.

What will each of the interviews be like? The study uses a Three-Interview Series format for interviewing. The purpose of the first interview is to gather detailed demographic and life history data. The purpose of the second interview is to gather data on the main content questions. The purpose of the third interview is to check the interviewer's understanding of the perceived meaning and interpretation of the previously collected interview data with the participant. The third interview gives the participant a chance to reflect on and to clarify what has been said. Participants have the right not to answer particular questions and have the right to withdraw from the study at any time and for any reason without prejudice. Data from participants who withdraw will not be used in the write-up.

Are you interested in participating?

Schedule first two interviews.

Preview consent form and questions to be asked in the interviews. 


\section{Informed Consent Form}

The following is a description of the dissertation research project being conducted by Dean S. T. Cascadden (565-6355, dscasc@mail.wm.edu), under the direction and guidance of Dr. Robert Hanny (221-2334) from the College of William and Mary.

1) The primary purpose of this proposed study is to explore how selected elementary school principals describe and define their work in terms of leadership and management. There are three sub-areas of investigation under this primary purpose: a) exploring the principal's

conceptions about the constructs of leadership and management, b) exploring the principals' beliefs about the role of their personal philosophies, goals, or values in relation to their practice; and c) exploring the language that principals use to describe themselves, their work or their schools.

2) The results will primarily be used in a doctoral dissertation but may be developed into subsequent presentations or publications.

3) The research will provide a rich description of the participants' perspectives on the principalship along with rich description of the study participants themselves. This description and analysis of it will then be compared to the existing literature on management, leadership and the elementary school principalship. The focus of this proposed study is to describe the role of the principal from the perspective and voice of the participants. All names of places, schools and people will be known only to me, the researcher, and possibly to my dissertation chairperson, Dr. Hanny. Pseudonyms will be used in all writing.

4) The data collection will be accomplished using a series of three, tape recorded, 90 minute interviews (scheduled approximately a week apart). The purpose of the first interview is to gather detailed demographic and life history data. The purpose of the second interview is to gather data on the main content questions. The purpose of the third interview is to check the interviewer's understanding of the perceived meaning and interpretation of the previously collected interview data with the participant. The third interview gives the participant a chance to reflect on and to clarify what has been said. Participants have the right to participate or to not participate, have the right not to answer particular questions, and have the right to withdraw from the study at any time and for any reason without prejudice. Data from participants who withdraw will not be used in the write-up.

By signing this form, the participant ascertains that they have been informed of the purpose and conditions of the study, and agrees to begin participation in the study.

Signed:

Date: 


\section{First Interview Guide}

Review Informed Consent and Obtain Signature (review form, see that it is signed)

1) If I were a new parent visiting your school, what is some of the factual information about this school and its context that you might give me?

probes: demographics, student population, community profile, organizational structure

2) Talk to me about yourself as a principal. How would you describe yourself to me if I were first meeting you, (perhaps at a professional conference)?

3) Tell me about how you came to be the principal here.

probes: educational preparation, previous experiences, when did you first know you wanted to be principal?

4) Where does this job fit into your career plans?

probes: personal goals, career goals

5) Tell me about your daily work. What is it like?

6) Tell me about how your work changes or cycles during the year.

Probes: what are the big things that you must do during the year?

7) Lets talk about your role or function as principal. How do you want others to view you?

8) You've already given me some factual information, but now I'd like to discuss the ambiance or atmosphere of your school. Tell me about your school, what would you like it to be like? 


\section{Second Interview Guide}

1) Please describe management from your perspective. Management is....

2) Please describe leadership from your perspective. Leadership is....

3) How are these two constructs related?

(Use graphic organizer for a probe.)

4) Describe and/or define your work in terms of leadership and management.

probes: Who's responsible management? Who's responsible for leadership? What is the role of the central office?

5) What role do you believe your personal educational views (e.g., philosophies, goals or values) should play in your practice?

6) What effect do you see your personal educational views having on this school?

Follow-up: Can you cite any examples or evidence of this?

7) Do you perceive any external constraints or restraints that affect the role that your personal views are allowed to play? 
Graphical representation of the Relationship of

Mänagement and Leadership
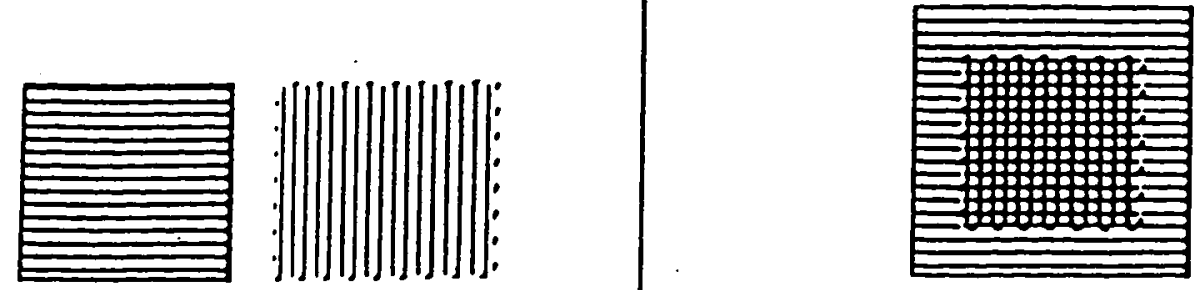

Lèadership

1. Separate

2. Management
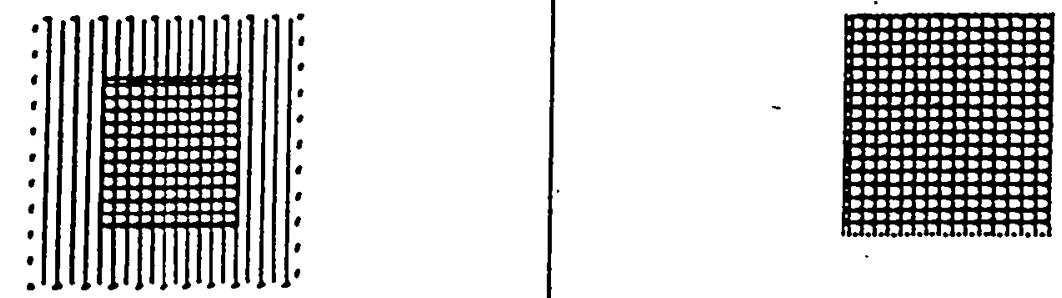

3.

Managément

Leadershịp

4. Synonyms

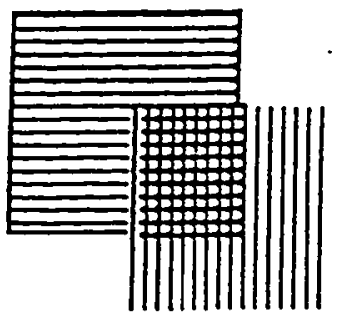

Overlapping

5. Terms

6.

MEY

Adapted from Alexander and Dochy (1991). 


\section{Third Interview Guide}

1) Is there anything in this description that you would like to clarify, comment or expand upon? (How do you feel about it?)

2) Is there anything else you would like to tell me about being a principal?

3) How has your view of the principalship changed during your tenure? What do you see as possible future directions for the principalship?

4) During this study you have been asked to be reflective. Do you engage in this type thought on your own? (How?, When?, What purpose?)

5) Are there any theorists or books that have particularly influenced you?

6) The following questions will help with some of the analysis from this study:

a) Who do you consider the primary stakeholders of this school to be (students, teachers or parents?

What is the role of the other groups?

b) Do you mostly see your self as having direct contact with students or do you influence students through teachers?

c) In deciding what type of decision making to use for a particular issue (authoritarian through collaborative) what factors do you consider? 
Appendix B: My Story

The following narrative was written in December of 1995 , after my dissertation proposal was approved, but before I began contacting possible participants. It was written in first person because it is a personal document that described my views related to the investigation and some of my personal history describing, in part, how I came to hold those views. The perspective and methodology I chose for this study explicitly recognized a lack of objectivity that I, the researcher, might have tried to adopt with the participants. I purposed to present my representation of the participant's subjective realities, and I felt a need to explicitly state my views on management and leadership as related to educational administration so that the reader would be able to make judgments about how my conceptions and biases might influence the description and analyses generated from the investigation.

I became interested in education in my senior year at Dartmouth College. My undergraduate education was in the liberal arts tradition and focused a lot of attention on the social contexts and issues of education as opposed to the practical preparation and certification of teachers. After graduation, I became certified as a Biology teacher and taught for one half year in a New Hampshire public high school. I then taught high school math and science for four years in a private, Christian school sponsored by the church I had been attending. When the founding principal of that school resigned, I was designated as the teaching principal. For four years I taught full-time and acted as administrator for the eighty student, $\mathrm{k}-12$ school supervising four other staff members.

I characterized the Christian school principalship as being much more leadership than management oriented. With such a small number of staff and students, the administrative details were not too overwhelming, and the administration of the building was shared by the church leadership. As a private school vying for enrollments, I felt a need to constantly focus the school around our vision and mission. As principal, I often had reason to expound and explain the vision of the school especially to parents who were considering enrolling their children. Also, the sectarian, ideological nature of the school called for a constant enunciating of the school's vision 
and purpose, even to those who had been with us for a long time, at annual meetings and in school communications. During my time as principal, I revised the school's policy handbook including the mission and purpose statements. These were changed to reflect some of my emerging educational views. As principal, I was overseen by a school board, but often I was setting the agenda and practically acting as school board chair. When I look back on that time, I marvel at how much freedom and latitude was given to me, in shaping the purpose, vision and mission of that school.

After four years as principal, I felt the need for a master's degree in order to further my career. I enrolled at Regent University in Virginia Beach, Virginia. Regent is a sectarian institution with the motto: "Christian Leadership to Change the World." The Regent course catalog stated the following purpose for the Educational Leadership program:

The essence of a superb administrator cannot be captured simply by the ability to plan, organize, and control the many diverse functions for which he is responsible. The true essence of an administrator who can be called an educational leader is found in the ability to carry the vision of the school, to motivate, encourage, and guide staff to higher levels of personal and professional excellence, and to create an atmosphere of mutual trust and respect. This type of leader promotes unity, cooperation, and caring through which every person, adult and child, has the opportunity to grow and prosper. The School of Education has developed an educational leadership program which not only trains people to handle the diverse tasks of administration, but focuses on developing educational leaders who can create and maintain the type of school program which in every aspect reflects excellence and compassion. (Regent University Graduate Catalog 1991-92, p. 66)

Courses at Regent emphasized examining education from the perspective of worldviews. The Education Components Model, describing the philosophy of the School of Education at Regent University, placed worldview in the center of the model and defined worldview as "presuppositions, orientations, and beliefs that act as filters or screens in interpreting life" (Regent University Graduate Catalog 1991-92, p. 64 ). Students at Regent were prepared for careers both in public and sectarian schools, but they were encouraged to be visionary leaders in either context. Directly from Regent, I was accepted into advanced graduate studies at the College of William and Mary. The summer following my graduation from Regent and before I matriculated at 
William and Mary, I returned to New Hampshire to work at a private, boarding summer school. I had worked summers at this school previously, commuting to the school to teach and coach sailing. This school served students in grades four through nine and had a rich tradition associated with it. During that summer when I was involved in the total program including acting as a house parent, I was immersed in the culture of Cardigan Mountain School as I had never been previously. I saw that the school had a very distinctive purpose and mission that was operationalized throughout the program.

Thus, prior to my enrolling at William and Mary, most of my experience with education had been with or in private schools, and my characterization of the principal or headmaster position was one of visionary leadership. In every private school I had been in, there had been a very distinctive mission and purpose that the leaders of those schools were cognizant of and were actively proclaiming. I knew that these leaders had administrative details to attend to, but I saw that as definitely secondary to the real purpose-that of leading the school through propagating ideas and ideals. All of my studies in education, up to that point, had been in private schools where the certification function and the practical or technical preparation for teaching had been de-emphasized in favor of examining issues.

The School of Education at William and Mary characterized itself as attempting to creatively blend the theoretical and the practical. I attended as a full-time student, but many of my classmates were working professionals who were completing degrees for certification purposes. I soon found that I approached education from a very different perspective than many of my classmates. I was frequently asking questions of "why?" and wanting to deal with issues or concepts in theoretical or abstract terms, while many of my classmates asked questions of "how?" and were much more interested with "real world" applications and the practical implementation of the things being studied. I loved the theoretical courses and somewhat disdained the technical ones (e.g., finance and facilities); whereas, many of my classmates felt just the opposite.

I began to form an opinion of public school administration, especially at the principal level, as being very concerned with management and little concerned with leadership. This opinion was 
buttressed by "war stories" told by some professors about certain practitioners concerned only with "administrivia" and who were so caught up in managing that they had forgotten what a classroom was like and had lost touch with the real purpose of school-educating students. During this time I also read Callahan's (1962) classic Education and the Cult of Efficiency, which characterized public school administrators as mindless managers unconcerned with the greater philosophical issues of education.

This developing characterization of public school principals as solely middle managers was challenged by two people that I met in the second year of my studies. The first person was a classmate who was principal of a large middle school. He carried note cards in his jacket pocket outlining educational theories and stated that he often referred to those cards when dealing with situations in his school. He had a very detailed and well articulated vision and purpose for his school that he was constantly sharing. In response to my characterization of public school principals as being constrained only to management, he responded that it just wasn't so. In his opinion, the principal had wide discretion and a lot of power to implement vision. The second person was also a principal of a middle school. I spent a twenty hour mini-internship in this person's school observing and reflecting on the nature of the principal's role. This principal was definitely concerned with some of the larger issues of education and society. I was impressed by how the principal was involved with a number of committees and projects that went far beyond managing the school and touched upon leadership both in the district and the community at large.

In my third year of study at William and Mary, I began to seriously think about a dissertation topic. I had always been interested in philosophic or worldview issues as they related to education, but I found that the language involved in talking about philosophy turned off many practitioners. I began to explore and read historical and theoretical writings on administration, especially as I prepared for my doctoral comprehensive exams. I took a course in qualitative research methodology. I also joined some international, education oriented, discussion lists on the Internet. One man from Australia recommended that I read Hodgkinson and Greenfield in relation to educational administration as their views on leadership were very popular in English speaking 
countries other than the U. S., and was surprised that I had never even heard of these writers. All of these things coalesced into the problem statement contained in chapter one of my dissertation.

This narrative was written to give the readers of my dissertation some insight to possible biases I might have had as I conducted the investigation and interacted with the participants in this study. The following statement characterized my thoughts as I contemplated beginning the investigation:

I am not sure what I will find when I ask elementary school principals about their views on leadership and management. I might find some who characterize themselves as leaders, some as managers, or some who see themselves creatively mixing both functions. I know that I will find individuals who each have a story of their own, and I am not sure what commonalties will emerge from these individual stories. I am especially interested to see how the published literature on this topic matches with the principals' perspectives. I have chosen to go the field first and the library second because I want the theory to emerge from the data and not vice versa.

I recognize that I (and perhaps many others) have a simplified notion of leadership=good and management=bad, but also recognize that management is a necessary, but perhaps insufficient component of good leadership. I am interested in exploring this simplified notion and am anticipating that there is more complexity to the issue. I believe that I am conducting this investigation honestly seeking answers to my questions. Like all people, I do have my personal, subjective biases (which I have tried to inform the reader of) but I do not feel that I am going into this study trying to prove something or that I am trying to characterize the elementary school principalship in a certain way. Recognizing that I have had limited contact with public school principals and thus I am somewhat naive, I endeavor to characterize the principalship in the way that my participants do, and then compare their perspectives with what has been written by others.

At the conclusion of the study the following definitions were written:

Management: a technical, rational process of implementing how a group or organization gets from point A to point B by use of authority, power or rewards.

Leadership: a cultural, symbolic process of influencing a group or organization to move from point A to point $B$ by facilitating the identification of common purposes and exploring why moving from point $A$ to point $B$ is a good thing for the group or organization to do. 
Leadership is more collaborative than management and functions more in the realm of ideas and values. Additionally, I would distinguish between visionary leadership where the leader is the primary source of vision and values and democratic leadership in which the vision and values of the collective group are more dominant. 
References

Alexander, P. A. \& Dochy, F. J. (1995). Conceptions of knowledge and beliefs: A comparison across varying cultural and educational communities. American Educational Research Journal, 32 (2). 413-442.

Beck, L. \& Murphy, J. (1993). Understanding the principalship: Metaphorical themes 1920s1990s. NY: Teachers College Press.

Berg, B. L. (1989). Qualitative research methods for the social sciences. Needham, MA: Allyn and Bacon.

Blumberg, A. \& Greenfield, W. (1980). The effective principal: Perspectives on school leadership. Boston: Allyn and Bacon.

Bolman L. G. \& Deal T. E. (1995). Leading with soul: An uncommon journey of spirit. San Francisco: Jossey Bass.

Bolman, L. G. \& Deal, T. E. (1991). Reframing organizations; Artistry choice and leadership. San Francisco: Jossey-Bass.

Bookbinder, R. (1992). The principal; Leadership for the effective and productive school. Springfield, IL: Charles C Thomas.

Callahan, R. E. (1962). Education and the cult of efficiency: A study of the forces that have shaped the administration of the public schools. Chicago: University of Chicago Press.

Deal, T. E. \& Peterson, K. D. (1994). The leadership paradox: Balancing logic and artistry in schools. San Francisco: Jossey Bass.

Deal, T. E. (1987). The culture of schools. In Sheive, L. T. \& Schoenheit, M. B. Leadership: Examining the elusive. (pps. 3-15). Reston, VA: ASCD.

DePree, M. (1989). Leadership is an art. New York: Dell.

Duffie, L. G. (1991). The principal: Leader or manager? Paper presented at the Annual Meeting of the Canadian Society for the Study of Education, Kingston, Ontario, June, 1991. (ERIC Document Reproduction Service No, ED 339 109) 
Educational Research Services (1982). The role of elementary school principals: A summary of research. Arlington, VA: ERS.

English, F. W. (1994). Theory in educational administration. New York: Harper Collins.

Farrar, E. (1990). Reflections on the first wave of reform: Reordering America's educational priorities. In Jacobson, S. L. \& Conway, J. A. (eds.), Educational leadership in an age of reform. (pp. 3-13). New York: Longman.

Foster, W. (1989). The administrator as a transformative intellectual. Peabody Journal of Education, 66 (3). 5-18.

Girling \& Keith (1991). Education, management, and participation: New directions on educational administration. Boston: Allyn and Bacon.

Glickman, C. D., Allen, L. R., \& Lunsford, B. F. (1994). Voices of principals from democratically transformed schools. In Murphy, J. \& Louis, K. S. (1994). Reshaping the principalship: Insights from transformational reform efforts. (pp. 203-218). Thousand Oaks, CA: Sage.

Greenfield, T. \& Ribbins, P. (1993). Greenfield on educational administration: Towards a humane science. New York: Routledge.

Griffiths, D. E. (1988) Administrative theory. In Boyan N. J. (ed) 1988 Handbook of Research on Educational Administration. (259-277). New York: Longman.

Gronn, P. \& Ribbins, P. (1993). The salvation of educational administration: Better science or alternatives to science?. Educational Management and Administration. 21 (3). 161-69.

Guba, E. G. (1990). The paradigm dialog. London: Sage.

Hallinger, P. \& Hausman, C. (1994). From Attila the Hun to Mary had a little Lamb: Principals role ambiguity in restructured schools. In Murphy, J. \& Louis, K. S. (1994). Reshaping the principalship: Insights from transformational reform efforts. (pp. 154-176). Thousand Oaks, CA: Sage.

Hickman, C. R. (1990). Mind of a manager. Soul of a leader. New York: Wiley.

Hodgkinson, C. (1978). Towards a philosophy of administration. New York: St. Martin's Press. 
Hodgkinson, C. (1991). Educational leadership: The moral art. Albany: State University of New York.

Howe, W. (1994). Beyond garbage cans: An analysis of theory and research in educational leadership and recommendations for the future. Paper presented at the Annual Meeting of the American Educational Research Association, New Orleans, LA, April, 1994. (ERIC Document Reproduction Service No, ED 373 454)

Huberman, A. M. \& Miles M. B. (1994) Data management and analysis methods. In Denzin N. K. \& Lincoln, Y. S. (eds.) Handhook of qualitative research. London: Sage.

Hughes, L. W. \& Ubben, G. C. (1989). The elementary principal's handbook; A guide to effective action. Boston: Allyn and Bacon.

Immegart, G. L. (1988) Leadership and leader behavior. In Boyan N. J. (ed) 1988 Handbook of Research on Educational Administration. (259-277). New York: Longman.

Jacobson, S. L. \& Conway, J. A. (eds.). (1990). Educational leadership in an age of reform. New York: Longman.

Jacobson, S. L. (1990). Reflections on the third wave of reform: Rethinking administrator preparation. In Jacobson, S. L. \& Conway, J. A. (eds.), Educational leadership in an age of reform. (pp. 30-44). New York: Longman.

Janis, I. L. (1971). Group think. Psychology Today, November, 1971.

Kessels, J. P. \& Korthagen, F. A. (1996). The relationship between theory and practice: Back to the classics. Educational Researcher. 25 (3), 17-23.

Knight, G. R. (1989). Philosophy and education: An introduction in Christian perspective. Berrien Springs, MI: Andrews University Press.

Kowalski, T. J. \& Reitzug, U. C. (1993). Contemporary school administration: An introduction. Toronto: Longman.

Krajewski, R. J., Martin, J. S. \& Walden, J. C. (1983). The elementary school principalship: Leadership for the 1980s. New York: Holt, Rinehart and Winston. 
Krathwohl, D. R. (1993). Methods of educational and social science research: An integrated approach. NY: Longman.

Kuhn, T. S. (1962). The structure of scientific revolutions. Chicago: University of Chicago Press.

Leithwood, K., Begley, P. T., \& Cousins, J. B. (1994). Developing expert leadership for future schools. Washington D. C.: Falmer.

Maxcy, S. J. (1991). Educational leadership: A critical pragmatic perspective. New York: Bergin \& Garvey.

Miles, M. B. \& Huberman, A. M. (1994) Qualitative data Analysis: An expanded sourcebook of new methods.

Mitchell, J. G. (1990). Re-visioning educational leadership: A phenomenological approach. New York: Garland.

Murphy, J. \& Beck, L. G. (1994). Reconstructing the principalship: Challenges and possibilities. In Murphy, J. \& Louis, K. S. (1994). Reshaping the principalship: Insights from transformational reform efforts. (pp. 3-19). Thousand Oaks, CA: Sage.

Murphy, J. \& Louis, K. S. (1994). Reshaping the principalship: Insights from transformational reform efforts. Thousand Oaks, CA: Sage.

Murphy, J. (1994). Transformational change and the evolving role of the principal: Early empirical evidence. In Murphy, J. \& Louis, K. S. (1994). Reshaping the principalship: Insights from transformational reform efforts. (pp. 20-56). Thousand Oaks, CA: Sage.

Odden, A. R. (1995). Educational leadership for America's schools. New York: McGraw-Hill.

Owens, R. G. (1987). The leadership of educational clans. In Sheive, L. T. \& Schoenheit, M. B. Leadership: Examining the elusive. (pps. 16-29). Reston, VA: ASCD.

Owens, R. G. (1991). Organizational behavior in education. Englewood Cliffs, NJ: Prentice Hall. 
Petrie, H. G. (1990). Reflections on the second wave of reform: Restructuring the teaching profession. In Jacobson, S. L. \& Conway, J. A. (eds.), Educational leadership in an age of reform. (pp. 14-29). New York: Longman.

Razik \& Swanson (1995). Fundamental concepts of educational leadership and management. Columbus, OH: Prentice Hall.

Richardson, M. D., Short, P. M., \& Prickett, R. L. (1993). School principals and change. New York: Garland.

Robbins, P. \& Alvy, H. B. (1995). The principal's companion: Strategies and hints to make the job easier. Thousand Oaks, CA: Sage.

Seidman, I. E. (1991). Interviewing as qualitative research. New York: Columbia Teachers College.

Sergiovanni, T. J. (1987). The theoretical basis for cultural leadership. In Sheive, L. T. \& Schoenheit, M. B. Leadership: Examining the elusive. (pps. 116-130). Reston, VA: ASCD.

Sergiovanni, T. J. (1990). Value-added leadership; how to get extraordinary performance in schools. New York: Harcourt Brace Jovanovich.

Sergiovanni, T. J. (1992). Moral leadership: Getting to the heart of school improvement. San Francisco: Jossey-Bass.

Sergiovanni, T. J. (1993). Organizations or communities? Changing the metaphor changes the theory. Paper presented at the Annual Meeting of the American Educational Research Association, Atlanta, GA, April, 1993. (ERIC Document Reproduction Service No, ED $376008)$

Sergiovanni, T. J. (1995). The principalship: A reflective practice perspective. Boston: Allyn and Bacon.

Sergiovanni, T. J., Burlingame, M., Coombs, F. S. \& Thurston, P. W. (1992). Educational governance and administration. Boston: Allyn and Bacon. 
Sheive, L. T. \& Schoenheit, M. B. (1987). Vision and the work life of educational leaders. In Sheive, L. T. \& Schoenheit, M. B. Leadership: Examining the elusive. (pps. 39-104). Reston, VA: ASCD.

Shepard, I. S., Farmer, R. F., \& Counts, G. E. (1995). Leadership Definitions and Theorists: Do practitioners and professors agree? Paper presented at the NCPEA Annual Meeting Williamsburg, VA, August, 1995.

Smith, W. F. \& Andrews, R. L. (1989). Instructional leadership: How principals make a difference. Alexandria, VA: ASCD.

Stronge, J. H. (1990). Managing for productive schools: The principal's role in contemporary education. NASSP Bulletin, March 1990.

Stronge, J. H. (1993). Defining the principalship: Instructional leader or middle manager. NASSP Bulletin, May 1993.

Taylor, P. (1994). Leadership in education: A review of the literature. Emergency Librarian. 21 (3) 9-17.

Tierney, W. G. \& Foster, W. (1989). Introduction: Educational leadership and the struggle for the mind. Peabody Journal of Education, 66 (3). 5-18.

Warner, B. W. (1983). Should school administrators be leaders or managers? Paper presented at the Annual Meting of the American Association of School Administrators, Atlantic City NJ, February, 1983. (ERIC Document Reproduction Service No, ED 228 743)

Wolcott, H. F. (1973). The man in the principal's office: An ethnography. New York: Holt, Rinehart and Winston.

Wolcott, H. F. (1990). Writing up qualitative research. London: Sage.

Wren, T. J. (ed.). The leader's companion: Insights on leadership through the ages. New York: Free Press.

Zaleznik, A. (1977). Managers and leaders: Are they different? Harvard Business Review. 55 (3), 67-78. 